\title{
Degradation of thermal barrier coatings on an Integrated Gasification Combined Cycle (IGCC) simulated film-cooled turbine vane pressure surface due to particulate fly ash deposition
}

Kevin Luo

Follow this and additional works at: https://researchrepository.wvu.edu/etd

\section{Recommended Citation}

Luo, Kevin, "Degradation of thermal barrier coatings on an Integrated Gasification Combined Cycle (IGCC) simulated film-cooled turbine vane pressure surface due to particulate fly ash deposition" (2014). Graduate Theses, Dissertations, and Problem Reports. 6123.

https://researchrepository.wvu.edu/etd/6123

This Thesis is protected by copyright and/or related rights. It has been brought to you by the The Research Repository @ WVU with permission from the rights-holder(s). You are free to use this Thesis in any way that is permitted by the copyright and related rights legislation that applies to your use. For other uses you must obtain permission from the rights-holder(s) directly, unless additional rights are indicated by a Creative Commons license in the record and/ or on the work itself. This Thesis has been accepted for inclusion in WVU Graduate Theses, Dissertations, and Problem Reports collection by an authorized administrator of The Research Repository @ WVU. For more information, please contact researchrepository@mail.wvu.edu. 
DEGRADATION OF THERMAL BARRIER COATINGS ON AN INTEGRATED

GASIFICATION COMBINED CYCLE (IGCC) SIMULATED FILM-COOLED TURBINE VANE PRESSURE SURFACE DUE TO PARTICULATE FLY ASH DEPOSITION

\author{
Kevin Luo \\ Thesis submitted \\ to the Benjamin M. Statler College of Engineering and Mineral Resources \\ at West Virginia University \\ in partial fulfillment of the requirements for the degree of \\ Masters of Science in \\ Mechanical Engineering \\ Andrew Nix, Ph.D., Chair \\ Edward Sabolsky, Ph.D. \\ Bruce Kang, Ph.D. \\ Department of Mechanical and Aerospace Engineering
}

\author{
Morgantown, West Virginia
}

2014

Keywords: Gas Turbines; Thermal barrier coating; Fly ash deposition Copyright 2014 Kevin Luo 


\begin{abstract}
Degradation of Thermal Barrier Coatings on an Integrated Gasification Combined Cycle (IGCC) Simulated Film-Cooled Turbine Vane Pressure Surface due to Particulate Fly Ash Deposition
\end{abstract}

\begin{abstract}
Kevin Luo
Coal synthesis gas (syngas) can introduce contaminants into the flow of an Integrated Gasification Combined Cycle (IGCC) industrial gas turbine which can form molten deposits onto components of the first stage of a turbine. Research is being conducted at West Virginia University (WVU) to study the effects of particulate deposition on thermal barrier coatings (TBC) employed on the airfoils of an IGCC turbine hot section. WVU had been working with U.S. Department of Energy, National Energy Technology Laboratory (NETL) to simulate deposition on the pressure side of an IGCC turbine first stage vane to study the effects on film cooling. To simulate the particulate deposition, TBC coated, angled film-cooled test articles were subjected to accelerated deposition injected into the flow of a combustor facility with a pressure of approximately 4 atm and a gas temperature of $1560 \mathrm{~K}$. The particle characteristics between engine conditions and laboratory are matched using the Stokes number and particulate loading [1].
\end{abstract}

To investigate the degradation on the $\mathrm{TBC}$ from the particulate deposition, non-destructive evaluations were performed using a load-based multiple-partial unloading micro-indentation technique and were followed by scanning electron microscopy (SEM) evaluation and energy dispersive X-ray spectroscopy (EDS) examinations. The micro-indentation technique used in the study was developed by Kang et al. [2] and can quantitatively evaluate the mechanical properties of materials. The indentation results found that the Young's Modulus of the ceramic top coat is higher in areas with deposition formation due to the penetration of the fly ash. The increase in the modulus of elasticity has been shown to result in a reduction of strain tolerance of the 7\% yttria-stabilized zirconia (7YSZ) TBC coatings [3]. 
The increase in the Young's modulus of the ceramic top coat is due to the stiffening of the YSZ columnar microstructure from the cooled particulate fly ash. SEM evaluation was used to evaluate the microstructure of the layers within the TBC system, and the SEM micrographs showed that the TBC/fly ash deposition interaction zone made the YSZ coating more susceptible to delamination and promoted a dissolution-reprecipitation mechanism that changes the YSZ morphology and composition. EDS examination provided elemental maps which showed a shallow infiltration depth of the fly ash deposits and an elemental distribution spectrum analysis showed yttria migration from the YSZ top coating into the molten deposition. This preliminary work should lead to future studies in gas turbine material coating systems and their interaction with simulated fly ash and potentially CMAS or volcanic ash deposition. 


\section{ACKNOWLEDGEMENTS}

First, I would like to thank the members of my committee. Dr. Edward M. Sabolsky served as an instructor for my independent study on ceramic material characterization and processing. He gave me numerous pointers for the materials testing and tips for publication of my research. In addition, he and his wife, Kathy Sabolsky, allowed access to his lab for metallographic preparation.

I would like to extend my gratitude to Dr. Bruce S. Kang and his Ph.D. student Dumbi A. Otunyo for providing the multiple partial unloading indentation system. Without guidance and use of the system, I would not have been able to perform a quantitative strain tolerance analysis. I've had the pleasure of having Dr. Kang as a supportive figure in my life since I was a young lad at Christian \& Missionary Alliance (C\&MA) Church.

I would like to acknowledge the support of the Department of Energy, Office of Science, Experimental Program to Stimulate Competitive Research (EPSCoR) under grant/contract number DEFG02-09ER46615, monitored by Dr. Tim Fitzsimmons. In addition, the project was partially funded by the US Department of Energy, National Energy Technology Laboratory through a cooperative agreement with EPSCoR. Without their support, I would have never been able to start this project and complete my MS degree.

The Shared Research Facilities (SRF) at WVU also deserves a thank you. The staff provided safety and SEM/EDS training to allow me to do microstructural analysis. I would also like to thank the WVU Chemical Engineering Department for collaborating with SRF and allowing use of their SEM. There would be no microstructure characterization of the TBC system without their help.

I would like to thank the members of my office in ESB 280 for dealing with me for the duration of my stay in graduate school and going out for the countless lunches during the day for a reprieve from the daily grind. 
A special thank you goes to my advisor Dr. Andrew Nix. Thank you for putting me in the gas turbine field and suggesting and helping me secure the Department of Energy (DOE) University Turbines System Research (UTSR) Fellowship through Southwest Research Institute (SwRI). Through research at WVU and the work at GE Power \& Water during the summer of 2013, I greatly expanded my knowledge in gas turbines and the high temperature materials associated with them. My taste buds would also like to thank Drew for increasing my food palette in these last two years.

Lastly, I would like to thank my family. Your love and support has made me the person I am today, and I am forever grateful. 


\section{TABLE OF CONTENTS}

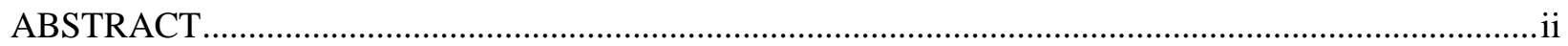

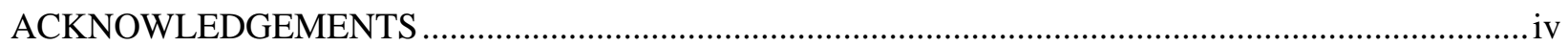

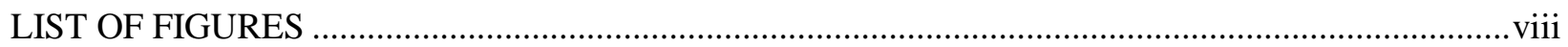

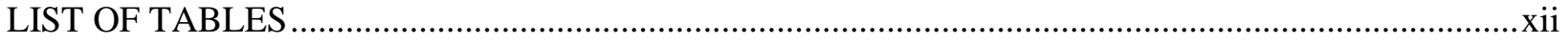

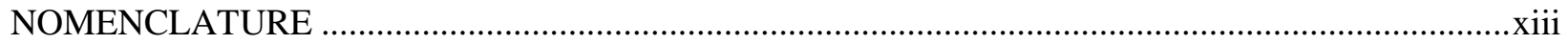

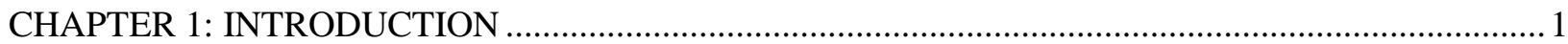

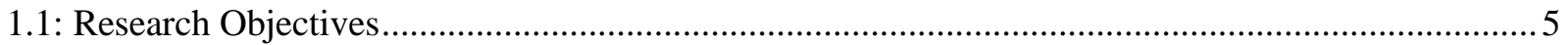

CHAPTER 2: THERMAL BARRIER COATINGS (TBCs) ................................................................ 6

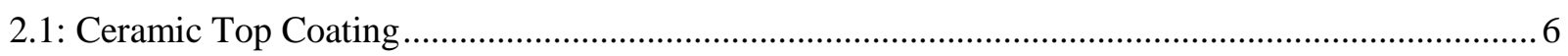

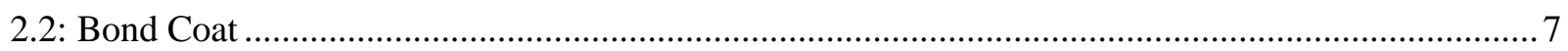

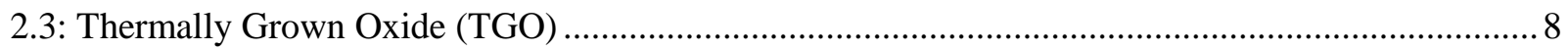

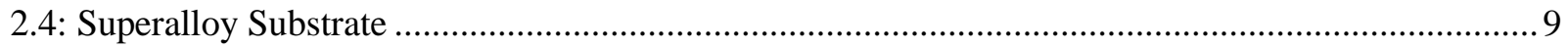

CHAPTER 3: THERMAL BARRIER COATING FAILURE MECHANISMS .................................. 10

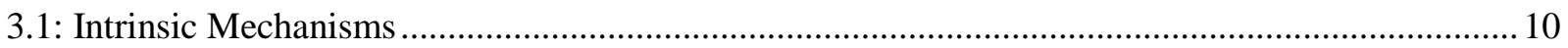

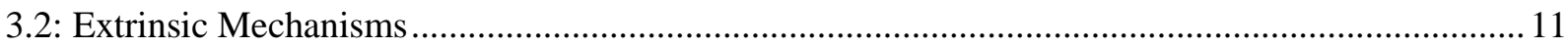

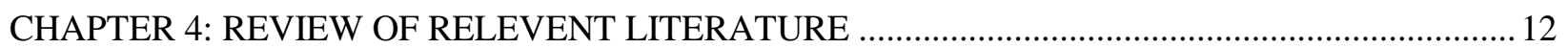

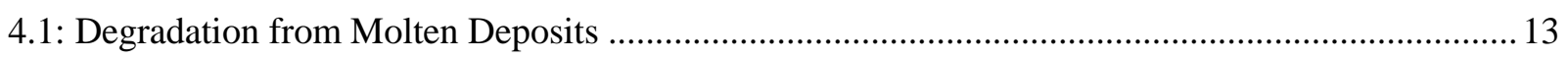

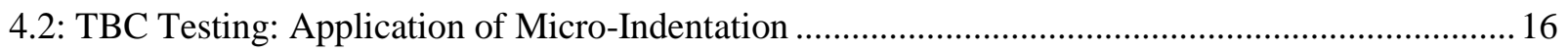

CHAPTER 5: TEST ARTICLE DESIGN, FLY ASH DEPOSITION PARAMETERS, AND TEST

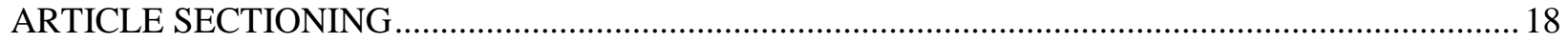

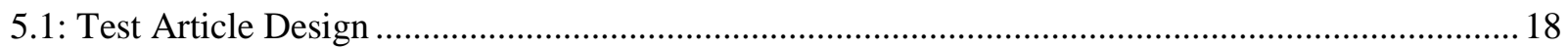

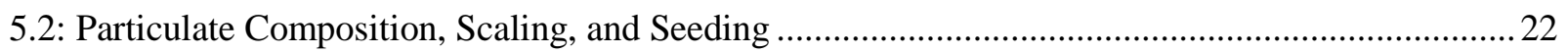

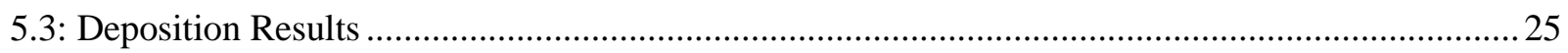

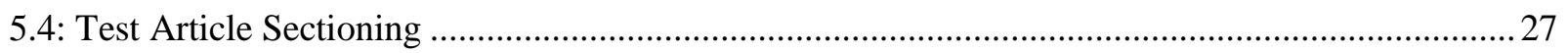

5.5: Elemental Composition of the Molten Deposits ............................................................................29

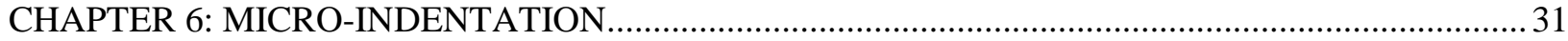

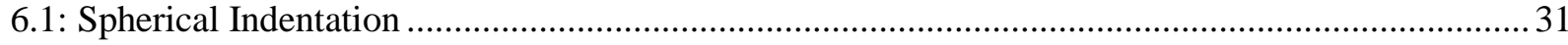

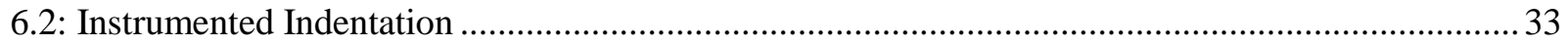

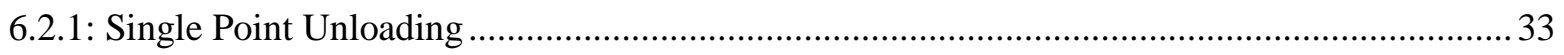

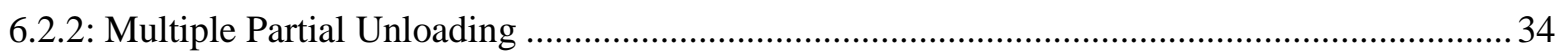

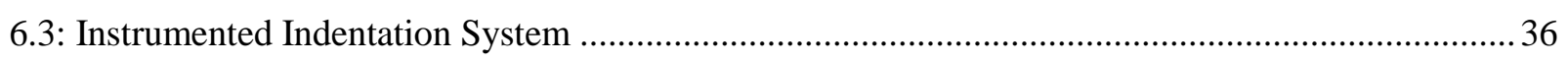




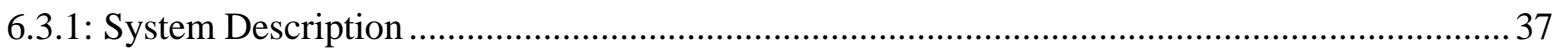

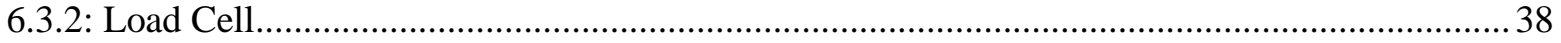

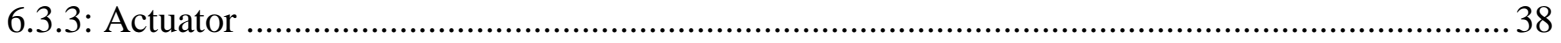

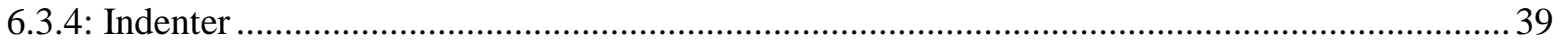

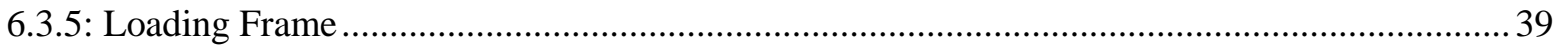

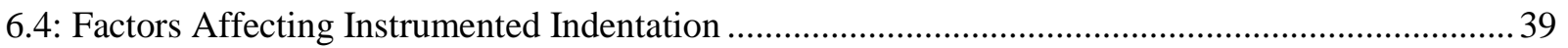

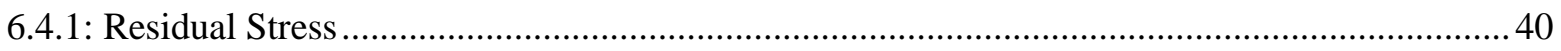

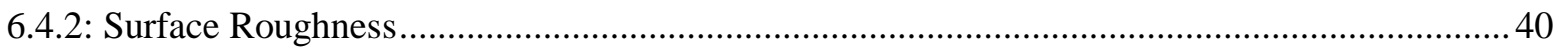

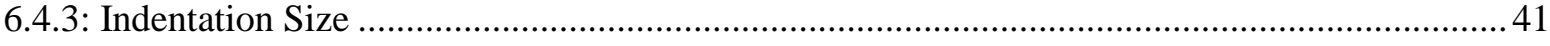

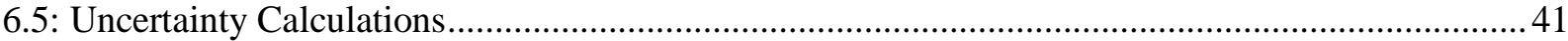

6.6: Literature Review of Elastic Modulus for Typical TBC Layers ..................................................... 42

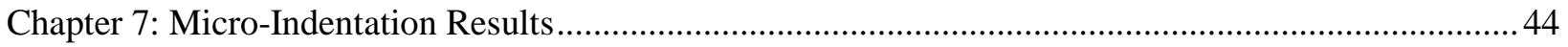

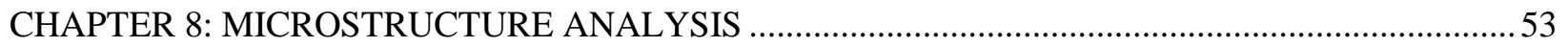

8.1: Scanning Electron Microscopy (SEM) views of TBC …..........................................................53

8.2: Degradation of TBC from Fly Ash Deposition...............................................................................55

CHAPTER 9: CONCLUSIONS AND FUTURE WORK RECOMMENDATIONS .............................63

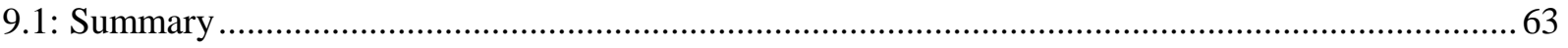

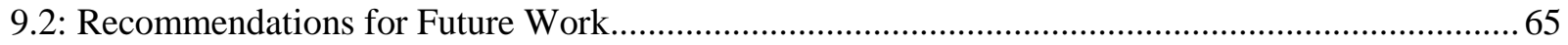

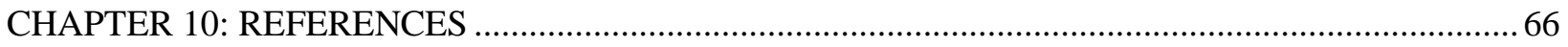

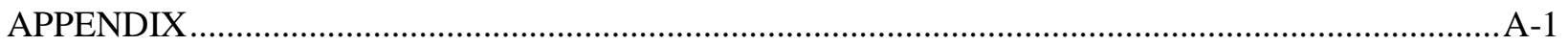

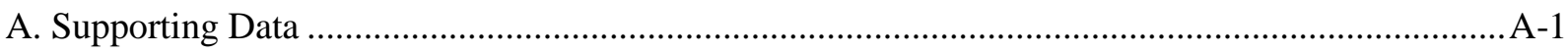

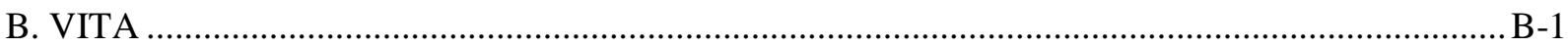

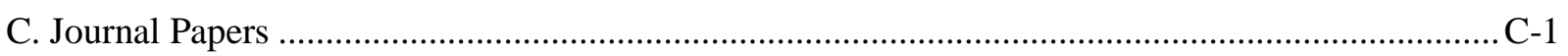




\section{LIST OF FIGURES}

Figure 1: Schematic of a gas turbine turbofan engine used in most modern aircrafts [5]........................ 1

Figure 2: Cross-sectional scanning electron micrograph (SEM) of an electron-beam physical-vapor deposited (EB-PVD) TBC, superimposed onto a schematic diagram showing the temperature reduction provided by the TBC. The turbine blade contains internal air cooling and TBC to set up a temperature

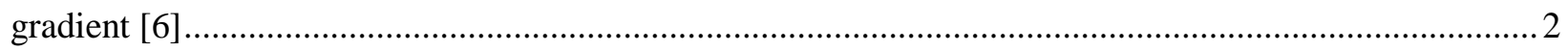

Figure 3: Film-cooled turbine vane covered by particulate matter from volcanic ash [8] ........................ 4 Figure 4: Progression of the temperature capabilities of Ni-based superalloys and TBC materials over the past 50 years. Red lines indicate the progression of the maximum allowable gas temperatures in the

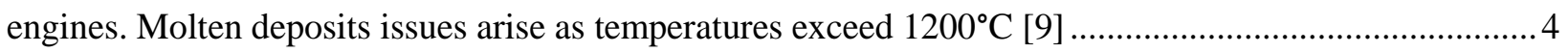

Figure 5: Schematic microstructure of TBCS applied by (a) air plasma spray (APS) and (b) electron-beam

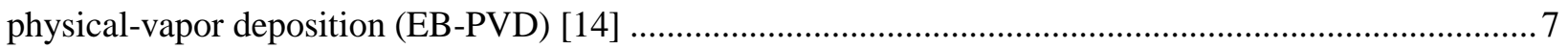

Figure 6: As-deposited SEM micrographs of TBCS applied by (a) air plasma spray (APS) and (b)

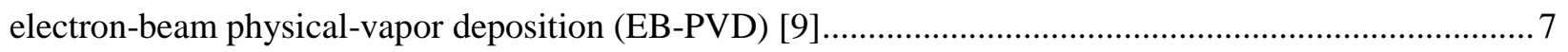

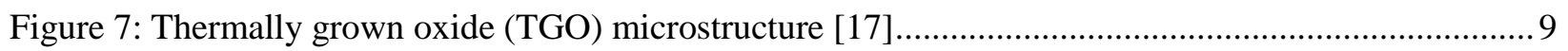

Figure 8: A summary of several mechanisms that promote spallation. Intrinsic mechanisms are governed by strain misfits between the layers during thermal cycling. Extrinsic mechanisms are from external

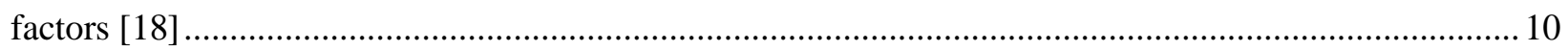

Figure 9: Particulate deposition capture zone on a gas turbine vane [22] ............................................ 12

Figure 10: Schematic Illustration of the delamination mechanism associated with CMAS [25] .............. 14

Figure 11: Cross-sectional schematic diagrams of APS TBCs with ash deposits before and after exposure

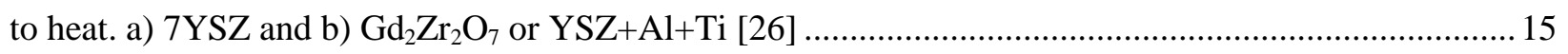

Figure 12: Isometric CAD model view of the (a) $10^{\circ}$ and (b) $20^{\circ}$ test articles [1] ............................... 19

Figure 13: Schematic of the directed vapor deposition (DVD) process developed by DVTI [33] .............20

Figure 14: Photographs of the (a) $10^{\circ}$ and (b) $20^{\circ}$ test articles with TBC before deposition testing [1] f...20 
Figure 15: SEM micrographs of DVD 7YSZ layer using a deposition rate of $\sim 15.0 \mu \mathrm{m} \mathrm{min}{ }^{-1}$ and temperature of $1000^{\circ} \mathrm{C}$ showing a) the polished cross-section, b) the twofold columnar structure, and c) the faceted surfaces of the finer columns [36] .21

Figure 16: Polished cross-section SEM micrograph of the as deposited DVD TBC system .21

Figure 17: a) NETL High Pressure Aerothermal Facility and b) cross-sectional schematic of the aerothermal test section [10] .22

Figure 18: Comparison of size distributions between the study by Murphy and previous literature [38]..23 Figure 19: Stokes numbers plotted with respect to particle diameter for fly ash particles in engine and laboratory conditions [1] .24

Figure 20: Side view of deposition on a) $10^{\circ}$ and b) $20^{\circ}$ test articles at blowing ratio of 0.25 [10] ..........26

Figure 21: Image of large deposit formation on the left side of the transition piece [38].......................26

Figure 22: Labels of the Test Articles: a) Test Article $1-20^{\circ}$, Deposition, b) Test Article $2-20^{\circ}$, Unexposed, c) Test Article 3 - 10, Deposition 27

Figure 23: Cut 1 requested for Test Article 1 .28

Figure 24: Sectioning diagrams and sample numbers for a) Test Article 1, b) Test Article 2, and c) Test Article 3 .28

Figure 25: Point \& ID location of acquisition of spectrum results on sample 3-1 ....................................30

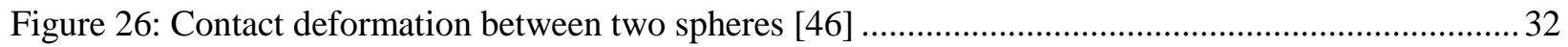

Figure 27: Load displacement curve for single point unloading algorithm [29] ....................................33

Figure 28: Load displacement curve for multiple partial unloading algorithm [29] ..............................34

Figure 29: Experimental Setup, i) $3.6 \mathrm{~nm}$ Resolution, Physik Instrumente, P-239.9S, $180 \mu \mathrm{m}$ piezoelectric actuator, ii) $\pm 0.15 \%$ Accuracy, Honeywell, Model 31, $100 \mathrm{lb}$. load cell, iii) spherical tungsten carbide (WC) $793.5 \mu \mathrm{m}$ radius indenter, and iv) sample stage [15] 37

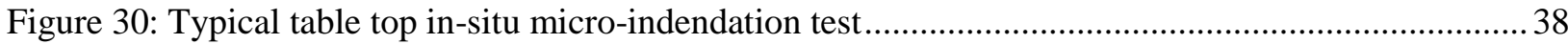

Figure 31: Elastic modulus variance with an imposed residual stress [54] .......................................... 40 
Figure 32: Excel sheet calculating the modulus of elasticity for the TBC............................................4

Figure 33: Image of unexposed Samples 2-3 and 2-4 and their values for TBC modulus elasticity .......... 45

Figure 34: Image of samples 1-1 and 1-2 and their values for averaged TBC modulus elasticity .............46

Figure 35: Image of samples 1-3 and 1-4 and their values for averaged TBC modulus elasticity ............47

Figure 36: Image of samples 3-1 and 3-2 and their values for averaged TBC modulus elasticity ............ 47

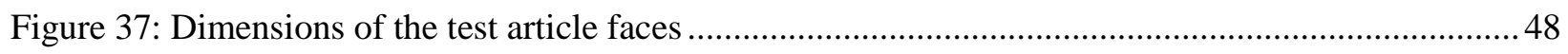

Figure 38: Normalized elastic modulus trend for Sample 1-1 \& 1-2 ................................................. 49

Figure 39: Normalized elastic modulus trend for Sample 1-3 \& 1-4 ......................................................50

Figure 40: Normalized elastic modulus trend for Sample 3-1 \& 3-2 .....................................................51

Figure 41: Normalized elastic modulus trends for samples 1-1, 1-2, 1-3, 1-4, 3-1, and 3-2 ..................52

Figure 42: Cross-sectional SEM micrographs of a) samples 2-3 (unexposed) and b) samples 1-3

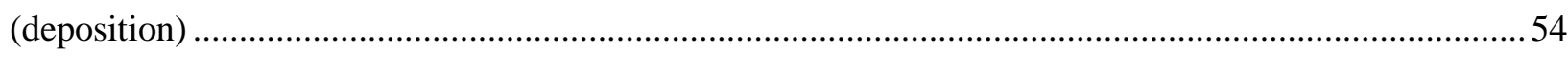

Figure 43: Top view SEM micrographs of a) samples 2-1 (unexposed) and b) samples 1-5 (deposition).54

Figure 44: Top view image of sample 1-7 with a large diagonal crack ...............................................55

Figure 45: Delamination in sample 1-3 YSZ coating a) after sectioning and b) after mounting and

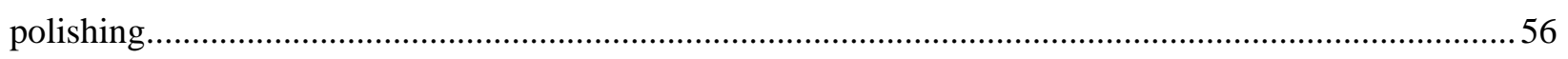

Figure 46: a) Cross-sectional SEM micrograph of sample 1-3 with molten fly ash interaction and their corresponding elemental maps: b) $\mathrm{Zr}$, c) Si, and d) Al. The horizontal red line show the original top

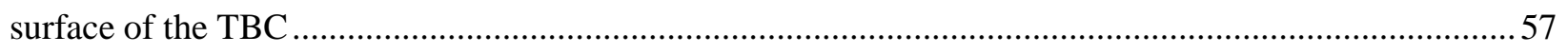

Figure 47: Cross-sectional views of a) top coating on sample 1-3 with molten deposits with their region

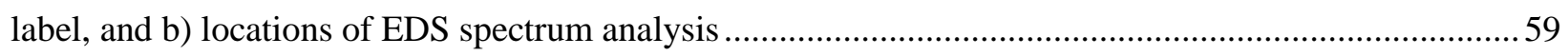

Figure 48: Unexposed columnar tips of sample 2-3 at a) 4000x magnification and b) $15000 x$

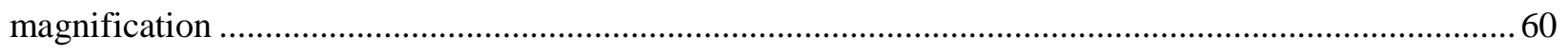

Figure 49: Schematic illustration of the dissolution-reprecipitation mechanism in YSZ due to CMAS [24] 
Figure 50: SEM micrographs of the reprecipitated YSZ columnar tips of sample 1-3 at a) 1000x magnification and b) 2500x magnification ......

Figure 51: Cross-sectional SEM micrograph of TBC with exposure to CMAS a) near the outer surface of the TBC (severe attack) and b) at the TBC/substrate interface [70]

Figure 52: TBC columns that have lost their identity and have formed a conglomerate of globular particles [70] 62 


\section{LIST OF TABLES}

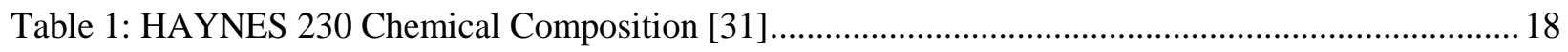

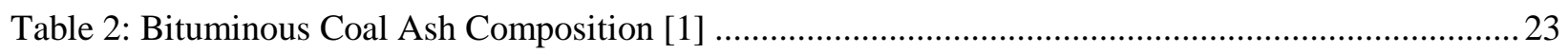

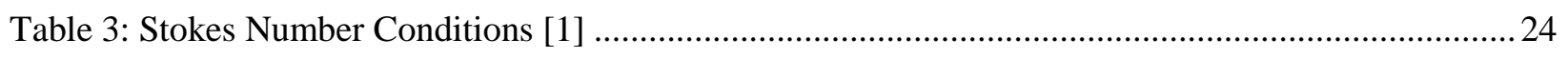

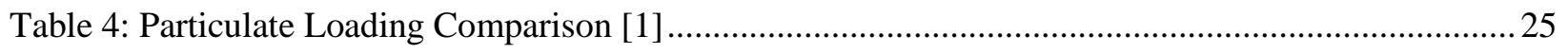

Table 5: Elemental Comparison between the processed fly ash and the molten deposit circled Figure 17

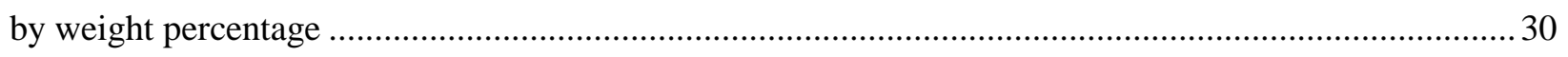

Table 6: Mechanical Properties of TBC Layers and Fly ash (Concrete) .............................................43

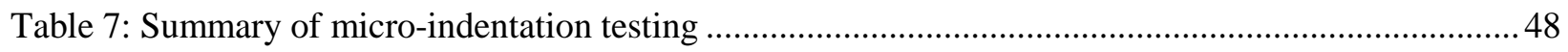

Table 8: Chemical composition (excluding oxygen) of the fly ash deposition and Zones 1-3 in Figure 44b 


\section{NOMENCLATURE}

\begin{tabular}{ll} 
A & Indentation contact area \\
$\mathrm{a}$ & Contact area between spheres \\
$\mathrm{C}$ & Slope \\
$\mathrm{d}$ & Film cooling hole diameter, $\mathrm{d}=3.9 \mathrm{~mm}$ \\
$\mathrm{~d}_{\mathrm{i}}$ & Diameter of spheres \\
$\mathrm{d}_{\mathrm{p}}$ & Particle diameter \\
$\mathrm{E}$ & Young's modulus \\
$\mathrm{E}_{\mathrm{R}}$ & Reduced modulus \\
$\mathrm{h}$ & Indentation depth \\
$\mathrm{k}$ & Thermal conductivity \\
$\mathrm{L}_{\mathrm{c}}$ & Cooling hole diameter length scale \\
$\mathrm{P}$ & Applied load \\
$\mathrm{m}$ & Power variable \\
$\mathrm{N}$ & Number of samples \\
$\mathrm{R}$ & Sphere radius \\
$\mathrm{S}$ & Standard deviation \\
$\mathrm{Stk}$ & Stokes number, Stk $=\rho_{\mathrm{p}} \mathrm{d}_{\mathrm{p}}^{2} \mathrm{U}_{\mathrm{p}} / 18 \mu \mathrm{L}_{\mathrm{c}}$ \\
$\mathrm{T}$ & Temperature \\
$\mathrm{t}$ & Student $\mathrm{t}$ \\
$\mathrm{U}$ & Velocity \\
$\mathrm{W}$ & Width of test article face \\
$\mathrm{X}$ & Best estimate variable \\
$\mathrm{x}$ & Distance across the width \\
$\mathrm{Greek}$ & \\
\hline $\mathrm{P}$ & Density \\
$\mu$ & Gas dynamic viscosity \\
$v$ & Poisson's ratio \\
Subscripts & Coolant \\
$\mathrm{c}$ & Elastic \\
$\mathrm{e}$ & Median \\
$\mathrm{med}$ & Particle \\
$\mathrm{p}$ & System \\
$\mathrm{s}$ & Mainstream \\
$\infty$ & \\
&
\end{tabular}




\section{CHAPTER 1: INTRODUCTION}

Today, there are continuing efforts to allow for operation of gas turbines at higher temperatures since higher gas inlet temperatures are directly proportional to higher efficiencies. Since 1950, the firing temperatures for industrial gas turbines have increased from more than $700^{\circ} \mathrm{C}$ to over $1400^{\circ} \mathrm{C}$ [4] with the aero-derivative gas turbines operating at even higher temperatures. The history of the turbine operating temperatures is shown in a later section in Figure 4. A schematic of a gas turbine turbofan engine is given in Figure 1 [5], and the highest temperatures are located after the combustion chamber and prior to the turbine inlet. To handle the high temperatures, the use of cooling schemes as well as high strength, directly solidified and single crystalline nickel based superalloys are required. Additionally, ceramic thermal barrier coatings (TBCs) have also been incorporated to allow operation at higher temperatures than the melting point of the superalloys.

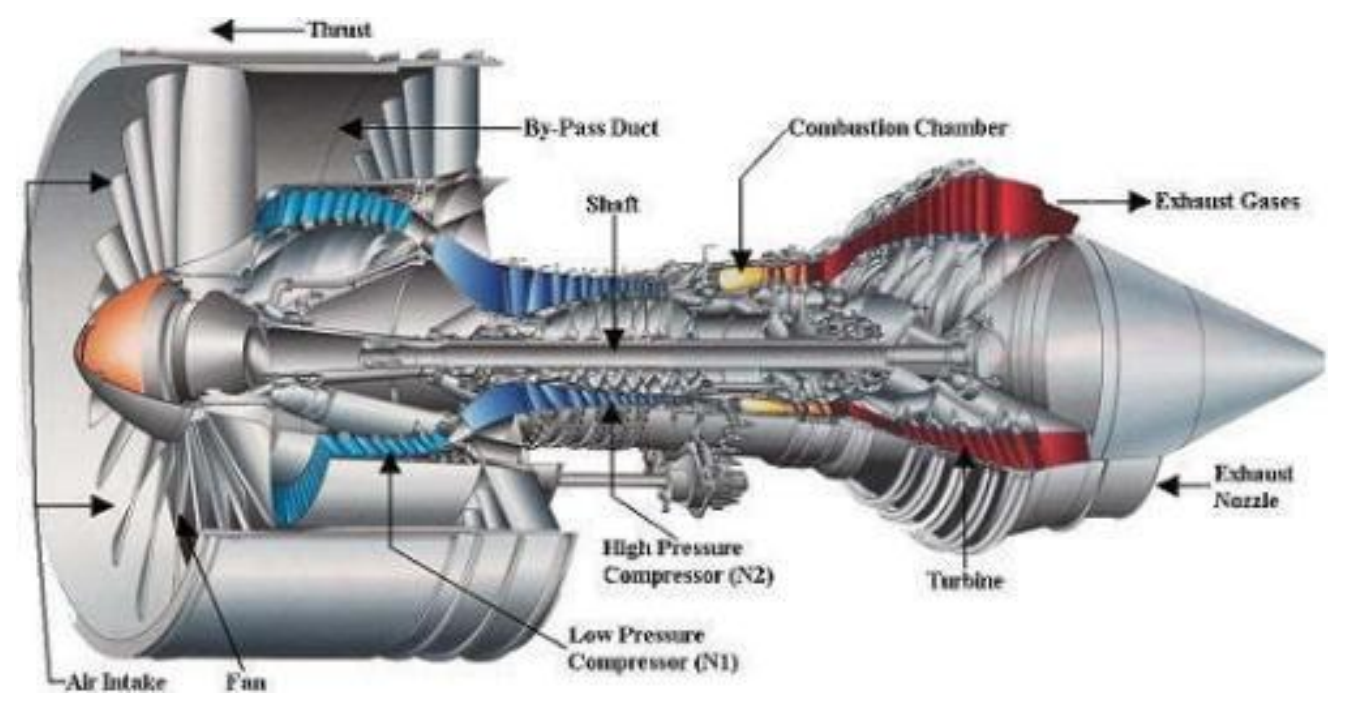

Figure 1: Schematic of a gas turbine turbofan engine used in most modern aircrafts [5]

Thermal barrier coatings are designed to withstand high temperatures and protect the component substrate below the layers of coating by lowering the surface temperature of the metallic substrate. A typical TBC system can be seen in Figure 2 [6]. The top layer of a TBC system, or "top coat," contains 
the ceramic top coat, typically comprised of yttria-stabilized zirconia (zirconia, $\mathrm{ZrO}_{2}$ partially stabilized by yttria, 7 8 $\mathrm{wt} \% \mathrm{Y}_{2} \mathrm{O}_{3}$ ). The material is commonly referred to as YSZ. The main function of the top coat is to extend the life of the component substrate and allow for higher turbine operating temperatures. For the as-deposited TBC coats, a metallic bond coat (BC) is applied to the superalloy substrate prior to the application of the ceramic top coat. The BC promotes adhesion between the top coat and the substrate, serves as a compliance layer for the coefficient of thermal expansion (CTE) difference between the top coat and the substrate, and provides an aluminum reservoir for the formation of alumina, $\alpha-\mathrm{Al}_{2} \mathrm{O}_{3}$, in the thermally grown oxide (TGO). TGO develops between the bond coat and ceramic top coat under thermal operating conditions and creates an oxidation resistant barrier for the remaining $\mathrm{BC}$ and substrate below. Due to the low thermal conductivity $(k)$ of the TBC system relative to the substrate, thermal insulation is provided to the metallic/superalloy substrate. This allows the turbine system to run at much higher gas temperatures than the substrates' melting point.

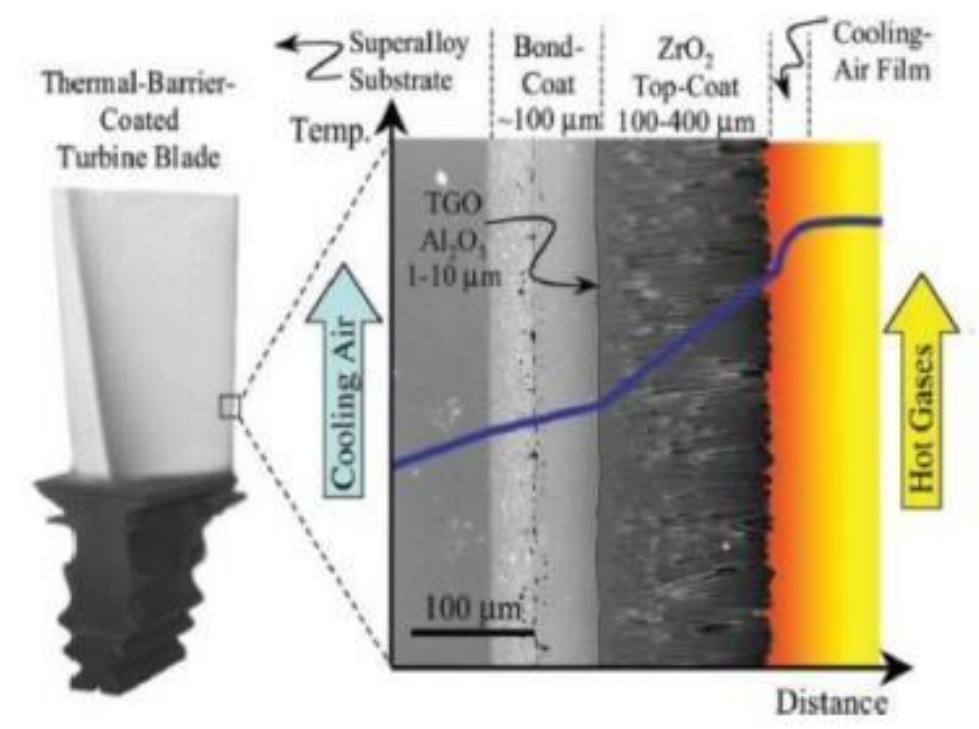

Figure 2: Cross-sectional scanning electron micrograph (SEM) of an electron-beam physical-vapor deposited (EB-PVD) TBC, superimposed onto a schematic diagram showing the temperature reduction provided by the TBC. The turbine blade contains internal air cooling and TBC to set up a temperature gradient [6] 
Although an increase in operating temperatures is beneficial to the efficiency of the gas turbine, elevated temperatures have brought about several durability issues for the TBCs. One particular issue is the degradation of the TBC system from particulates and contaminants that become molten deposits. In recent years, a growing interest has been shown to molten contaminant deposition that can degrade the components in the turbines, or inhibit cooling designs. Molten deposits in the gas turbine can form from impurities that enter through the inlet air (fine sand, volcanic ash, etc.) or the upstream combustion of particulate laden alternative fuels such as coal-derived synthesis gas (syngas). Even with modern filtration systems, contaminant particles smaller than $10 \mu \mathrm{m}$ may pass through into the engine [7]. Larger particles can also pass through as the filters wear out. These particles become molten as they pass through the combustor, and as they impact the components in the first stage of the turbine, the molten particles will deposit onto the components. Figure 3 shows an example of a turbine vane with molten deposits from volcanic ash [8]. Figure 4 contains the temperatures capabilities of nickel-based superalloys and TBCs over the past 50 years. Molten deposits become a factor as temperatures exceed roughly $1200^{\circ} \mathrm{C}$ [9]. Most of the common contaminants become molten around that temperature.

Understanding the degradation of the TBC from syngas particulate matter molten deposits will help extend the life of engine components and reduce down time for component repair and replacement. The following section documents research objectives and analysis procedures performed on the thermal barrier coated articles. The test articles are post-fly ash deposited TBC coated test articles from a previous study by Murphy et al. [10] to examine the interaction between fly ash and film cooling. 


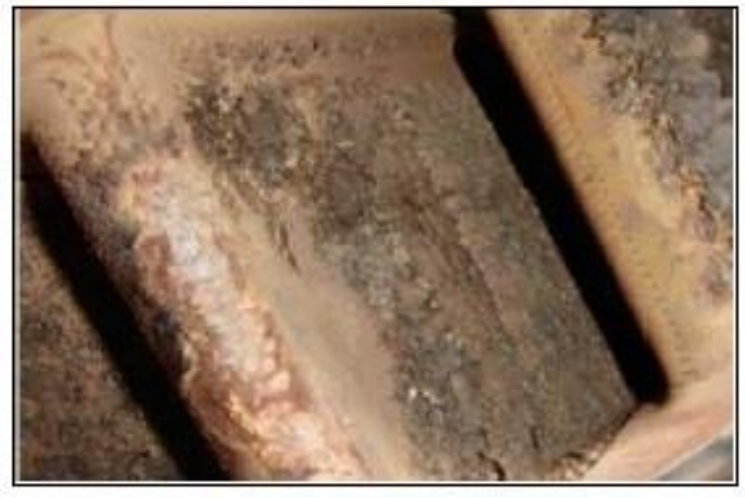

Figure 3: Film-cooled turbine vane covered by particulate matter from volcanic ash [8]

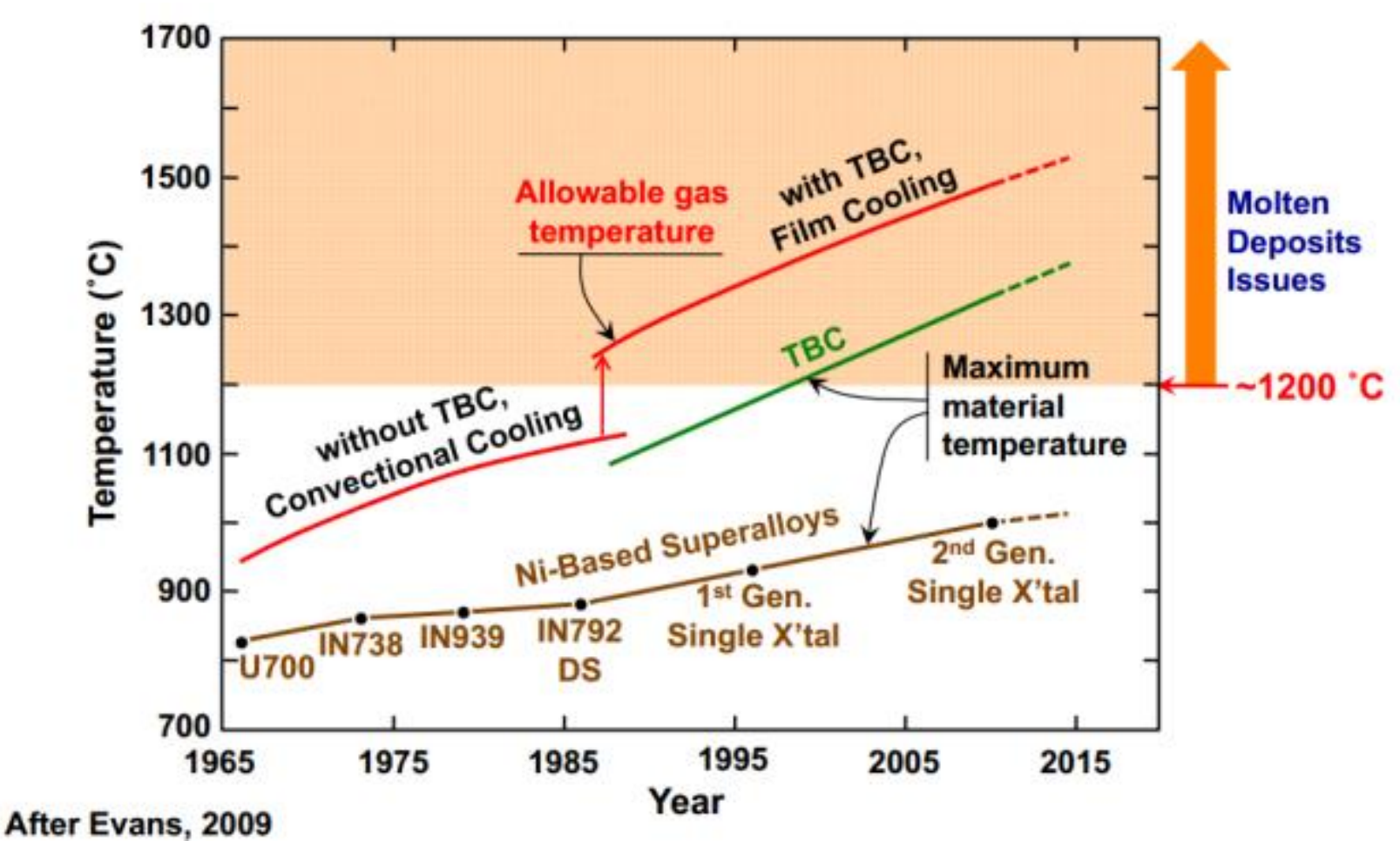

Figure 4: Progression of the temperature capabilities of Ni-based superalloys and TBC materials over the past 50 years. Red lines indicate the progression of the maximum allowable gas temperatures in the engines. Molten deposits issues arise as temperatures exceed $1200^{\circ} \mathrm{C}$ [9] 


\section{1: Research Objectives}

The purpose of the research was to characterize the effects of bituminous coal fly ash deposition on the directed vapor deposition (DVD) TBCs of non-dimensional representations first stage turbine vanes. This was accomplished through the following methods:

1) Use of a micro-indentation technique as a NDE evaluation to find the surface stiffness responses (elastic modulus) of exposed and unexposed areas and quantitatively characterize the strain tolerance differences.

2) Analysis of TBC systems using scanning electron microscopy (SEM) to provide microstructural differences between areas exposed to deposition and unexposed areas.

3) Energy dispersive X-ray spectroscopy (EDS) examinations to provide elemental mapping of cross sections that show the depth of the deposition penetration and elemental distribution of various areas within the $\mathrm{TBC} /$ deposition interaction zone. 


\section{CHAPTER 2: THERMAL BARRIER COATINGS (TBCS)}

A thermal barrier coating consists of several layers, each with different physical, thermal, and mechanical properties, as described in Chapter 1 . The system has metallic and ceramic components that form the complex insulation system. The typical TBC layers are the ceramic top coat, bond coat, thermally grown oxide (TGO), and the substrate. The descriptions of the layers are expanded upon below.

\section{1: Ceramic Top Coating}

The top layer of a TBC system typically contains the ceramic top coat comprised of yttriastabilized zirconia (YSZ). The top coating is typically the thickest layer and is the layer most responsible for insulating the substrate. The reduction in heat transfer is accomplished by the layer's low thermal conductivity (k). In addition to the low thermal-k, the layer should also consist of a low coefficient of thermal expansion (CTE) that closely matches that of the substrate, high resistance to oxidation, strain tolerance, microstructural/phase stability, chemical compatibility, and resistance to mechanical erosion [11].

The two most common TBC application methods are air plasma sprayed (APS) and electronbeam physical-vapor deposition (EB-PVD). Air plasma spray (APS) deposition is a low cost method that incorporates an intersplat process (successive impact of semi-molten powder particles on a substrate [12]) that lead to pores that lie parallel to the substrate surface and perpendicular to the temperature gradient. APS coatings have a very low thermal conductivity $(0.9-1 \mathrm{~W} / \mathrm{m} \cdot \mathrm{K})[13]$ and are used in stationary and rotating components of hot stage parts in industrial turbines. EB-PVD coats have a higher thermal-k (1.8$2 \mathrm{~W} / \mathrm{m} \cdot \mathrm{K})$ but are usually preferred due to the strain tolerance of the coat. The strain tolerance of the EB-PVD is provided by the resultant columnar grain microstructure. The EB-PVD method is commonly used on rotating and non-rotating components in the hot stage such as blades and vanes in jet engines. Schematics of the two coating types are shown in Figure 4 [14] and as-deposited coatings are given in Figure 5 [9]. 


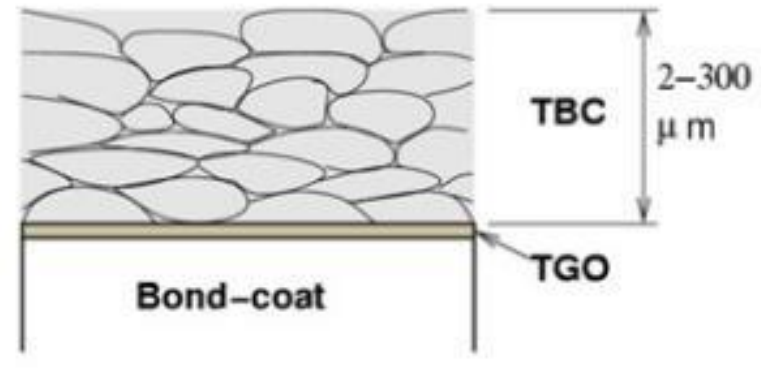

(a)

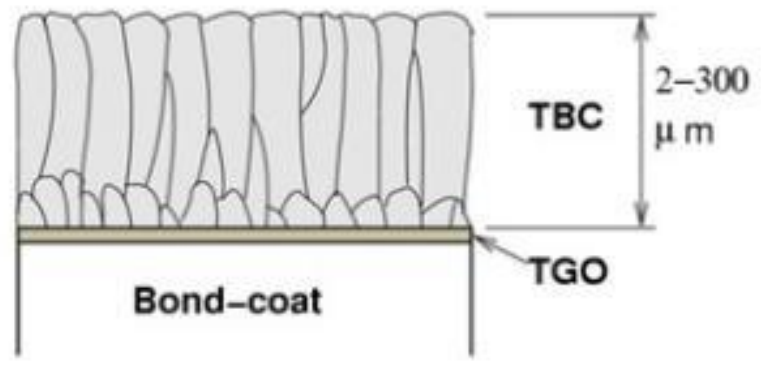

(b)

Figure 5: Schematic microstructure of TBCS applied by (a) air plasma spray (APS) and (b) electron-beam physical-vapor deposition (EB-PVD) [14]

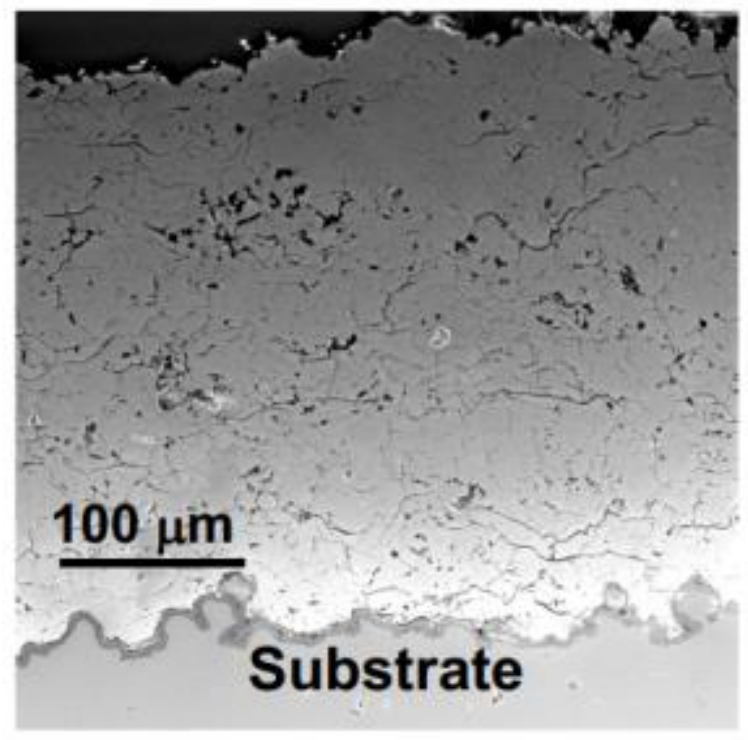

(a)

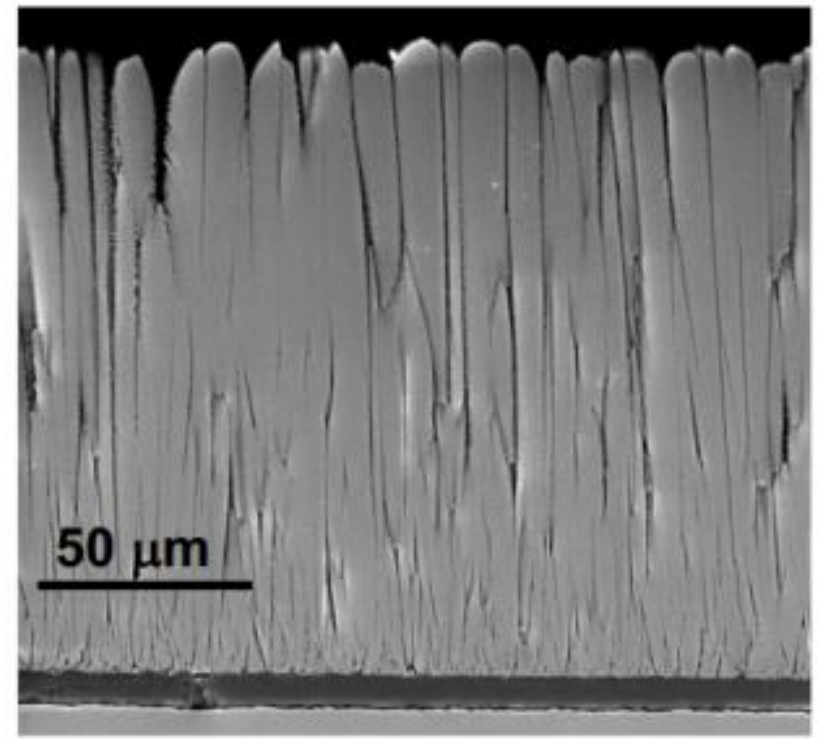

(b)

Figure 6: As-deposited SEM micrographs of TBCS applied by (a) air plasma spray (APS) and (b) electronbeam physical-vapor deposition (EB-PVD) [9]

\section{2: Bond Coat}

The bond coat (BC) plays a crucial role in the $\mathrm{TBC}$ system mechanically and chemically. Mechanically, the bond coat is responsible for the adhesion between the superalloy substrate and the ceramic top coat. The $\mathrm{BC}$ serves as a bridge to connect the creep and yield characteristics of the two 
separated layers [11]. Bond coats also contain the aluminum reservoir such that the alumina, $\alpha-\mathrm{Al}_{2} \mathrm{O}_{3}$ forms in the thermally grown oxide (TGO) between the $\mathrm{BC}$ and ceramic top coat. The TGO slows down oxidation in the remaining unaffected bond coat and the substrate. The two main classes of bond coats consists of MCrAlY (where $\mathrm{M}=\mathrm{Ni}$ and/or Co) bond coats or a Pt-modified aluminide bond coats. The difference is in the number of $\beta$ phases ( $\mathrm{MCrAlY}-2, \mathrm{PtAl}-1)$. The measurement of the coating life is often measured in terms of the depletion of $\beta$.

\section{3: Thermally Grown Oxide (TGO)}

During operating conditions, a thermally grown oxide (TGO) layer develops between the ceramic top coat and the bond coat. The TGO layer is an oxidation reaction product with the bond coat and is designed to be $\alpha$-alumina $\left(\alpha-\mathrm{Al}_{2} \mathrm{O}_{3}\right)$ [11]. The thermally grown oxide layer has a major influence on the durability of the TBC system. It acts as a diffusion barrier and reduces further oxidation of the bond coat, and becomes thicker as thermal exposure time increases. While TGO growth is inevitable, the growth rate can be controlled by the choice of bond coat.

The primary TGO morphology is rapid inward oxygen diffusion and slow outward diffusion of the aluminum [15]. This causes the TGO to grown towards the bond coat instead of the ceramic top coat. The three layers within the TGO microstructure consist of an $\mathrm{Al}_{2} \mathrm{O}_{3}-\mathrm{ZrO}_{2}$ interaction zone, a developed and crystalline $\mathrm{Al}_{2} \mathrm{O}_{3}$, and a fined grained $\mathrm{Al}_{2} \mathrm{O}_{3}$ layer mixed with spinel oxides formed from the bond coat such as $\mathrm{Ni}(\mathrm{Cr}, \mathrm{Al})_{2} \mathrm{O}_{4}[16]$ and can be seen in Figure 7 [17]. This growth of the TGO is referred to as growth strains and is responsible for a majority of the spallation failures in the TBC system. 


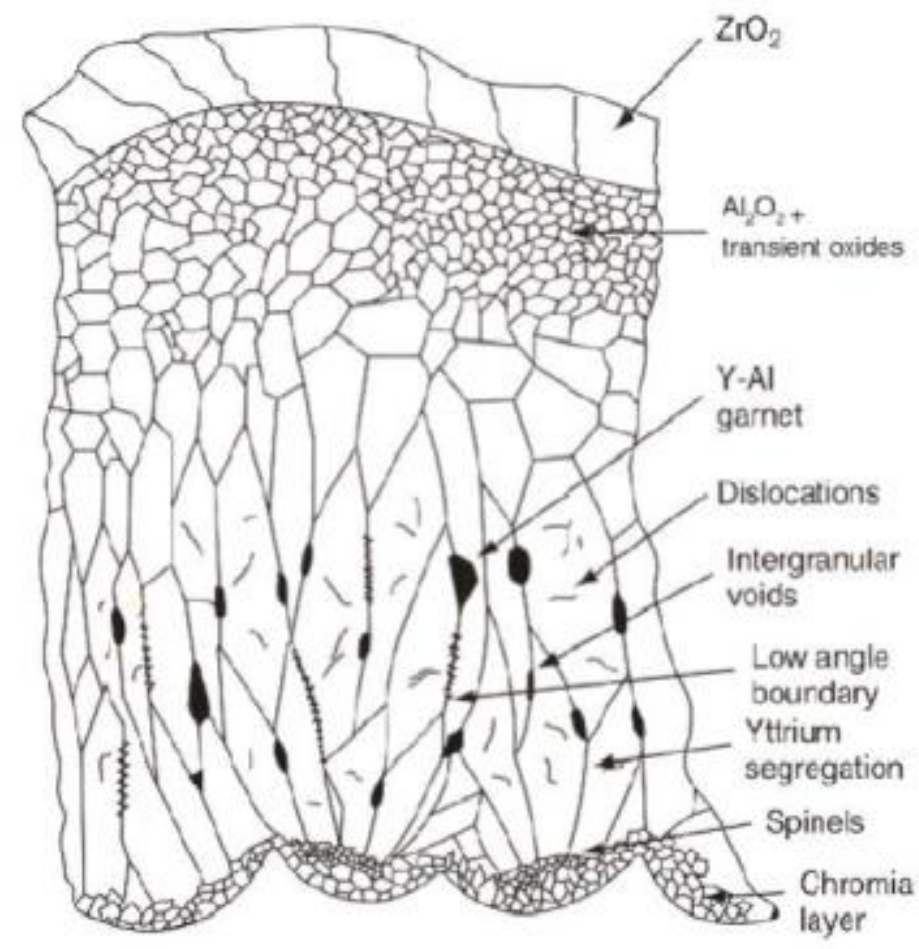

Figure 7: Thermally grown oxide (TGO) microstructure [17]

\section{4: Superalloy Substrate}

The bond coat and ceramic top coat are deposited on the metal substrate, which is usually a single or polycrystalline Cobalt or Nickel based alloy. The substrate of the turbine components must handle the stresses from the operational forces, but must also have mechanical properties necessary for high temperature endurance. Cobalt or Nickel based alloys provide excellent high temperature creep and corrosion resistance. The material properties are also enhanced by element additions and precipitation hardening. 


\section{CHAPTER 3: THERMAL BARRIER COATING FAILURE MECHANISMS}

There are several challenges that arise when a thermal barrier coating system is placed into turbine operating conditions. To study the failure mechanisms of a TBC system, furnace cycle and burner rig tests are widely used. Evans et al. [18] broke down the various mechanisms affecting EB-PVD TBCs into two basic categories, intrinsic and extrinsic, which can be seen in Figure 8. Studies of the failure mechanisms of EB-PVD TBCs are presented since the type of top coat is most similar to the direct-vapordeposition (DVD) coatings analyzed in the current work. Each failure category will be discussed in the following subsection.

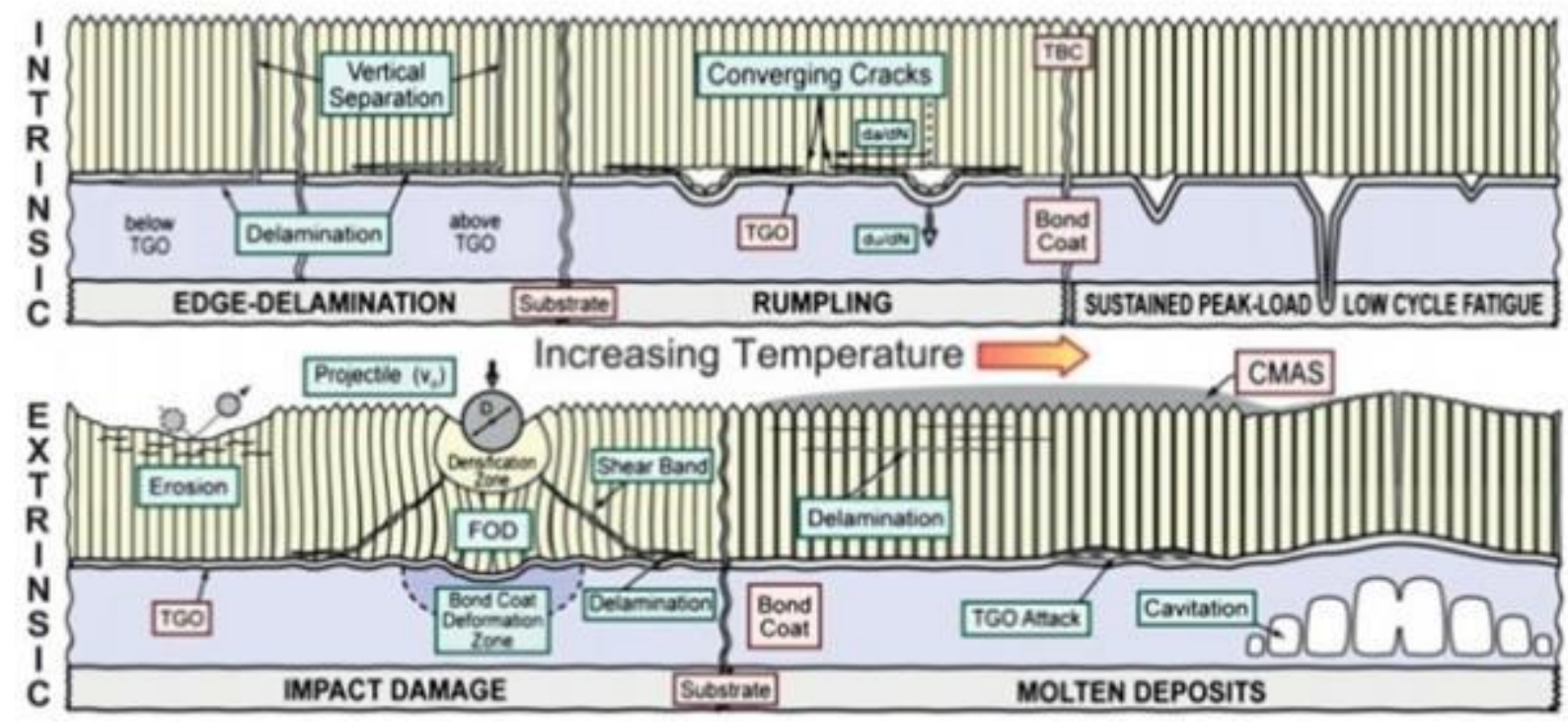

Figure 8: A summary of several mechanisms that promote spallation. Intrinsic mechanisms are governed by strain misfits between the layers during thermal cycling. Extrinsic mechanisms are from external factors [18]

\section{1: Intrinsic Mechanisms}

The intrinsic failure mechanisms are associated with the strain differences and misfits within the constituent materials. The mechanisms are studied with the help of furnace cycle and burner rig tests. Final TBC failure is generally characterized by buckling and/or spalling of the top coat. One mechanism 
involves the delaminations from the TGO formation between the $\mathrm{BC}$ and ceramic top coat and the grain boundary ridges on the $\mathrm{BC}$ surface. The bond coat exhibits imprints of the grains in the TGO, which suggests brittle failure from loss of adhesion at the metal/oxide interface [18]. Once the TGO reaches a critical thickness, delaminations around the TGO interfaces are common.

Another intrinsic mechanism is referred to as roughening, rumpling, or ratcheting. In rumpling, the BC surface along with the TGO becomes wavy upon thermal cycling [19]. Small cracks develop above the TGO and can lead to the buckling of the upper parts of the ceramic coat.

The last intrinsic failure mechanism comes from damages resulting from high temperature low cycle fatigue tests. Cracks initiate at the bond coat and TGO interface and propagate perpendicular to the load direction into the substrate [20]. Thus, integrity of the turbine components is compromised.

\section{2: Extrinsic Mechanisms}

Extrinsic mechanisms cannot be reproduced in furnace cycling or conventional burner rig tests. One mechanism is foreign object damage (FOD). Large particle damage can cause spallation at the leading edge of airfoils [21]. Less severe particles may just thin the TBC via erosion. Erosion and spallation can have disastrous effects on the performance of critically loaded components when TBC is relied upon to keep the component substrate below the melting point.

Molten deposits that adhere to the surface of the TBC are also listed as an extrinsic mechanism. The effect of the deposits will be discussed in the literature review in the next chapter and are the focus of this work. 


\section{CHAPTER 4: REVIEW OF RELEVENT LITERATURE}

Understanding the degradation effects of molten particulate deposition on TBC can help increase the life of the hot stage components in an integrated gasification combined cycle (IGCC) gas turbine and aid in the design of advanced TBC systems. Molten deposition can negatively impact the thermal and mechanical properties of the protective coatings applied to the components. In addition, the film-cooling scheme can be affected from the alteration of cooling patterns both upstream and downstream of the cooling holes. If the cooling holes are blocked from the deposition, the effectiveness of the TBC system becomes even more important. Deposits in the turbine section from fly ash become molten in the combustor and adhere to the to the first stage turbine vanes [22]. Figure 9 shows the path of the deposition created by Logan et al. [22].

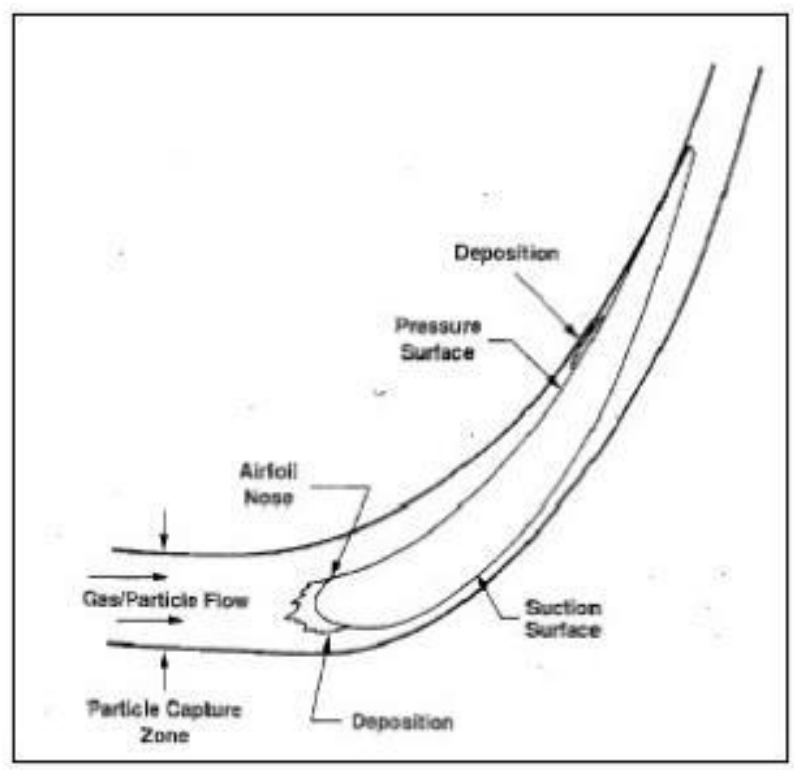

Figure 9: Particulate deposition capture zone on a gas turbine vane [22] 


\section{1: Degradation from Molten Deposits}

There are several sources of particulate matter that may melt and adhere to the turbine components. Among the sources are sand ingestion, volcanic ash ingestion, and particulates from the combustion of alternative fuels such as coal synthesis gas (syngas).

Primarily in aircraft engines, molten deposits from calcium-magnesium-alumino-silicate (CMAS) attacks develop from siliceous debris introduced through the intake air. Once the temperatures exceed $1150^{\circ} \mathrm{C}$, the ingested particles and debris become molten and adhere onto the top surface of ceramic top coat. Wellman et al. [23] found several degradation mechanisms from CMAS on the EB-PVD TBC. Mechanisms listed in the study are severe damage to the YSZ column morphology from dissolution which reduces the TBCs insulating properties and strain tolerance, change in the YSZ crystal structure from tetragonal to monoclinic from depletion in yttria, and an increase in the erosion rate of the top coat.

Levi et al. [24] also performed studies on the thermomechanical and thermochemical aspects of the CMAS interactions with an EB-PVD YSZ coating. The study found the molten deposits de-stabilized the non-transformable, metastable tetragonal $t^{\prime}$-YSZ top coat as it infiltrate the ceramic top coat towards the TGO. The infiltration can lower the strain tolerance after the deposit cools within the TBC. In addition, the stress mismatch from the difference in the coefficient of thermal expansion (CTE) between the YSZ and the molten deposits during the CMAS solidification can cause spallation within the top ceramic coatings. This occurs when the turbine cools and heats up during shutdown and startup (low cycle fatigue). An illustration of the delamination mechanism of the YSZ coating from Whitman and Wellman is given in Figure 10 [25]. Levi also lists creep cavitation of the bond coat as a degradation mechanism if the CMAS heavily penetrates the TBC. 


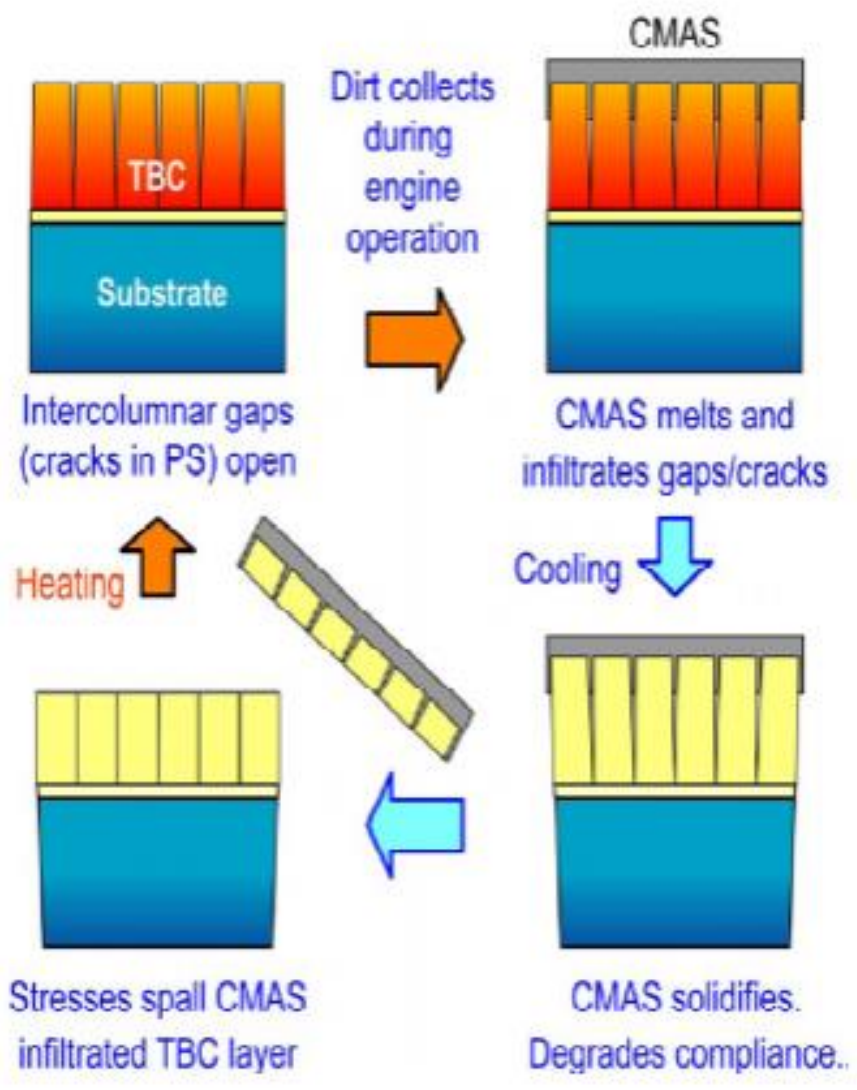

Figure 10: Schematic Illustration of the delamination mechanism associated with CMAS [25]

Deposits can also form due to the intake of volcanic ash. Drexler et al. [26] found that volcanic ash ingested by jet engines can to damage conventional APS YSZ thermal barrier coatings. The eruption of the Eyjafjallajökull volcano in Iceland in 2010 sent volcanic ash clouds into the air. A jet aircraft can inadvertently fly through the clouds and intake the ash. The ash from Eyjafjallajökull has been examined in many studies and found to form a glass at roughly a melting point of $1160^{\circ} \mathrm{C}$. The nature of the damage is similar to the degradation caused by molten CMAS when the molten deposits are able to infiltrate the pores and cracks of an APS 7YSZ TBC. The molten ash penetrates towards the bond coat and substrate and depletes the Y content, destabilizing the tetragonal phase of the YSZ to the monoclinic phase. The study by Drexler et al. also looks at newer TBCs (a Gadolinium doped YSZ, $\operatorname{Gd}_{2} \mathrm{Zr}_{2} \mathrm{O}_{7}$, and another 
composed of $\mathrm{ZrO}_{2}$ solid solution containing $\mathrm{Y}_{2} \mathrm{O}_{3}, \mathrm{Al}_{2} \mathrm{O}_{3}$, and $\mathrm{TiO}_{2}$ ) and their mitigation to the volcanic ash. Figure 11a contains the general mechanism that molten volcanic ash can attack a conventional 7YSZ APS TBC [26]. Figure 11b shows that the newer TBCs prevent significant penetration of the molten ash.

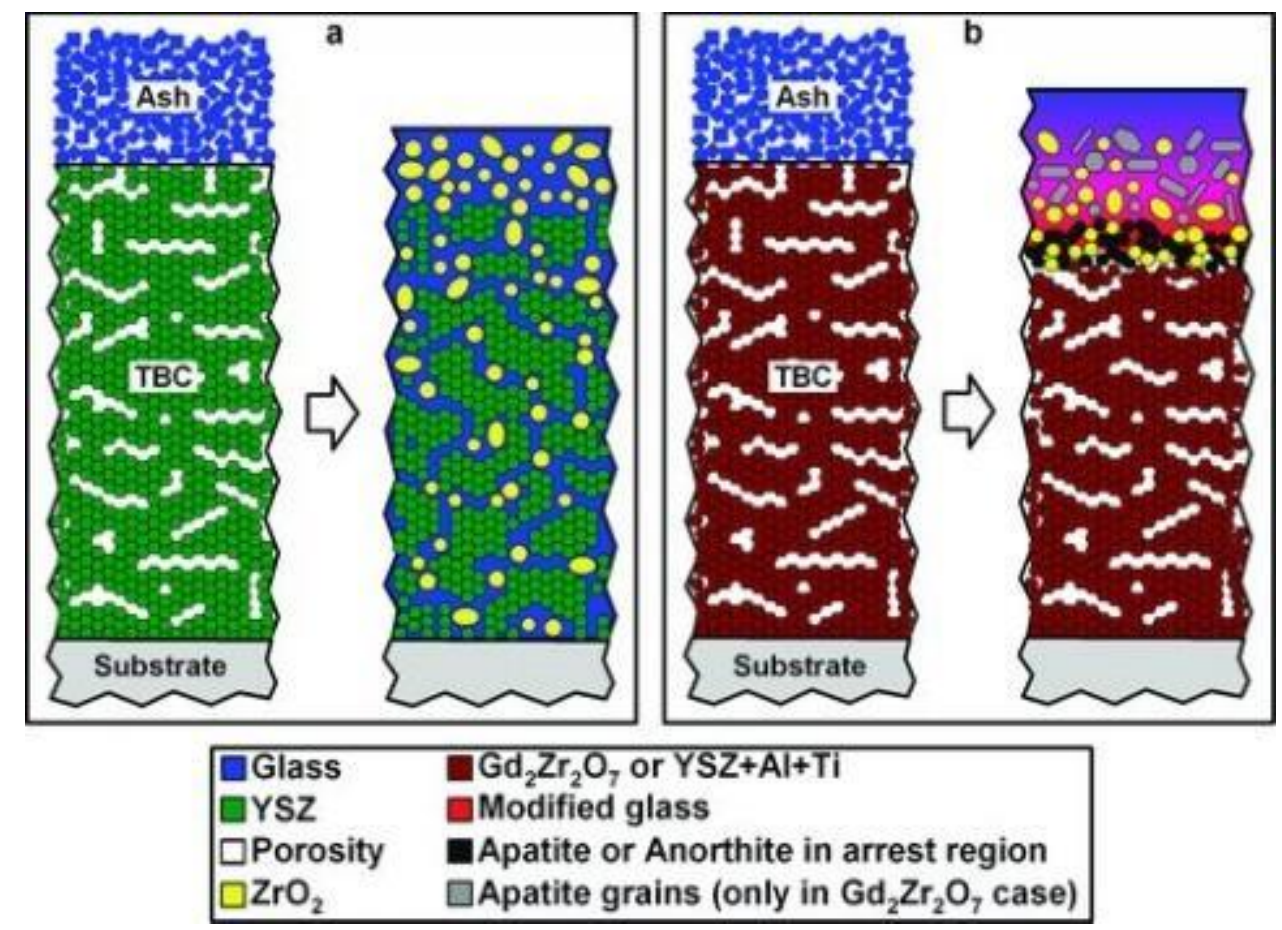

Figure 11: Cross-sectional schematic diagrams of APS TBCs with ash deposits before and after exposure to heat. a) $7 \mathrm{YSZ}$ and b) $\mathrm{Gd}_{2} \mathrm{Zr}_{2} \mathrm{O}_{7}$ or $\mathrm{YSZ}+\mathrm{Al}+\mathrm{Ti}$ [26]

Padture [27] also experimented with traditional APS YSZ coatings and a newer TBC $\left(\mathrm{Gd}_{2} \mathrm{Zr}_{2} \mathrm{O}_{7}\right)$ and their mitigation of molten deposits from syngas simulated lignite fly ash. The lignite fly ash was found to penetrate $100 \%$ of the APS 7YSZ TBC and the nature of the damage is similar to that of CMAS and Eyjafjallajökull fly ash. The APS $\mathrm{Gd}_{2} \mathrm{Zr}_{2} \mathrm{O}_{7} \mathrm{TBC}$ resisted significantly more of the molten lignite fly ash deposition attack, which penetrated roughly $25 \%$ of the TBC thickness. The lack of infiltration depth appeared to be due to a formation of an impervious, stable crystalline layer at the fly ash/ $\mathrm{Gd}_{2} \mathrm{Zr}_{2} \mathrm{O}_{7} \mathrm{TBC}$ interface. 
The molten deposits on TBC from foreign objects all change the morphology of the YSZ coatings, destabilize the crystal structure of the ceramic coating, and cause a degradation in the thermal and mechanical properties of the YSZ. The purpose of the current work was to investigate the type of degradation of molten deposits from syngas on the DVD TBC system. Many of the degradation mechanism discussed in the chapter should apply for the current study, and with the application of a micro-indentation procedure (discussed in a later chapter), the mechanical properties of the TBC system can be evaluated.

\section{2: TBC Testing: Application of Micro-Indentation}

Several non-destructive evaluation (NDE) techniques have been developed to assess the mechanical qualities of the thermal barrier coatings. Zhao and Xiao [28] measured the residual stresses in TBCs using a photoluminescence piezospectroscopy and indentation technique. The techniques which include a nano-indenter with a Berkovich (three-sided pyramid) indenter tip found that the Young's modulus decreased the further away from the TGO-TBC interface.

Tannenbaum [29] studied the use of a load-based micro-indentation method at West Virginia University to predict the failure location of the TBC before its occurrence. First, the study showed that the micro-indentation system provided accurate surface stiffness responses, and through the use of scanning electron microscopy, the evaluation technique was proven not to cause micro-cracking or debonding of the TBC system [30]. Once the NDE is verified, the study found that the area that displayed a relative increase in the surface stiffness response enabled early detection of initial TBC spallation failures (verified using SEM).

Otunyo [15] performed similar experiments at WVU to evaluate the surface stiffness responses but at room and elevated temperatures. Additionally, the elevated temperature tests were also exposed to an air or carbon dioxide (CO2)/steam environmental conditions to simulate the harsh conditions the TBC components would experience. The research showed that an increase in the stiffness response meant an 
increase in residual stresses from high interfacial rumpling and non-uniform oxide growth, which allowed to determination of the TBC's thermal life cycle.

The two studies by Tannenbaum [29] and Otunyo [15] show that the micro-indentation systems at WVU can be used as a non-destructive test to evaluate the mechanical properties of the TBC. For the current study, the use of the micro-indentation systems allowed for evaluation of the effects of deposition on the mechanical properties of the DVD TBC system. 


\section{CHAPTER 5: TEST ARTICLE DESIGN, FLY ASH DEPOSITION PARAMETERS, AND TEST ARTICLE SECTIONING}

Chapter 5 contains the experimental set-up from the previous study by Murphy [10] and the current study. The test article design section discusses the design of the articles to simulate a first stage turbine vane and a description of the TBC layers deposited on top. The fly ash parameter describes the matching of the laboratory conditions to the engine condition for the simulated particulate matter completed by Murphy. Lastly, the sectioning section describes the fabrication of the test samples from the aforementioned test articles.

\section{1: Test Article Design}

The test articles were designed to simulate the pressure side of a first stage turbine vane at incline angles of $10^{\circ}$ and $20^{\circ}$. HAYNES 230 (HA230) alloy was used as the substrate material because of the material's excellent high-temperature strength, resistance to oxidizing environments, and lower thermal expansion characteristics than most high-temperature alloys. The chemical composition of HA230 is listed below in Table 1 [31]. Each article has four round cooling holes with a $3.9 \mathrm{~mm}$ diameter placed on the face at an angle $30^{\circ}$ to the surface. The cooling holes were scaled to $8 \mathrm{X}$ the size of an actual gas turbine cooling hole using Reynolds similarity. A hollowed out backside is connected to a high-pressure air system that allows cooling air to be delivered evenly to the face. Figure 12 displays isometric views of the test article design [1].

Table 1: HAYNES 230 Chemical Composition [31]

\begin{tabular}{|cccccccccccc|}
\hline \multicolumn{10}{|c|}{ HAYNES 230 alloy, Nominal Chemical Composition, Weight Percent } \\
\hline $\mathrm{Ni}$ & $\mathrm{Cr}$ & $\mathrm{W}$ & $\mathrm{Mo}$ & $\mathrm{Fe}$ & $\mathrm{Co}$ & $\mathrm{Mn}$ & $\mathrm{Si}$ & $\mathrm{Al}$ & $\mathrm{C}$ & $\mathrm{La}$ & $\mathrm{B}$ \\
\hline 57 & 22 & 14 & 2 & 3 & 5 & 0.5 & 0.4 & 0.3 & 0.10 & 0.02 & 0.015 \\
\hline
\end{tabular}



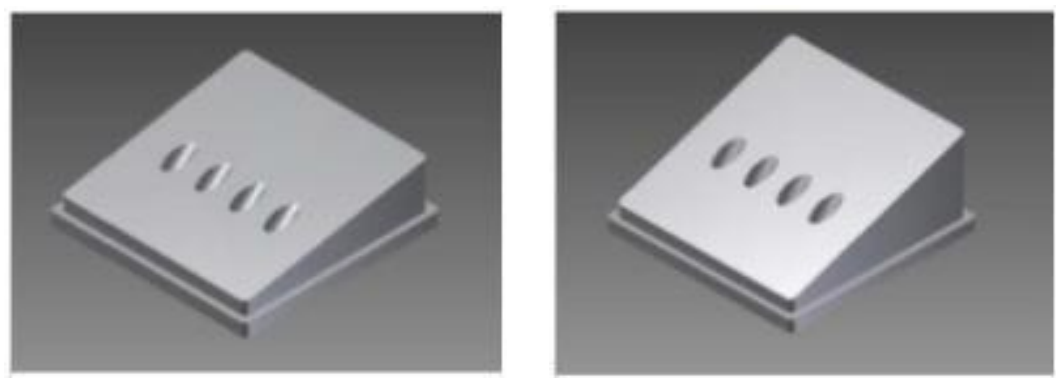

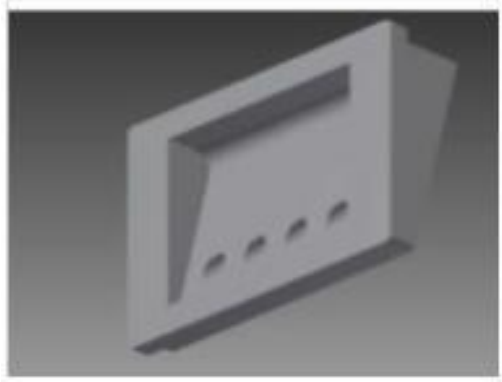

(a)

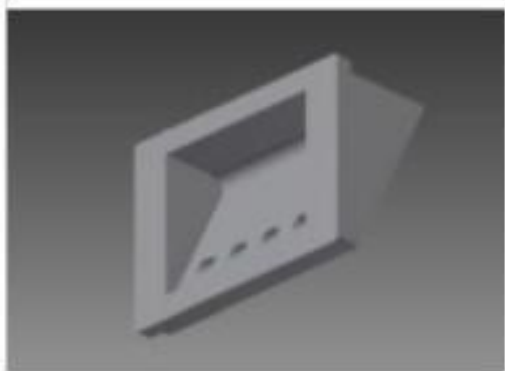

(b)

Figure 12: Isometric CAD model view of the (a) $10^{\circ}$ and (b) $20^{\circ}$ test articles [1]

Thermal barrier coatings (TBC) were applied to each test article using a Directed Vapor Deposition (DVD) process developed and applied by Directed Vapor Technologies International, Inc. (DVTI) [32]. The DVD process, shown in Figure 13, uses an inert gas jet around the vapor to direct it toward the surface, which is a more efficient process than electron beam physical vapor deposition (EBPVD) [33]. In addition to the efficient high deposition rate, the DVD process features non line-of-sight deposition and controlled intermixing during multiple source evaporation. These two features allow for coating deposition on complex engine components and enable novel coating architectures. The bond coat of the TBC system is a $\Upsilon-\Upsilon^{\prime}$ platinum aluminide (PtAl) developed by Brian Gleeson at the University of Pittsburgh and Iowa State University and has an approximate thickness of 15-20 $\mu \mathrm{m}$ [34]. The $\Upsilon-\Upsilon^{\prime} \mathrm{PtAl}$ bond coat allows for the phase properties to closely match those of the nickel-based superalloy. The ceramic top coat layer was applied as 7\% Yttrium Stabilized Zirconia (7YSZ) with an approximate thickness of $400 \mu \mathrm{m}$. The cooling holes were masked during the coating process, which created a shallow trench. A trench is actually employed in modern day gas turbine film-cooling schemes [35]. Figure 14 displays the two angled test articles after TBC had been applied [1]. 


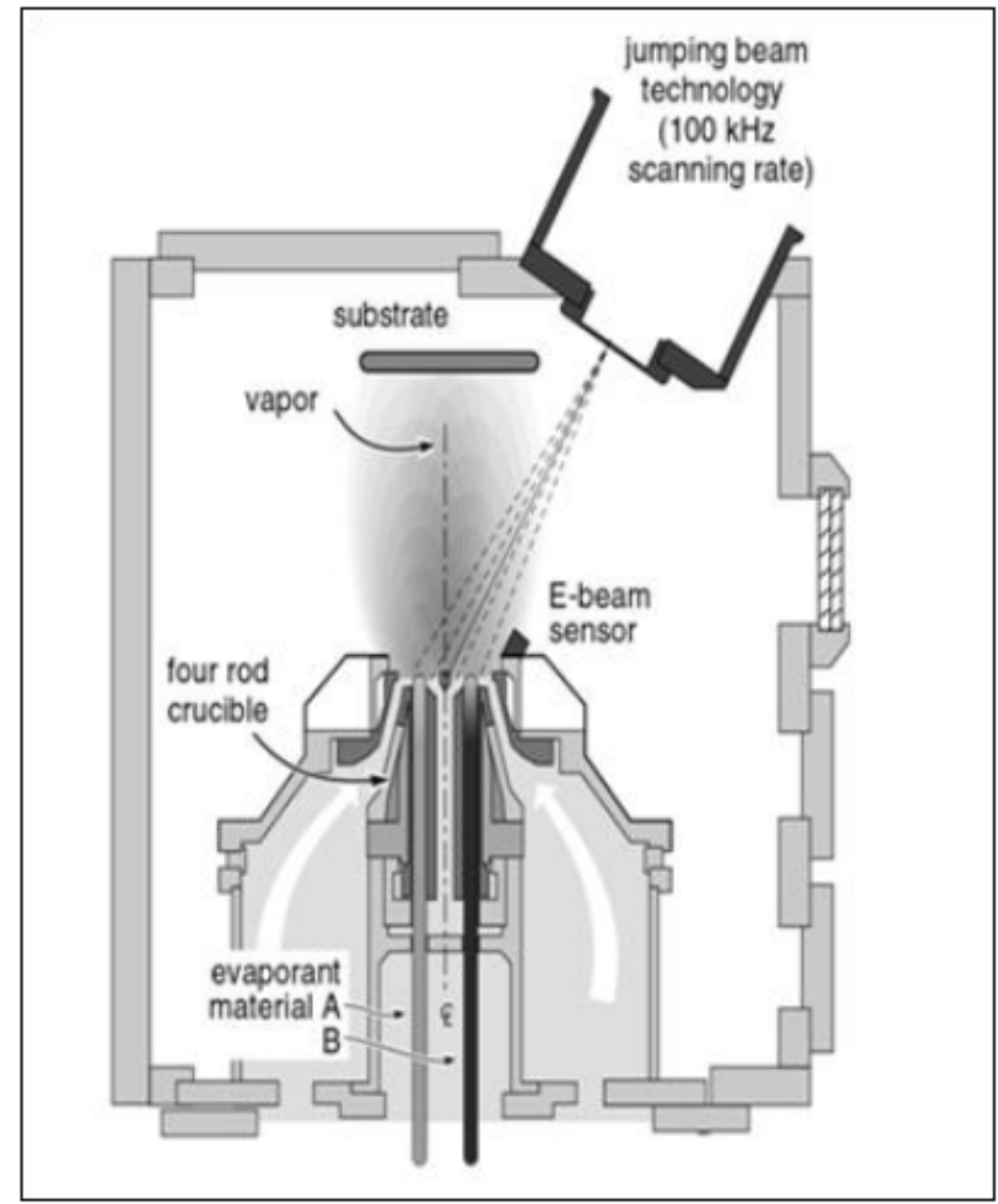

Figure 13: Schematic of the directed vapor deposition (DVD) process developed by DVTI [33]

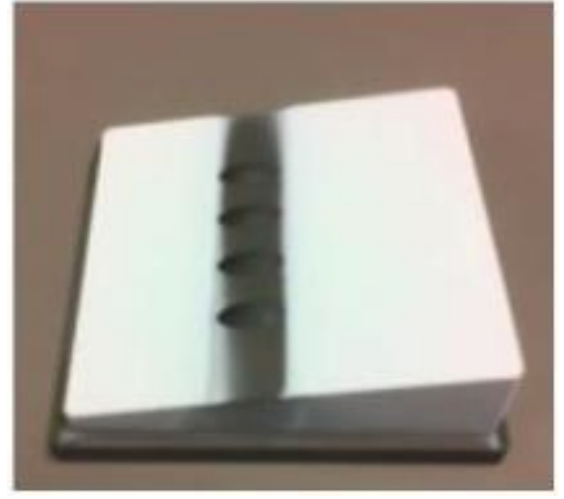

(a)

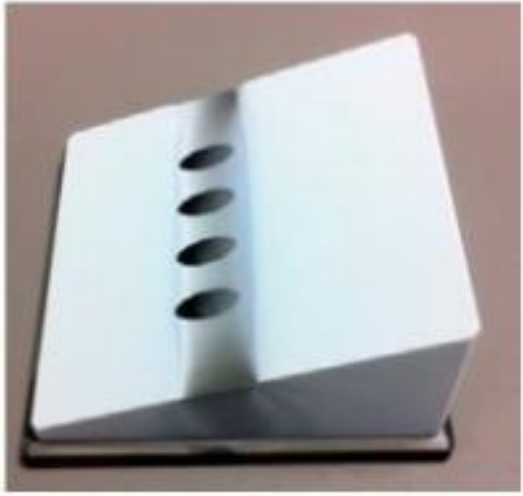

(b)

Figure 14: Photographs of the (a) $10^{\circ}$ and (b) $20^{\circ}$ test articles with $\mathrm{TBC}$ before deposition testing [1] 
Below in Figure 15 contains the morphology of a DVD YSZ coating during the development of the deposition process by Hass et al. [36]. The DVD YSZ layer reveals a columnar structure with fine columns with 1-2 $\mu \mathrm{m}$ diameter and coarser columns with diameters of 10-20 $\mu \mathrm{m}$. The YSZ columns exhibit parallel growth and have perpendicular intercolumnar voids. The porosity was generally aligned to the substrate. The 7YSZ coatings produced using the DVD technique have also been found to have thermal conductivities as low as $0.8 \mathrm{~W} / \mathrm{mK}$ if a zig-zag pore microstructure is used [37]. The zig-zag microstructure allows for a longer thermal diffusion path. A cross-section SEM micrograph of the asdeposited TBC system in the current study can be seen in Figure 16.

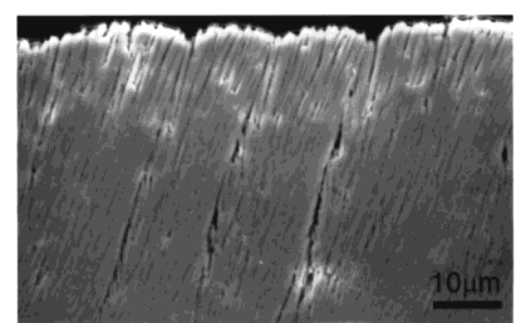

(a)

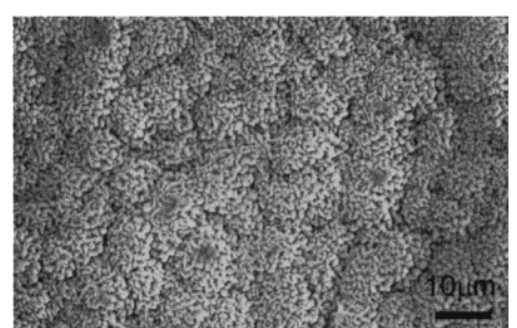

(b)

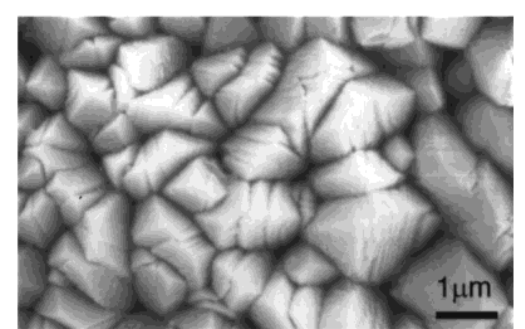

(c)

Figure 15: SEM micrographs of DVD 7YSZ layer using a deposition rate of $\sim 15.0 \mu \mathrm{m} \mathrm{min}^{-1}$ and temperature of $1000^{\circ} \mathrm{C}$ showing a) the polished cross-section, b) the twofold columnar structure, and c) the faceted surfaces of the finer columns [36]

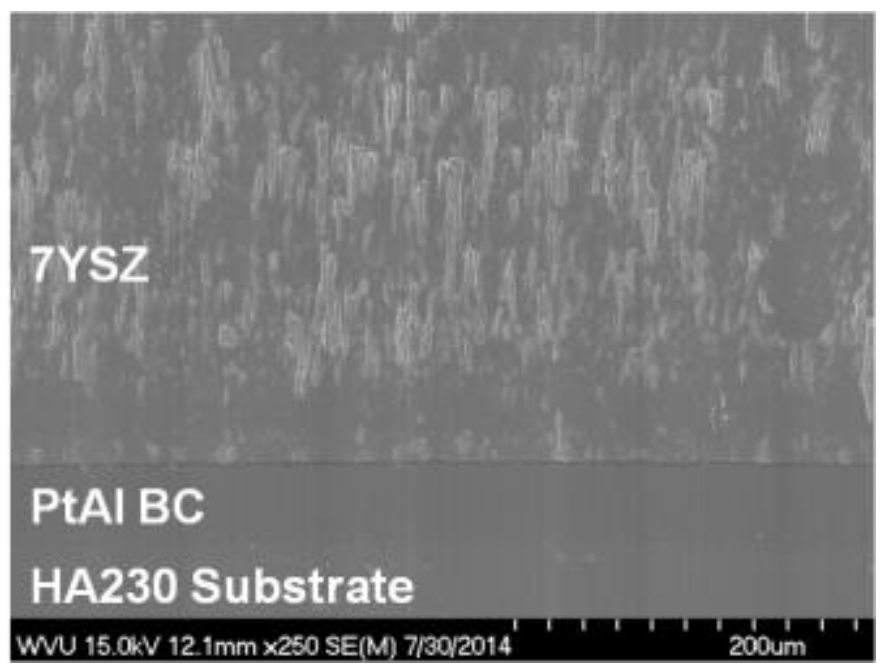

Figure 16: Polished cross-section SEM micrograph of the as deposited DVD TBC system 


\section{2: Particulate Composition, Scaling, and Seeding}

Unlike previous molten deposit and $\mathrm{TBC}$ studies where the molten deposit was formed by applying a paste onto the TBC and heat treated, in the current study, the ash particulate was injected into a high pressure, high temperature facility and impacted onto the TBC coated articles. The aerothermal facility operates at temperatures ranging from 1350-1560 K, a pressure of 45 psig, and has a mass flow rate of $12 \mathrm{~kg} / \mathrm{s}$ [10]. It converts the circular flow from the combustor to a rectangular channel at the test section and allows backside cooling with front side optical access to the test articles. An image of the aerothermal facility and a cross-sectional schematic of the facility can be seen in Figure 17 [10].

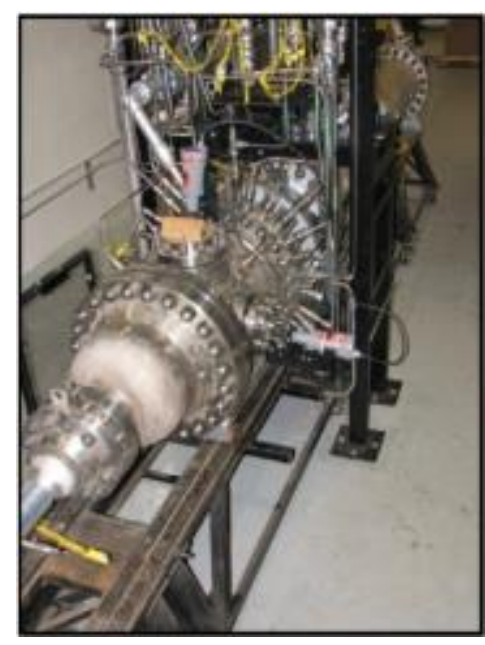

(a)

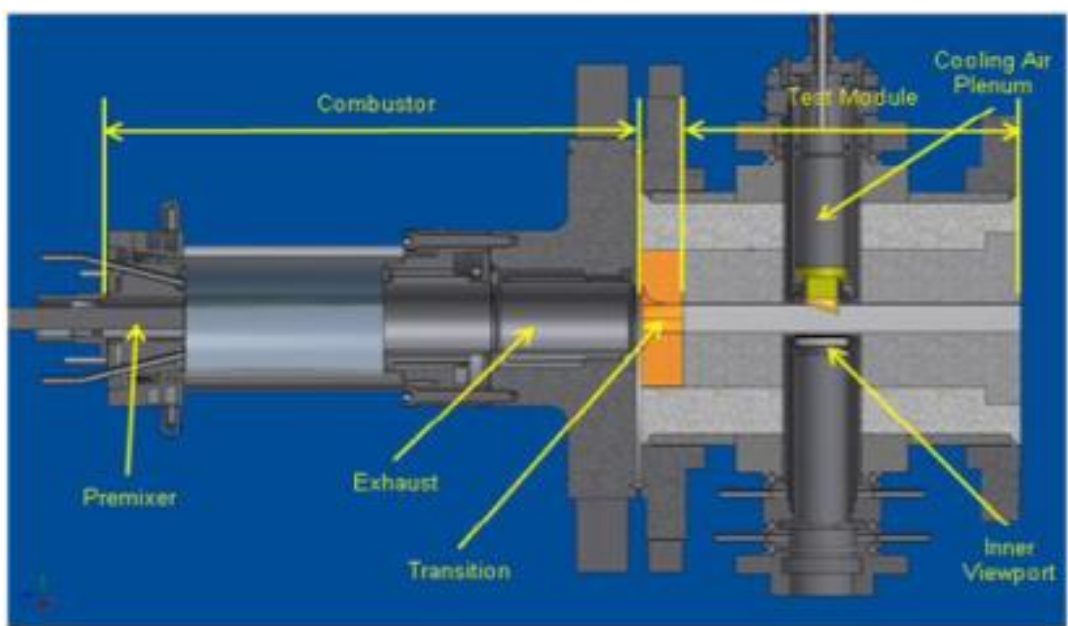

(b)

Figure 17: a) NETL High Pressure Aerothermal Facility and b) cross-sectional schematic of the aerothermal test section [10]

Fly ash was processed by Murphy et al. [1] prior to injection into the high-pressure combustion facility. Preparation steps included baking for moisture removal and grinding and sieving to achieve the particle size distribution desired for the scaling of particle inertial characteristics from engine to laboratory conditions. After filtration, an LS Particle Size Analyzer measured the mean particle size of the processed fly ash to be approximately $13 \mu \mathrm{m}$. Table 2 below displays the composition of the bituminous fly ash in the current study [1]. The size distributions of the processed fly ash can be seen in Figure 18 [38] and was compared to the results from a previous study completed by Smith et al. [39]. 
Table 2: Bituminous Coal Ash Composition [1]

\begin{tabular}{|lcccccc|}
\hline Oxides: & $\mathbf{S i O}_{\mathbf{2}}$ & $\mathbf{C a O}$ & $\mathbf{F e}_{\mathbf{2}} \mathbf{O}_{\mathbf{3}}$ & $\mathbf{A l}_{\mathbf{2}} \mathbf{O}_{\mathbf{3}}$ & $\mathbf{S O}_{\mathbf{3}}$ & $\mathbf{K}_{\mathbf{2}} \mathbf{O}$ \\
\hline wt. $\%$ & 53.8 & 4.39 & 8.87 & 25.35 & 1.15 & 2.23 \\
\hline
\end{tabular}

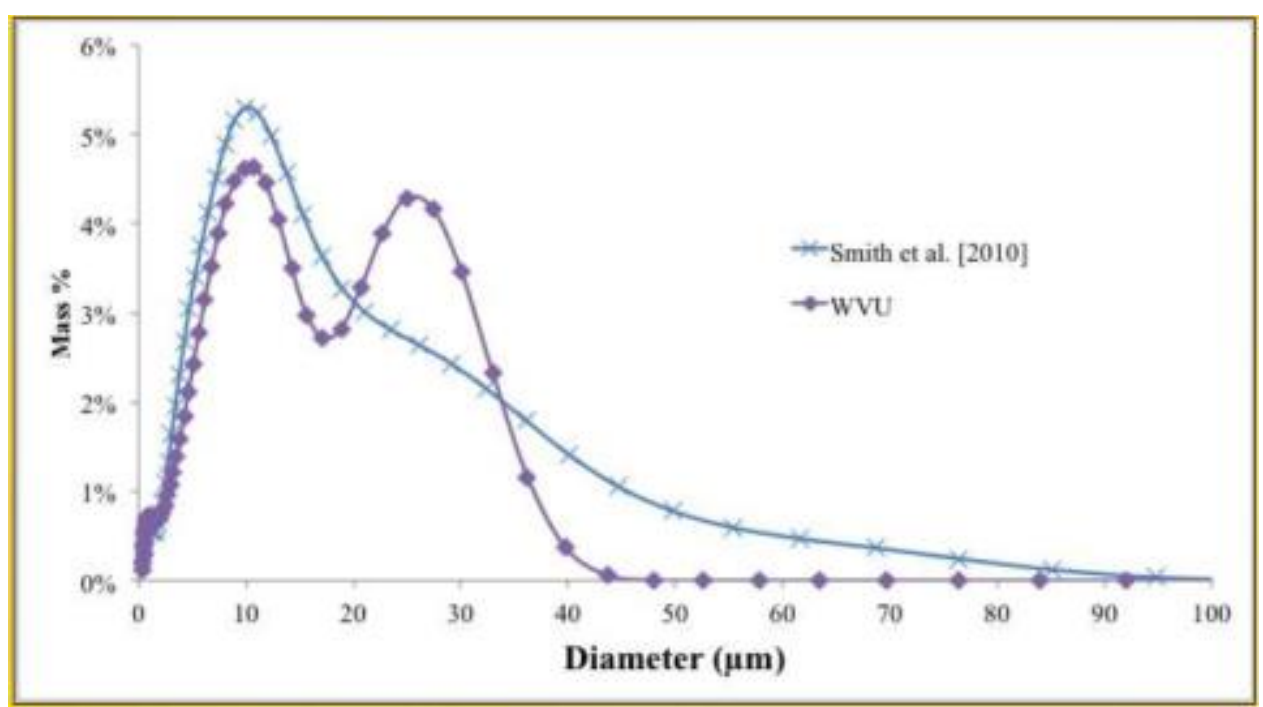

Figure 18: Comparison of size distributions between the study by Murphy and previous literature [38]

To scale the particle inertial characteristics, the Stokes number was matched between engine conditions and laboratory, which set the desired mean particle diameter [40]. The Stokes number determines the behavior of the particles in a fluid flow, whether it follows the fluid streamlines or their own inertial path. For the study by Murphy et al. [1], the Stokes numbers were calculated for fly ash particles that range from $0.5 \mu \mathrm{m}$ to $47 \mu \mathrm{m}$ for the engine and laboratory conditions and shown in Table 3 [1]. For the calculations, the following assumptions were made: 1) the fly ash particles have zero slip velocity meaning that they traveled with the same velocity as the mainstream hot gas path. The engine mainstream velocity, 2) $U_{\infty}=150 \mathrm{~m} / \mathrm{s}$, which was calculated assuming a turbine inlet Mach number of 0.2 , and 3) a turbine inlet temperature of $1509 \mathrm{~K}$ [41]. Because the study by Murphy et al. [1] was designed to determine the effects of particle interaction with and deposition around film cooling holes, the film-cooling hole diameter was chosen as the obstacle length scale for calculating Stokes number. 
Table 3: Stokes Number Conditions [1]

\begin{tabular}{|l|c|c|}
\hline & Laboratory & Engine \\
\hline Mainstream Temperature, $\mathrm{T}_{\infty}(\mathrm{K})$ & 1339 & $1509[41]$ \\
\hline Fly Ash Density $[7], \rho_{\mathrm{p}}\left(\mathrm{kg} / \mathrm{m}^{3}\right)$ & 1980 & 1980 \\
\hline Cooling Hole Diameter, $\mathrm{d}(\mathrm{mm})$ & 4.0 & 0.5 \\
\hline Mainstream Velocity, $\mathrm{U}_{\infty}(\mathrm{m} / \mathrm{s})$ & 66 & 150 \\
\hline Mainstream Viscosity, $\mu$ & $4.9 \times 10^{-5}$ & $5.3 \times 10^{-5}$ \\
\hline Median Particle Size, $\mathrm{d}_{\mathrm{p}, \text { med }}(\mu \mathrm{m})$ & 13.0 & 3.2 \\
\hline Median Particle Stokes Number, Stk $\mathrm{med}_{\text {med }}$ & 6.3 & 6.3 \\
\hline
\end{tabular}

The Stokes number was plotted relative to the fly ash particle diameter in laboratory and engine conditions and is shown in Figure 19 [1]. The results showed that, to match the inertial characteristics of an approximately $3 \mu \mathrm{m}$ particle in the engine, the laboratory fly ash particle was required to be $13 \mu \mathrm{m}$. This meant that particle sizes greater than $13 \mu \mathrm{m}$ generated for the experiments would interact with the scaled-up film cooling jets in the same way that smaller particles would interact with true scale film cooling jets in an actual engine.

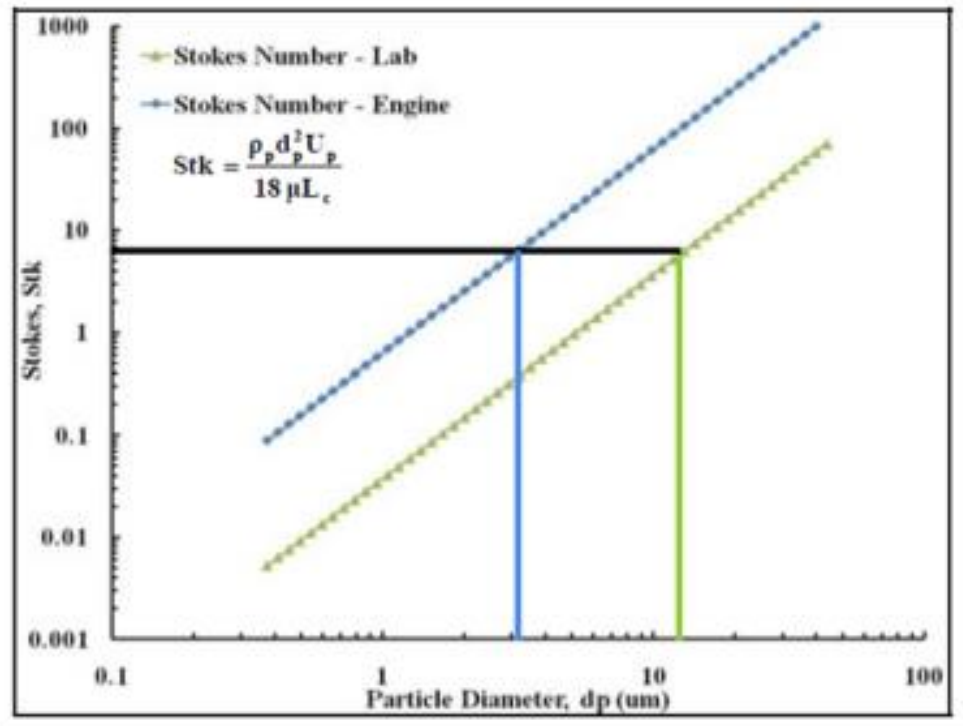

Figure 19: Stokes numbers plotted with respect to particle diameter for fly ash particles in engine and laboratory conditions [1]

Lastly, to inject the fly ash particulate into the high pressure combustion rig, a PS-20 Scitek pressurized particle seeder was used. The laboratory study was desired to match the particulate loading in 
parts-per-million by weight hour (ppmw-hr) that exist in actual gas turbine engines that operate over a period of 10,000 hours. To achieve this, the particulate concentration (ppmw) was increased which allowed the required hours to be decreased by the same scale. The particulate loading comparison is shown in Table 4 [1].

Table 4: Particulate Loading Comparison [1]

\begin{tabular}{|l|c|c|}
\hline & Engine & Laboratory \\
\hline Particulate Concentration (ppmw) & 0.02 & 33.3 \\
\hline Operation Duration (hr) & 10000 & 6 \\
\hline Particulate Loading (ppmw-hr) & $\mathbf{2 0 0}$ & $\mathbf{2 0 0}$ \\
\hline
\end{tabular}

Bons et al. found that bituminous fly ash that is injected in a similar fashion experiences a volumetric decrease when it becomes molten and from sintering [42]. The fly ash had a similar chemical composition as the one used in this study. This meant that the fly ash impacting the test articles would be slightly smaller than when it was injected using the particle seeder.

\section{3: Deposition Results}

In the study by Murphy et al. [1], deposition formed on only one side of the test articles. Figure 20 contains the side view of the test articles from the study performed by Murphy et al. [10]. The images are from a comparison between the face angles of the test articles at an operating temperature of $2315^{\circ} \mathrm{F}$ and a blowing ratio (ratio of the coolant mass flux over the freestream mass flux) of 0.25 . Murphy et al. [10] found that the impaction angle led to an increase in deposition from this particular trial, which is consistent with the results from the study by Jensen et al. [43]. Additionally, Murphy found that the amount of deposition increased as the freestream temperature and particulate loading increases and when the blowing ratio decreases [10]. 


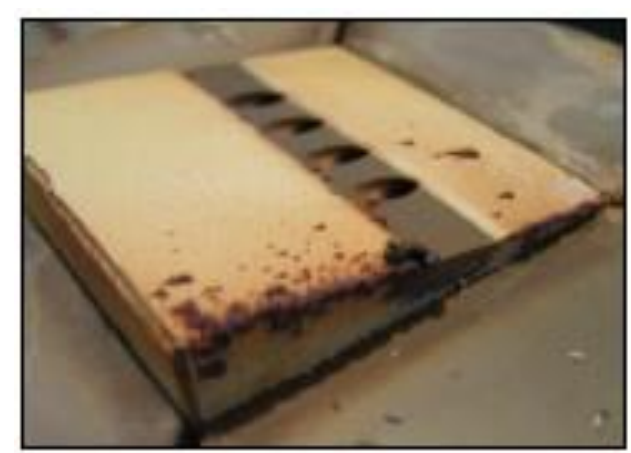

(a)

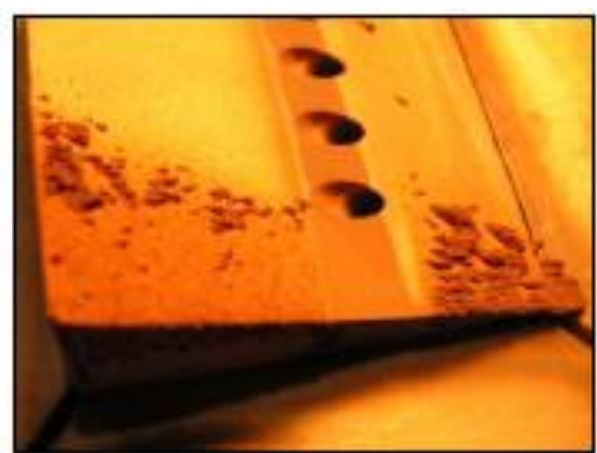

(b)

Figure 20: Side view of deposition on a) $10^{\circ}$ and b) $20^{\circ}$ test articles at blowing ratio of 0.25 [10]

Deposit formation on only one side of the test articles was due to a large deposit structure forming on the transition piece of the test section [38]. This transition piece is located upstream of the test articles. Figure 21 displays the structure with deposits on the left side of the piece [38]. The deposit structure on the test section transition piece created a swirl effect which promotes an uneven distribution of fly ash into the test section. This limited heavy deposition in areas and created a "stratified" amount of deposition. The swirl effect is unrealistic in a first stage vane flow of an actual gas turbine. Dilatation flow would help straighten the flow prior to entering the turbine.

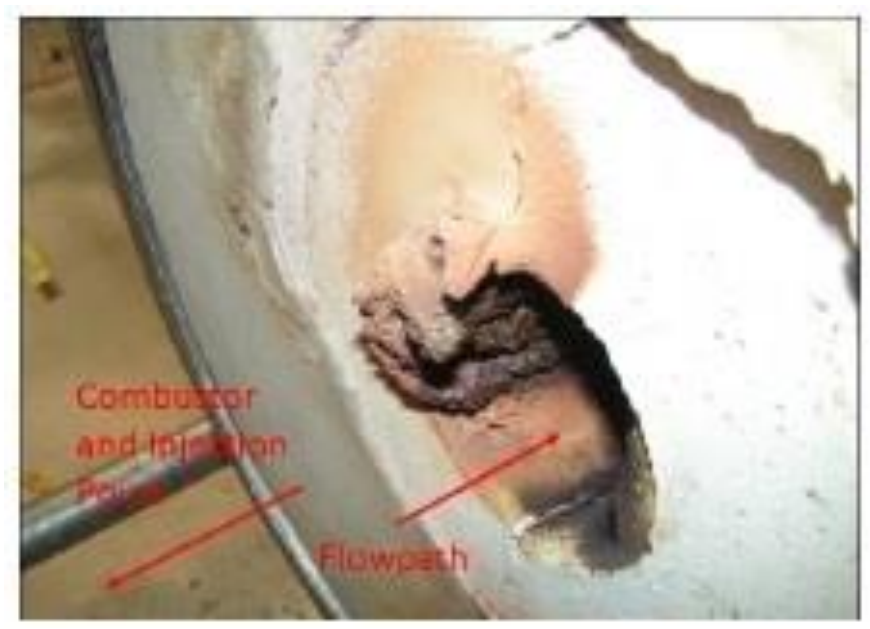

Figure 21: Image of large deposit formation on the left side of the transition piece [38] 
Additional deposit testing was performed after those seen in Figure 12. The test articles that are used for material analysis in this study are displayed in Figure 22 in the next chapter. The deposition stratification allows for the study to test and compare different sections within the same test article.

\section{4: Test Article Sectioning}

To determine the effect of the fly ash deposition on the mechanical properties and microstructure of the $\mathrm{TBC}$, the test articles had to be sectioned and trimmed into materials testing samples. A number of defects may be generated during the cutting process such as the formation of cracks. In order to section larger elements with ceramic coverings, devices such as abrasive saws and diamond precise saws are used [44]. The samples used in this study were sent to Westmoreland Mechanical Testing \& Research, Inc. to be cut using an abrasive saw method. Three of the test articles that were labeled and sent to be cut are shown in Figure 22. Test article 1 is a 20-degree angled article with the heaviest amount of deposition adherence. Test article 2 is also a 20-degree angled article, but has been unexposed to testing. The last test article, test article 3, has an angle of 10-degree and experienced significantly less deposition than test article 1.

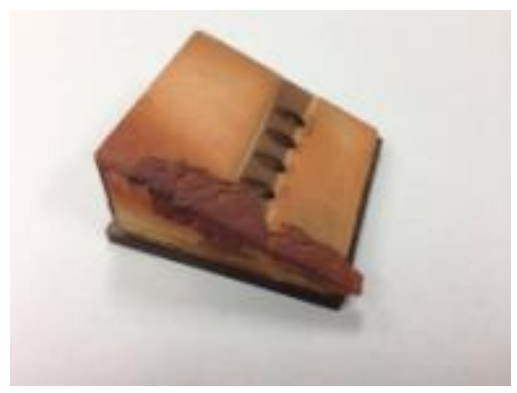

Test Article 1

(a)

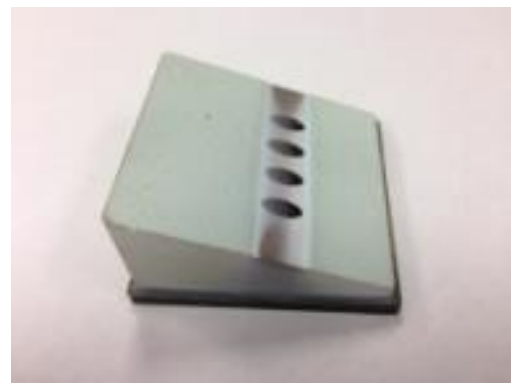

Test Article 2

(b)

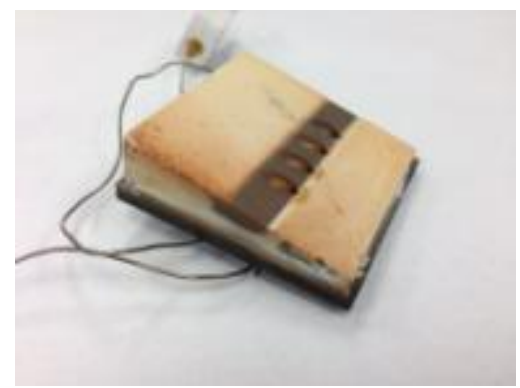

Test Article 3

(c)

Figure 22: Labels of the Test Articles: a) Test Article $1-\mathbf{2 0}^{\circ}$, Deposition, b) Test Article $2-\mathbf{2 0}^{\circ}$, Unexposed, c) Test Article 3 - 10 ${ }^{\circ}$, Deposition

Removing the angle of all the test articles was the first step in creating test samples, Figure 23. After the angle cut, a substrate thickness of approximately $1 / 4$ inches remains. The purpose of the cut was 
to produce flat samples for system compliance during the micro-indentation test, discussed in the next chapter.

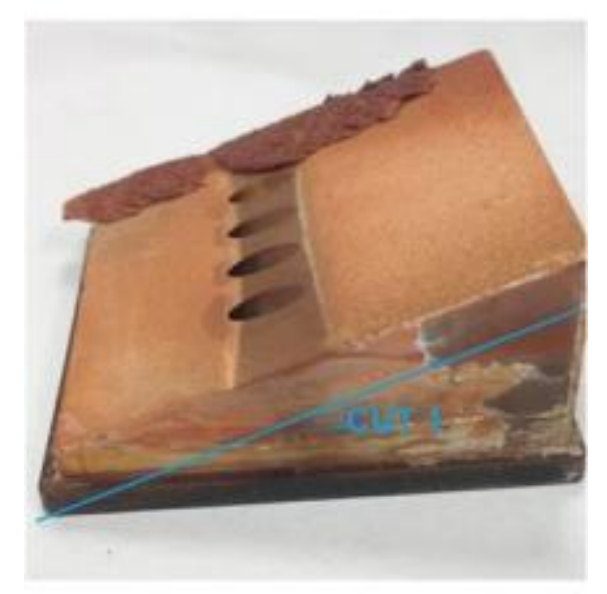

Figure 23: Cut 1 requested for Test Article 1

Once the angle was removed, a cut grid was created for the flat test articles to produce the test samples. Figure 21 details the cut list for the articles and labels for each test sample. The heavy deposition on test article 1 is outlined in Figure 21a.

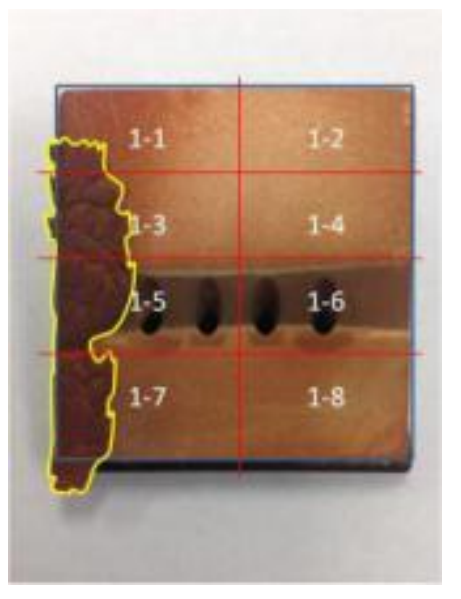

Test Article 1

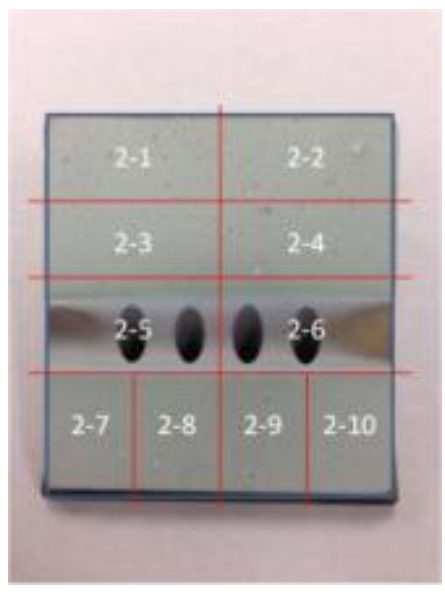

Test Article 2

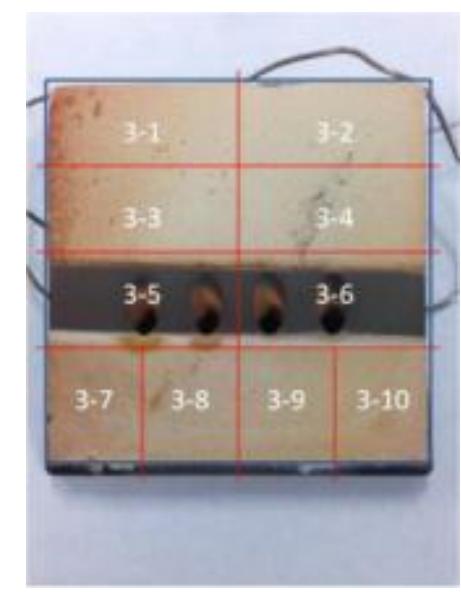

Test Article 3

(a)

(c)

Figure 24: Sectioning diagrams and sample numbers for a) Test Article 1, b) Test Article 2, and c) Test Article 3 
After completion of the sectioning, samples devoid of defects (delamination, cracking, etc.) were used for micro-indentation test and were then mounted and polished for SEM/EDS analysis.

\section{5: Elemental Composition of the Molten Deposits}

Prior to any micro-indentation, EDS spectrum analysis was used to confirm that the molten deposit on top of the YSZ coating has a similar elemental composition as the fly ash injected into the combustion facility (see Table 2). Figure 25 shows an SEM micrograph of a cross-section of sample 3-1 near the columnar tips of the YSZ coating. A "Point\&ID" X-ray spectrum was acquired at a single point placed in the deposition layer (circled in Figure 22).

Table 5 has the comparison between original processed fly ash and the results obtained from the EDS spectrum analysis of Figure 22 by weight percentage. Silicon, aluminum, and oxygen are chosen elements of interest since they have the highest weight percentage in Table 2. Table 5 confirms that the adhering deposits are the molten and cooled processed fly ash based on the elemental distribution results of the molten deposits. 


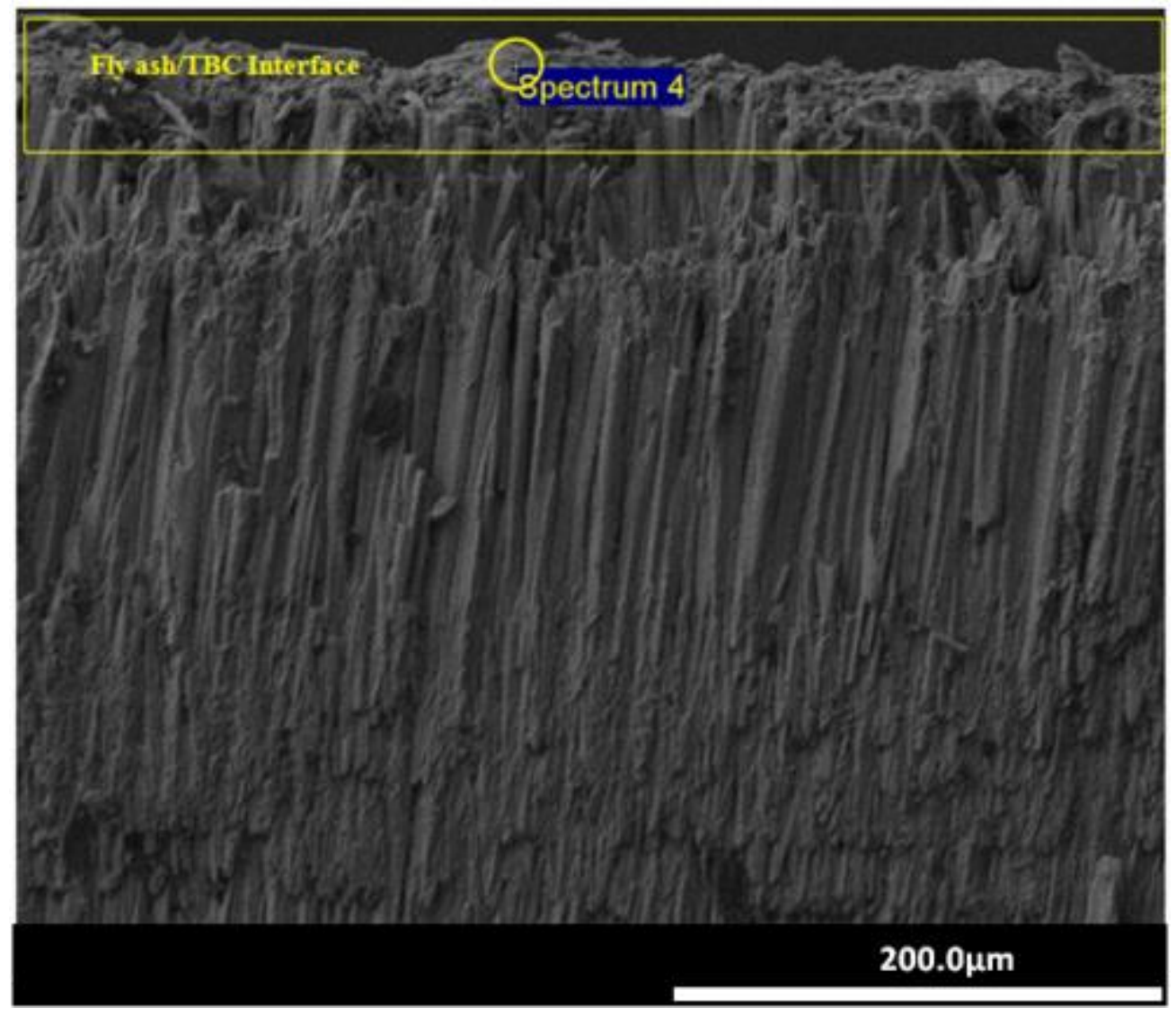

Figure 25: Point \& ID location of acquisition of spectrum results on sample 3-1

Table 5: Elemental Comparison between the processed fly ash and the molten deposit circled Figure 17 by weight percentage

\begin{tabular}{|l|c|c|c|}
\hline Constituent/wt\% & Si & Al & O \\
\hline Original Fly Ash & 28.09 & 14.98 & 51.74 \\
\hline Molten Deposit & 19.51 & 13.61 & 53.40 \\
\hline
\end{tabular}




\section{CHAPTER 6: MICRO-INDENTATION}

Since the 1800 s, indentation has been used as a mechanical testing process to determine the mechanical properties of an unknown sample. A hard indenter tip, in which the geometry and properties are known, is submerged into an unknown sample's material with a predetermined applied load and amount of time. The sample's response to the load is dependent upon its material properties, and by measuring the depth and area of the impression with various optical technologies, the unknown mechanical properties can be derived.

Indentation testing was developed to evaluate alloys, but has been adopted up by other industrial sectors such as lumber, ceramics, and glass production. Smaller and more precise indenters have been developed to accommodate the increasing production of nanotechnology. With the ability to obtain mechanical properties from small volumes of the materials, the small, precise indentation testing can be labeled as a non-destructive evaluation (NDE). With the use high resolution displacement or optical sensors monitoring throughout the indentation procedures, the load-depth plots produced can accurately determine the material's mechanical property information.

\section{1: Spherical Indentation}

Heinrich Hertz isn't just known for his contributions to the electrodynamics field. Two of his articles became crucial in the field of contact mechanics. While studying the Newton's ring phenomenon, he decided to study the deflection occurring at the points of contact between the two lenses [45]. In particular, Hertz was concerned with the how to quantify the localized deformation and pressure between the two spherical surfaces [29], seen in Figure 26 [46]. 


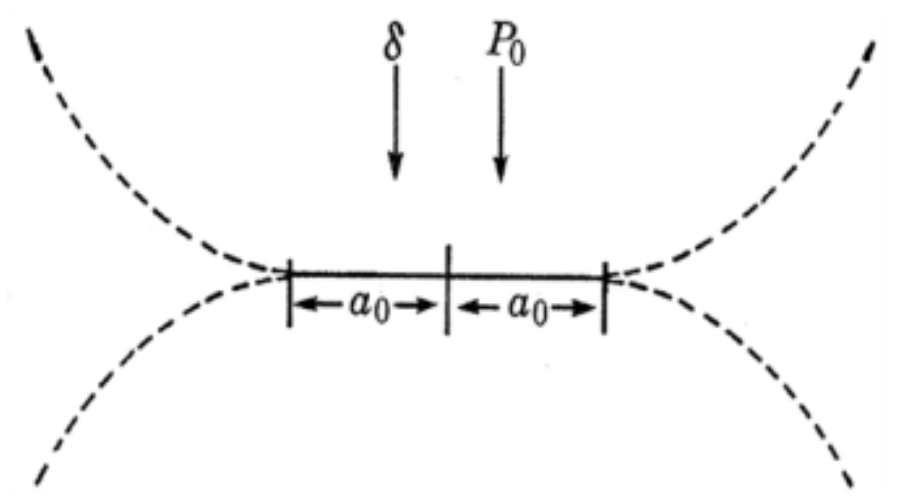

Figure 26: Contact deformation between two spheres [46]

He sought to assign the contact area and material relationship with a quadratic function. The relationship he developed became the basis in which all modern day contact mechanics theories are derived. In Equations (1) and (2), $P$ is the applied load, $d_{i}$ is the diameter of the spheres, $a$ is the contact area, $E_{R}$ is the reduced modulus, and $E$ and $v$ are the Young's modulus and Poisson's ratio respectively.

$$
\begin{aligned}
& a^{3}=\sqrt{\frac{3 P}{8 E_{R}\left[\frac{1}{d_{1}}+\frac{1}{d_{2}}\right]}} \\
& \frac{1}{E_{R}}=\frac{1-v^{2}}{E}+\frac{1-v_{i}^{2}}{E_{i}}
\end{aligned}
$$

Hertz established that the stresses and defections that arise from contact between two elastic solids, regardless of the shape, were subjected to geometrical deformation [47]. If the diameter of the second sphere is assumed to approach infinity, a function between a rigid sphere (with radius $R$ ) and flat surface is developed, Equation (3). For spherical indentation under idealized conditions and shallow depth, $h=a^{2} / R$, Lurie developed Equation (4) where $h_{e}$ represents elastic depth only [48].

$$
a=\frac{3}{4} \frac{P R}{E_{R}}
$$




$$
P=\left(\frac{4}{3}\right) E_{R} R^{1 / 2} h_{e}^{3 / 2}
$$

\section{2: Instrumented Indentation}

Instrumented indentation tests can be used to obtain mechanical properties of materials such as the elastic modulus and hardness values. While the hardness test measures the indentation size directly, instrumented indentation calculates the value based on the indenter's geometry and indentation depth [29]. As load is applied to the indenter, the material of the specimen directly beneath the indenter tip deforms plastically leaving a residual impression upon removal of the load. The contact area is too small for optical techniques, so it is calculated using the known indenter geometry and depth of penetration, from which the hardness value is estimated. The elastic modulus calculation is more complicated and requires additional parameters. The elastic modulus calculation theory and details with single point and multiple partial unloading are discussed in the following sections.

\subsection{1: Single Point Unloading}

Single point unloading indentation tests use one unloading slope in the load-displacement curve, shown in Figure 27, to find the reduced modulus [29].

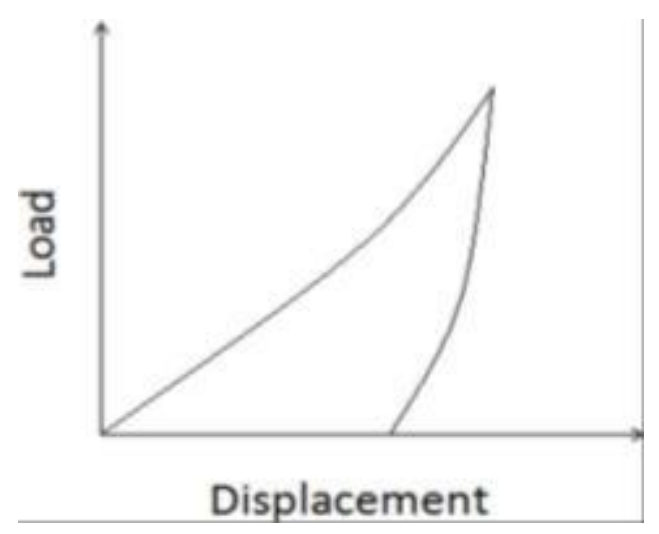

Figure 27: Load displacement curve for single point unloading algorithm [29]

This method provides an accurate and theoretically sound measurement of the material's elastic response. By using the slope of the load-displacement curve, the reduced elastic modulus $\left(E_{R}\right)$ can be 
calculated by Equation (5) where the contact area is calculated using a known indenter geometry and the indentation depth $\left(A=\pi a^{2}\right)$. In the equation, the derivatives of the load $(P)$ and indentation depth $(h)$ are used.

$$
E_{R}=\frac{1}{2} \frac{d P}{d h} \sqrt{\frac{\pi}{A}}
$$

The greatest advantage of this testing technique is the shallow penetration depths required. The testing technique can be deemed relatively non-destructive has it doesn't get interference from the substrate's material properties.

\subsection{2: Multiple Partial Unloading}

Developed at West Virginia University, the first generation of instrumented indentation analysis data reduction techniques required the use of a transparent sapphire spherical indenter. This transparent indenter measurement (TIM) system, along with phase shifting Twyman-Green and Moiré interferometer techniques can directly measure the out-of-plane deformation and contact radius throughout the process [29]. From the deformation and radii measurement, the elastic modulus and true stress strain relationship can be found. Since the technique requires use of sophisticated optical system, a second generation TIM data reduction technique was developed employing a partial unloading procedure shown in Figure 28 [29].

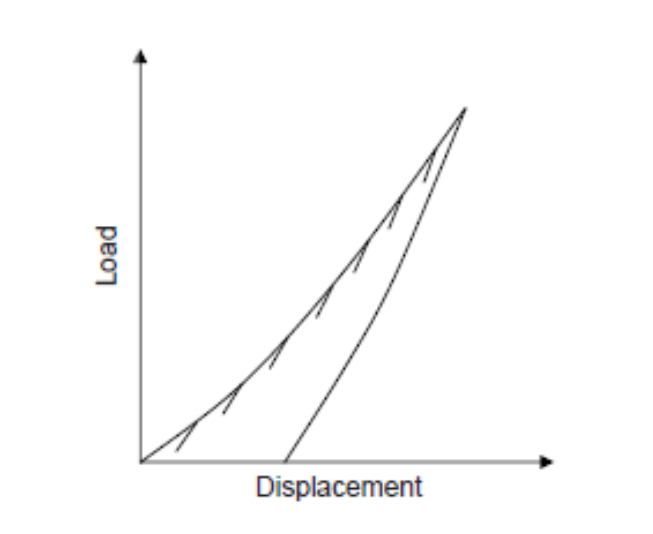

Figure 28: Load displacement curve for multiple partial unloading algorithm [29] 
The basic principle of the technique operates under the assumption that the total displacement is a function of the indentation depth and the compliance of the system. Equation (6) shows that the total displacement $\left(h_{\text {total }}\right)$ is the sum of the total indentation depth $(h)$ and the system deflection $\left(h_{s}\right)$. Furthermore, if the response is assumed to be solely elastic, the total indentation compliance $(d h / d P)$ is equivalent to the elastic compliance $\left(d h_{e} / d P\right)$. Taking the derivative of Equation (6) with respect to the indentation load $(P)$, Equation (7) is achieved. Finally, replacing the indentation compliance with the elastic compliance from Equation (5) yields Equation (8).

$$
\begin{gathered}
h_{\text {total }}=h+h_{s} \\
\frac{d h_{\text {total }}}{d P}=\frac{d h}{d P}+\frac{d h_{s}}{d P} \\
\frac{d h_{\text {total }}}{d P}=\frac{1}{2 E_{R}} \sqrt{\frac{\pi}{A}}+\frac{d h_{s}}{d P}
\end{gathered}
$$

The reduced elastic modulus $\left(E_{R}\right)$ is still to be determined. Under the assumption that the system compliance is constant throughout the indentation test $\left(d h_{s} / d P=0\right)$, Equation (8) can be rearranged to show the elastic modulus is a function of the differences in the contact area and the slope between the partial unloading, Equation (9).

$$
E_{R}=\frac{1}{2} \sqrt{\pi}\left(\left.\frac{1}{\sqrt{A}}\right|_{2}-\left.\frac{1}{\sqrt{A}}\right|_{1}\right)\left(\left.\frac{d h_{\text {total }}}{d P}\right|_{2}-\left.\frac{d h_{\text {total }}}{d P}\right|_{1}\right)^{-1}
$$

This second generation TIM method still requires the use of an optical area measurement. Although the technique is proven to be accurate, the evolution of load based equations has helped to reduce the cost of the elastic modulus acquisition. Thus, a third generation of the TIM method is developed to employ a variation of the multiple partial unloading technique from the second generation but without any contact area measurement. If Equation (7) is rewritten with $P=a h_{e}^{m}$, where $a=$ $4 / 3 E_{R} R^{-1 / 2}$ and $m=3 / 2$, solving for $h_{e}$ and taking the derivative with respect to $\mathrm{P}$ yields Equation (10). 


$$
\frac{d h_{\text {total }}}{d P}=C P\left(\frac{1}{m}\right)^{-1}+\frac{d h_{s}}{d P}
$$

Lastly, if the system compliance $\left(C_{S}\right)$ remains constant throughout the multiple partial unloading steps, the total displacement compliance $\left(d h_{\text {total }} / d P\right)$ and $P^{-\frac{1}{3}}$ must maintain a linear relationship. If an $m$ value of $3 / 2$ is plugged into $C=(1 / m) a^{-1 / m}$, Equation (11) is produced. The slope $(C)$ can be used to determine the reduced modulus, Equation (12).

$$
\begin{gathered}
C=\left(6 R E_{R}^{2}\right)^{-\frac{1}{3}} \\
E_{R}=\left(6 m^{3} R\right)^{-\frac{1}{2}}
\end{gathered}
$$

Previous indentation methods typically have an error associated with the elastic modulus measurement due to the applied load. The conventional indentation methods usually have either an overestimation or underestimation in the measurement. The multiple partial unloading method eliminates the loading influence and provides and accurate evaluation technique for the determination of the Young's modulus.

\section{3: Instrumented Indentation System}

Despite the appearance of a simplistic design, the indentation process requires quite a bit of planning and experimental resources. The indentation chain components are susceptible to vibrations and drastic temperature changes. To alleviate the sensitivity of the system to vibrations, the use of the optical table as a steady test platform and a rigid loading frame are incorporated in the system. The rigidity of the loading frame is essential in attaining the boundary conditions for the ideal contact mechanics equations. The tests performed in the experimental set-up in this study were performed at room temperature to allow the thermal expansion effects of the component materials to be neglected. The indentation system employed in this study is described in the next section. 


\subsection{1: System Description}

A table top system was used for the multiple partial unloading procedure to determine the elastic modulus of the desired areas of the TBC samples at room temperature. The table top indentation system is comprised of a spherical tungsten carbide (WC) indenter having a radius of $793.5 \mu \mathrm{m}$, combined with a piezoelectric actuator (3.6 nm Resolution, Physik Instrumente, P-239.9S, $180 \mu \mathrm{m}$ ) and a high accuracy $( \pm 0.15 \%$ Accuracy, Honeywell, Model 31, $100 \mathrm{lb}$.) load cell [15]. The system is shown below in Figure 29.

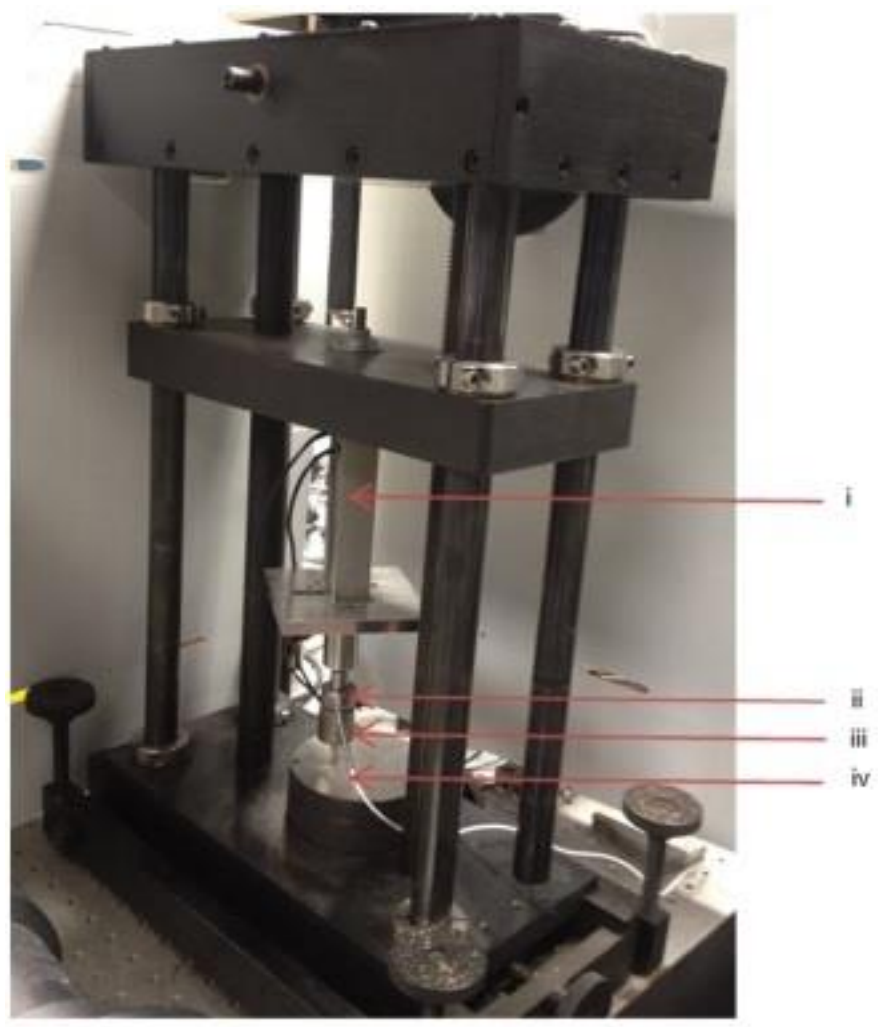

Figure 29: Experimental Setup, i) $3.6 \mathrm{~nm}$ Resolution, Physik Instrumente, P-239.9S, $180 \mu \mathrm{m}$ piezoelectric actuator, ii) $\pm 0.15 \%$ Accuracy, Honeywell, Model 31, $100 \mathrm{lb}$. load cell, iii) spherical tungsten carbide (WC) 793.5 $\mu \mathrm{m}$ radius indenter, and iv) sample stage [15]

Figure 30 shows the typical loading/unloading pattern of the table top indentation test. There was minimal difference in this pattern between tests performed in areas with deposition and areas without deposition. This shows that system compliance is achieved throughout the micro-indentation tests. 


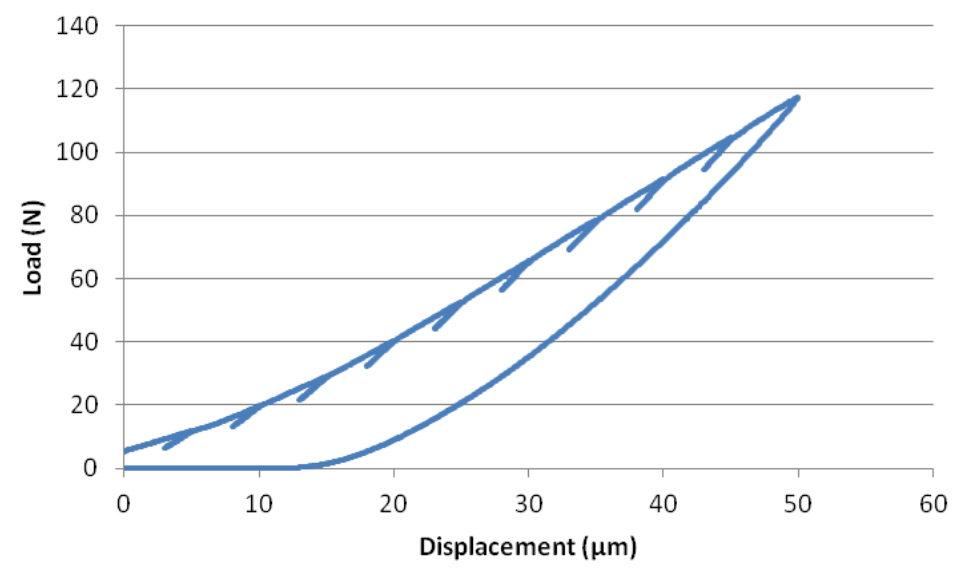

Figure 30: Typical table top in-situ micro-indendation test

\subsection{2: Load Cell}

The load cell in the indentation system was used to convert a load response to an electrical signal. Stress analysis is often performed by measuring strains on the surface of deformed elements with the electrical resistance strain gauges [49]. Strain gauge load cells are accurate and reliable, and when applied to a known material with a known geometry, a respective load can be measured. This is the principle on which a strain gauge load cell operates. Lastly, due to the small variations in voltage from the electrical load signals, a Wheatstone bridge configuration was used to amplify the signals acquired throughout the indentation test [50].

\subsection{3: Actuator}

A piezoelectric actuator was used in the system for its depth sensing indentation application with a high resolution. It is comprised of multiple piezoelectric discs, and the displacement is a function of the applied electric field. As voltage is applied to the materials, a quick but sensitive mechanical strain (displacement) is produced. The active material of the positioning element is composed of piezoelectric discs. These disks are separated by thin metallic electrodes and provide stability from its stiffness at high pressures [45]. Small factors such as thermal drift and overheating must be considered in the use of a piezoelectric actuator as they may affect the precision of the results. 


\subsection{4: Indenter}

The indenter material and geometry in the system was chosen based on the type of information desired during the test. Sharp indenters, such as Vickers, Berkovich, and Knoop, induce plasticity early in the process. These are common in determining the hardness or modulus of the top coat of thin films, independent of a response from the substrate. Spherical indenters offer a gradual transition from elastic to elastic plastic response. The gradual transition also allows for characterization of the material's strain hardening.

The material of the indenter also must be rigid and strain resistant. They must have a relatively high elastic modulus. Sapphire, tungsten carbide, and diamond are common as the material choice [50]. Sapphire indenters, although brittle, are desirable for their optical capabilities and low cost.

\subsection{5: Loading Frame}

The loading frame may be the most important part of the instrumented indentation system. The accuracy of the results is directly proportional to the compliance of the system. Due to this, great time and effort were required for the design and construction of the frame. In addition, the loading frame must also accommodate various sizes and geometries specified by the specimens while maintaining its rigidity. In order to minimize the compliance, a rigid stabilizing or clamping element must be utilized at each joint [51]. Issues such as weight and size must also be considered during the design.

\section{4: Factors Affecting Instrumented Indentation}

Experimental instrumented indentation testing has a range of errors usually arising from environmental or instrumentation malfunctions throughout the process [50]. In addition, there are errors related to the specimen material. Of the many errors, system compliance may be the most important. Large deflections in the loading frame result in shallow indentation depths and inaccurate material property measurements. The error from the deflection significantly affects the slope of the fitted line in Equation (11). Additional parameters that affect the accuracy of the load depths sensing material characterization are discussed in the following sections. 


\subsection{1: Residual Stress}

In the instrumented indentation analysis, the specimen was assumed to be stress free. However, residual stresses are often present from the processing of the specimen and/or the surface preparation. The level of residual stress within the material can be found by examining the shape of the pile-up at the edge of the indentation. General reports state that compressive residual stresses exist at smaller indentation depths and tensile residual stresses are present for larger indentation depths. Later reports recognized that for elastic contact, any residual stresses will alter the indentation stress and strain distributions [52]. Recently, researchers have demonstrated that residual stresses affect the indentation based mechanical property measurements as well [53]. Hardness and elastic modulus results using standard nanoindentation techniques and data analysis procedures were found to increase when the material had uniform compressive stresses and decrease under uniform tensile stresses, Figure 31 [54].

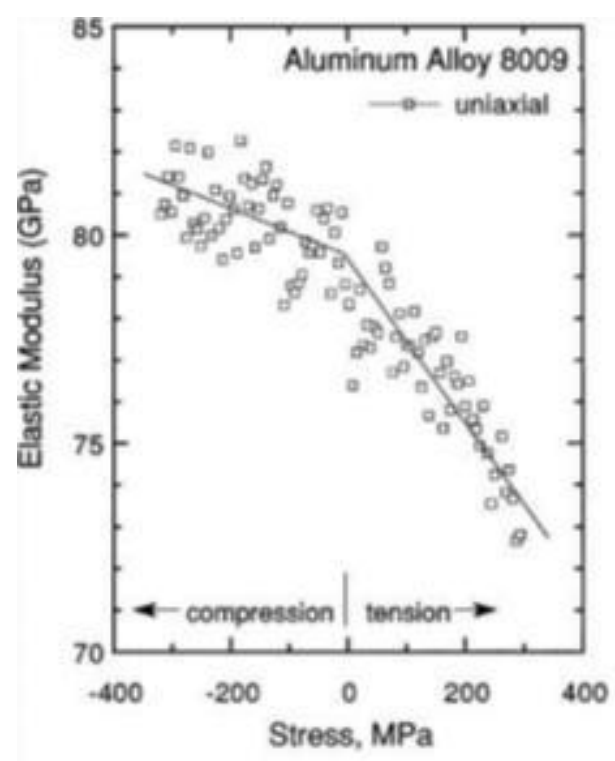

Figure 31: Elastic modulus variance with an imposed residual stress [54]

\subsection{2: Surface Roughness}

Since contact area was measured indirectly from the depth of penetration, the surface roughness of the material can affect the measurement of the elastic modulus measurement. Surface roughness is 
found to affect an instrumented indentation test if values greater than 0.05 are observed [55]. The overall effect of the surface roughness on the indentation test is an increase in the calculated radius with a reduction of the mean contact pressure. This will result in a lower measured elastic modulus.

\subsection{3: Indentation Size}

For isotropic homogeneous materials, the total indentation depth can cause a variation in the elastic modulus measurement. The variation in the modulus may be from the presence of thin oxide films whose material mechanical property substantially differs from the property of the substrate property the test was intended to measure [50]. Also, if the material exhibit indentation size effects, the conditions of plastic flow may not only depend on the strain but also the magnitude of strain gradients within the material. These strain gradients may occur in the vicinity of a crack or near an edge. Defects of this nature will result in the significant reduction in the surface stiffness response as indentation depth increases, particularly if shallow cracking is present [29].

\section{5: Uncertainty Calculations}

An uncertainty analysis was performed on the strain tolerance results in order to show the effect of measurement uncertainties on the accuracy of the elastic moduli results [56]. The first part of the uncertainty analysis centers around the measured value where the true value may lie. Kline and McClintock developed the framework of statistical inference of research experiments in estimating singlesample uncertainty. Continued work led to a multiple-sample analysis in which incorporate a confidence interval, usually 95\%, where the true value may lie.

A root-sum-square (RSS) combination was described by Moffat as one of the basic forms used for combined uncertainty contributions in both single-sample and multiple-sample analysis [57]. The following equation is presented to describe one variable.

$$
\mathrm{X}_{\mathrm{i}}=\mathrm{X}_{\mathrm{i}}(\text { measured }) \pm \delta \mathrm{X}_{\mathrm{i}} \quad(20: 1)
$$

The equation should be interpreted to mean the following: 
- $\mathrm{X}_{\mathrm{i}}$ (measured) is the best estimate of $\mathrm{X}_{\mathrm{i}}$

- $\pm \delta \mathrm{X}_{\mathrm{i}}$ is the uncertainty in $\mathrm{X}_{\mathrm{i}}$

- $(20: 1)$ are the odds the uncertainty of $X_{i}$ is greater than $\pm \delta X_{i}$

For the multiple-sample data in this study, $\mathrm{X}_{\mathrm{i}}$ (measured) was mean of the Young's modulus found in each sample set. The uncertainty, $\delta X_{i}$, was represented by $\mathrm{tS}_{(\mathrm{N})} / \sqrt{\mathrm{N}}$ where $\mathrm{S}_{(\mathrm{N})}$ is the standard deviation of the set of $\mathrm{N}$ observations and $\mathrm{t}$ is the Student's t statistic appropriate for the number of samples $\mathrm{N}$ and the confidence level required. A $95 \%$ confidence was used for the current study.

The second form of uncertainty came from the system/equipment measurement errors. Typically, these measuring errors come from the tolerances within the system. The current study has measurement tolerances in two variables: 1) $\pm 0.15 \%$ in the load from the Honeywell load cell and 2) typical tolerance for the piezoelectric actuator length [58]. A medium tolerance of $\pm 0.3 \mu \mathrm{m}$ was chosen for an actuator travel distance of $50 \mu \mathrm{m}$ [59]. The tolerance errors were inserted into the calculations and sequentially perturbated to calculate the uncertainty intervals for the measurement errors.

To complete the RSS analysis, the multiple-sample variable uncertainty and the measurement uncertainty were placed into Equation (14) to obtain the overall uncertainty.

$$
\delta E_{\text {overall }}=\left\{\left(\delta E_{\text {variable }}\right)^{2}+\left(\delta E_{\text {measurement }}\right)^{2}\right\}^{\frac{1}{2}}
$$

The calculated uncertainties for the micro-indentation procedures can be found in the appendices. The overall range of uncertainties is roughly between 3 and $10 \mathrm{GPa}$. The uncertainties are denoted by the error bars of the figures in Chapter 7.

\section{6: Literature Review of Elastic Modulus for Typical TBC Layers}

This section includes the Young's modulus and Poisson's ratio values found for the layers in this study. Since DVD is a novel deposition process and relatively recent, EB-PVD 7YSZ coat values are used in the review because of a similar columnar structure. The results at room temperature are compiled in 
Table 6 below. For the fly ash values, values observed for fly ash concrete are used. The modulus values for the bituminous fly ash are significantly less than Young's modulus of CMAS (E $\mathrm{E}_{\mathrm{CMAS}} \approx 90 \mathrm{GPa}$ [24]), so an increase in the 7YSZ/fly ash zones should be less pronounced than previous CMAS studies.

Table 6: Mechanical Properties of TBC Layers and Fly ash (Concrete)

\begin{tabular}{|l|c|c|}
\hline Layers & E - Modulus of Elasticity $(\mathrm{GPa})$ & $v$ - Poisson's Ratio \\
\hline Fly ash (Concrete) & $29-38[60]$ & $0.15-0.20[61]$ \\
\hline 7YSZ (EB-PVD) & $15-30[62]$ & $0.20-0.30[63][64]$ \\
\hline $\mathrm{Al}_{2} \mathrm{O}_{3}(\mathrm{TGO})$ & $360-380[64][65]$ & $0.20-0.22[64][65]$ \\
\hline $\mathrm{PtAl}$ & $118-145[66][67]$ & $0.27[67]$ \\
\hline $\mathrm{HA} 230$ & $211[31]$ & $0.34[68]$ \\
\hline
\end{tabular}

Since the indentation depth used in the study is only $50 \mu \mathrm{m}$, there should not be any influence from the TGO or bond coat on the elastic modulus results of the ceramic top coat. Any increase in surface stiffness response of the ceramic top coat should be from the infiltration of the fly ash which leads to stiffening of the YSZ microstructure or sintering and densification of the YSZ coatings during the deposition work by Murphy et al. [10]. 


\section{CHAPTER 7: MICRO-INDENTATION RESULTS}

In order to perform a normalized elastic modulus analysis, the Young's modulus was determined for the unexposed Test Article 2 using sections of samples 2-3 and 2-4. Neither sample has been subjected to fly ash deposition testing. The samples were secured in a clamping holder and undergo the multiple partial unloading procedure. Once the procedure was completed, the TIM system outputs a file containing two columns: $p$ (load) and $d p / d h$ (change in load over change in indentation depth). The data in the columns were imported into the Excel sheet shown in Figure 32 along with the known geometry and material properties of the indenter (indenter radius, $R$, indenter modulus of elasticity, $E_{0}$, and indenter Poisson's ratio, $v_{0}$ ). The $C$ value is the slope described in Equation (11). A Poisson's ratio value of 0.25 was chosen for the ceramic top coat since it lies in between the range in Table 6. TBC modulus of elasticity was recorded when the $R^{2}$ value in the plot is greater than 0.99 . The closer the $R^{2}$ value is to 1 , the closer it is to a linear relationship.

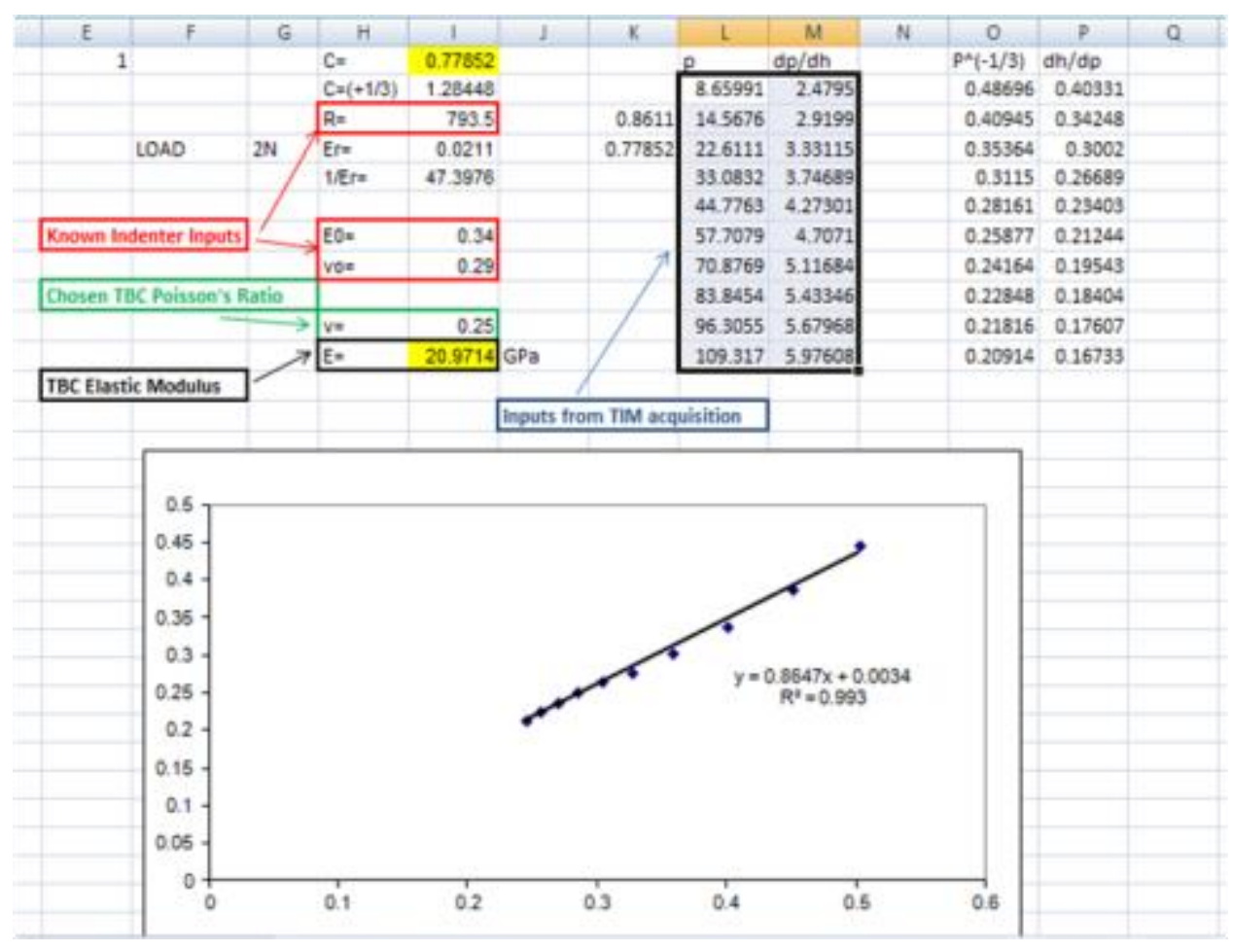

Figure 32: Excel sheet calculating the modulus of elasticity for the TBC 
Figure 33 below contains an image of the two unexposed samples, 2-3 and 2-4, and their respective averaged elastic modulus values respectively. The surface stiffness values were obtained after the micro-indentation loading was performed throughout top surfaces of each of the samples' top coat. The uncertainties of the samples were a combination of the number of indentations performed and the measurement errors and are denoted by the error bars. A cumulative average of all the individual tests on both samples is used to obtain a value for measureable elastic modulus ( $\left.\mathrm{E}_{\text {unexposed }}\right)$ of $20.93 \mathrm{GPa}$.
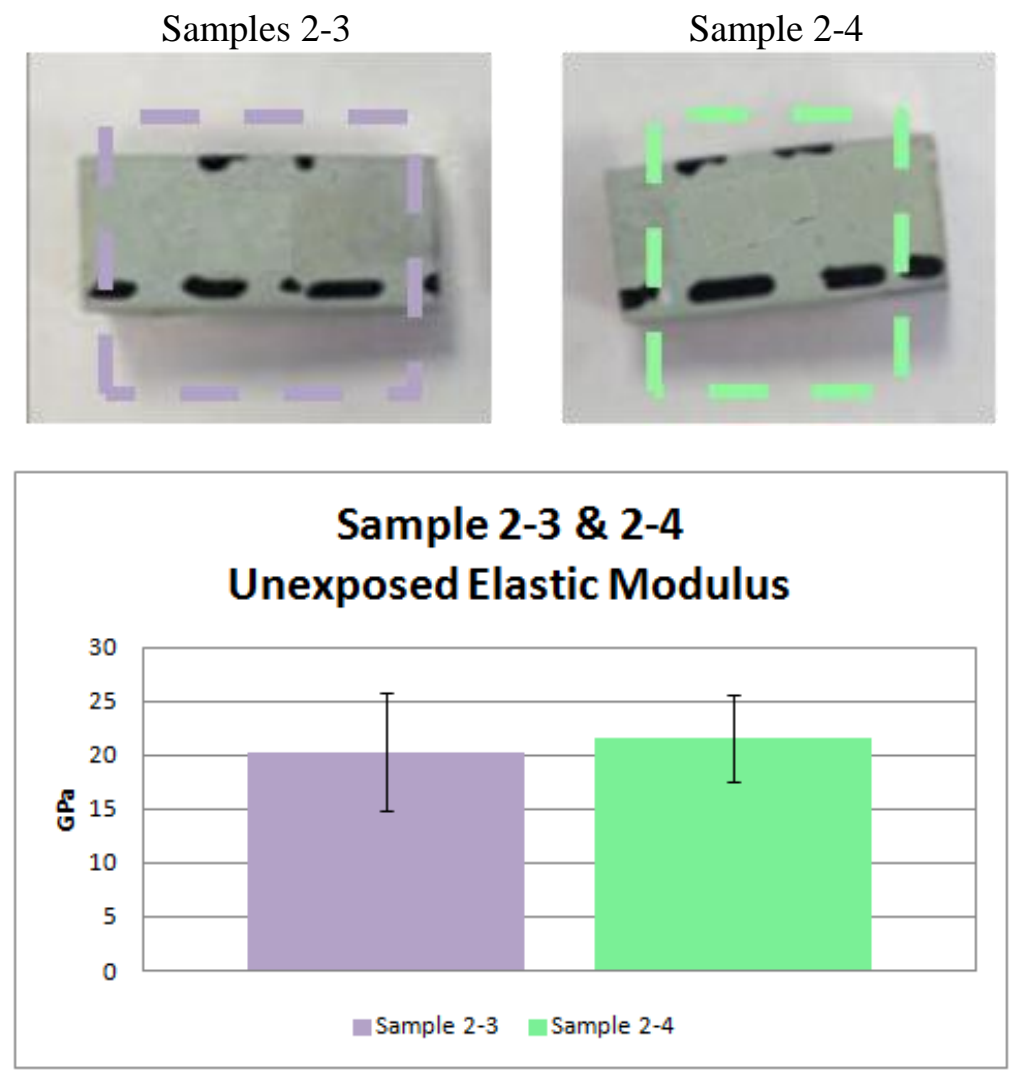

Figure 33: Image of unexposed Samples 2-3 and 2-4 and their values for TBC modulus elasticity

After the value of the averaged Young's modulus of the unexposed samples, $\mathrm{E}_{\text {unexposed, was }}$ obtained, the multiple partial unloading procedure was performed on Samples 1-1, 1-2, 1-3, 1-4, 3-1, and 3-2. Figure 34 contains the images and averaged elastic modulus values for Sample 1-1 and 1-2. The colored dashed boxes in the sample images correspond with the colored averaged elastic modulus values in the charts below. The portion of Sample 1-1 bordered with the blue dashed box contains an area where 
molten deposits had adhered onto the TBC prior to the sectioning. The fly ash infiltrated area of the YSZ coating in sample 1-1 exhibited a higher modulus of elasticity than the ceramic top coating of the unexposed articles or areas along the same sample or same plane without heavy deposition adherence. The same analysis is completed for samples 1-3 and 1-4 and for samples 3-1 and 3-2. The results in for these samples are shown in Figure 35 and Figure 36 respectively. The deposition infiltrated YSZ areas within sample 1-3 and 3-1 also exhibit a higher surface stiffness values than their relatively clean counterparts. The area in sample 3-1 without heavy deposition was not evaluated due to system compliance issues. A summary of the micro-indentation testing is shown in Table 7.

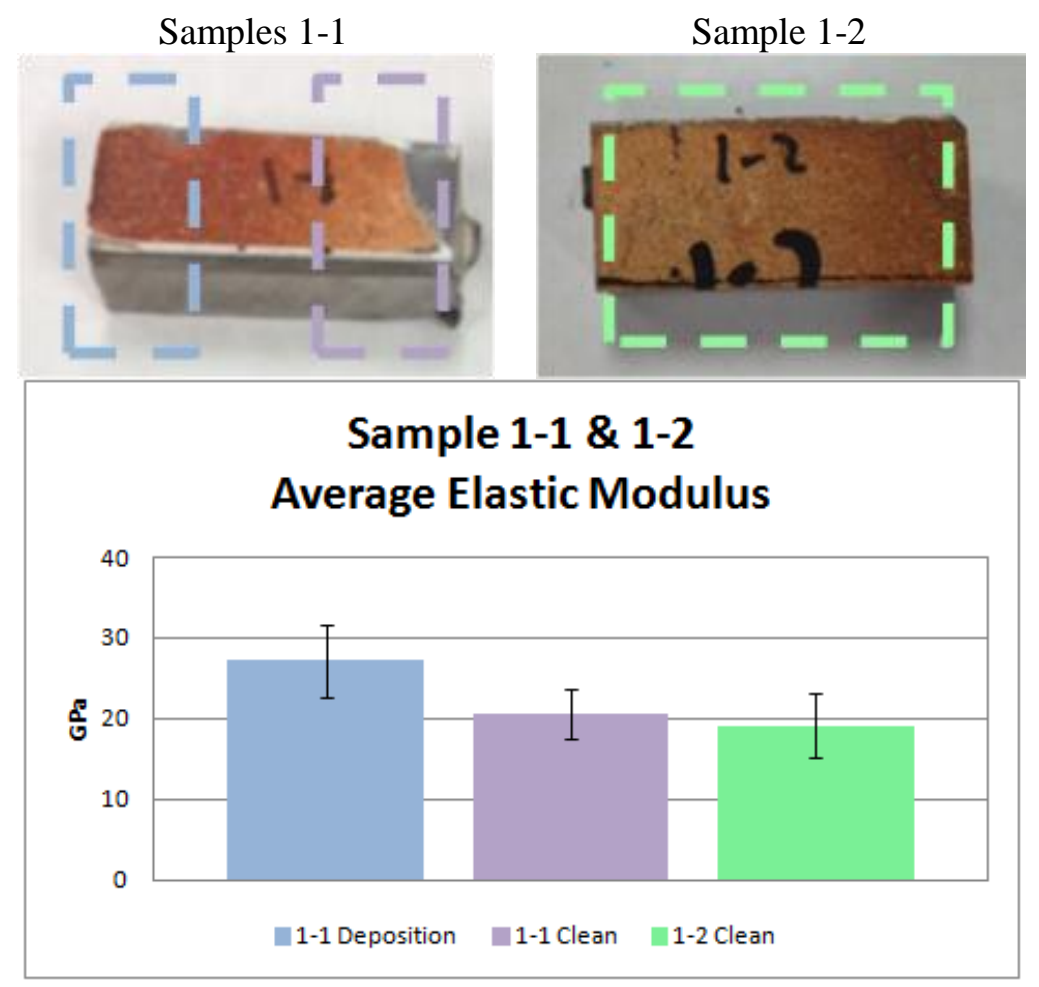

Figure 34: Image of samples 1-1 and 1-2 and their values for averaged TBC modulus elasticity 


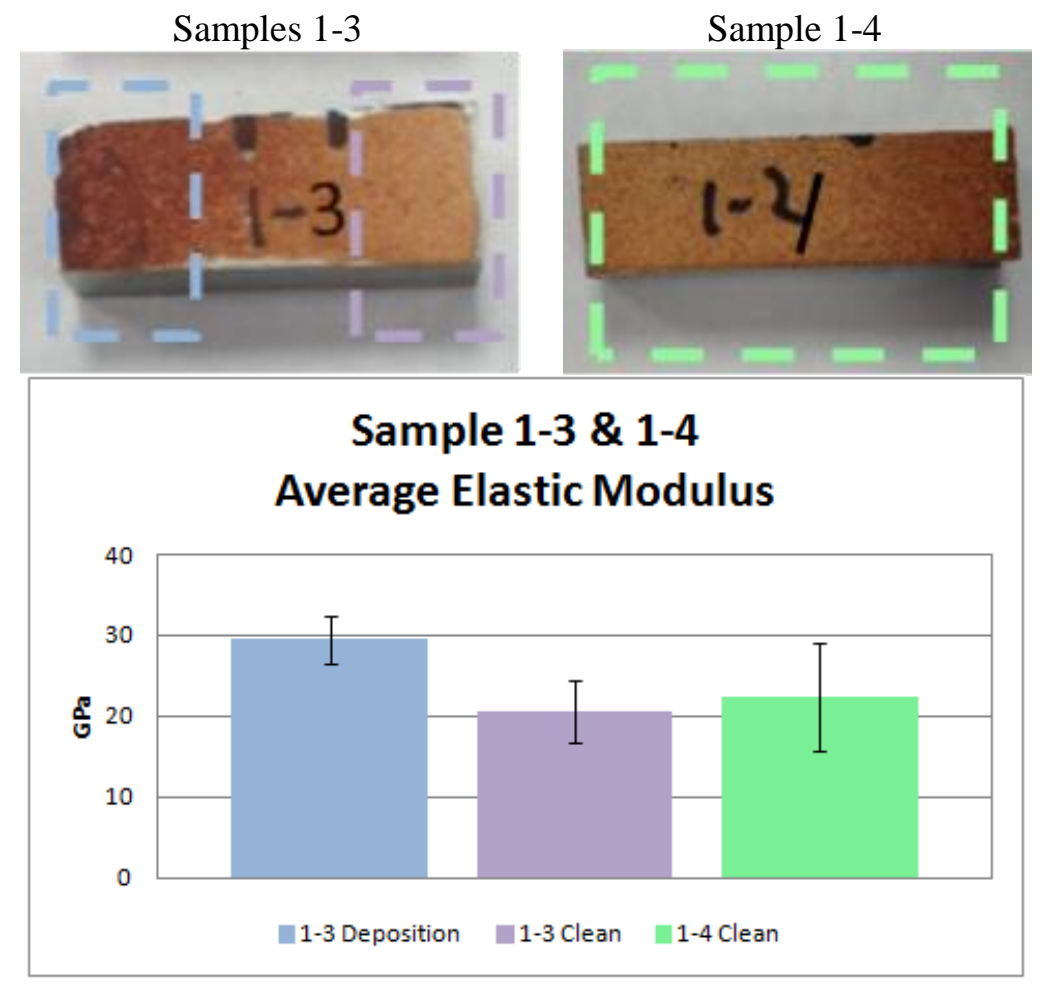

Figure 35: Image of samples 1-3 and 1-4 and their values for averaged TBC modulus elasticity

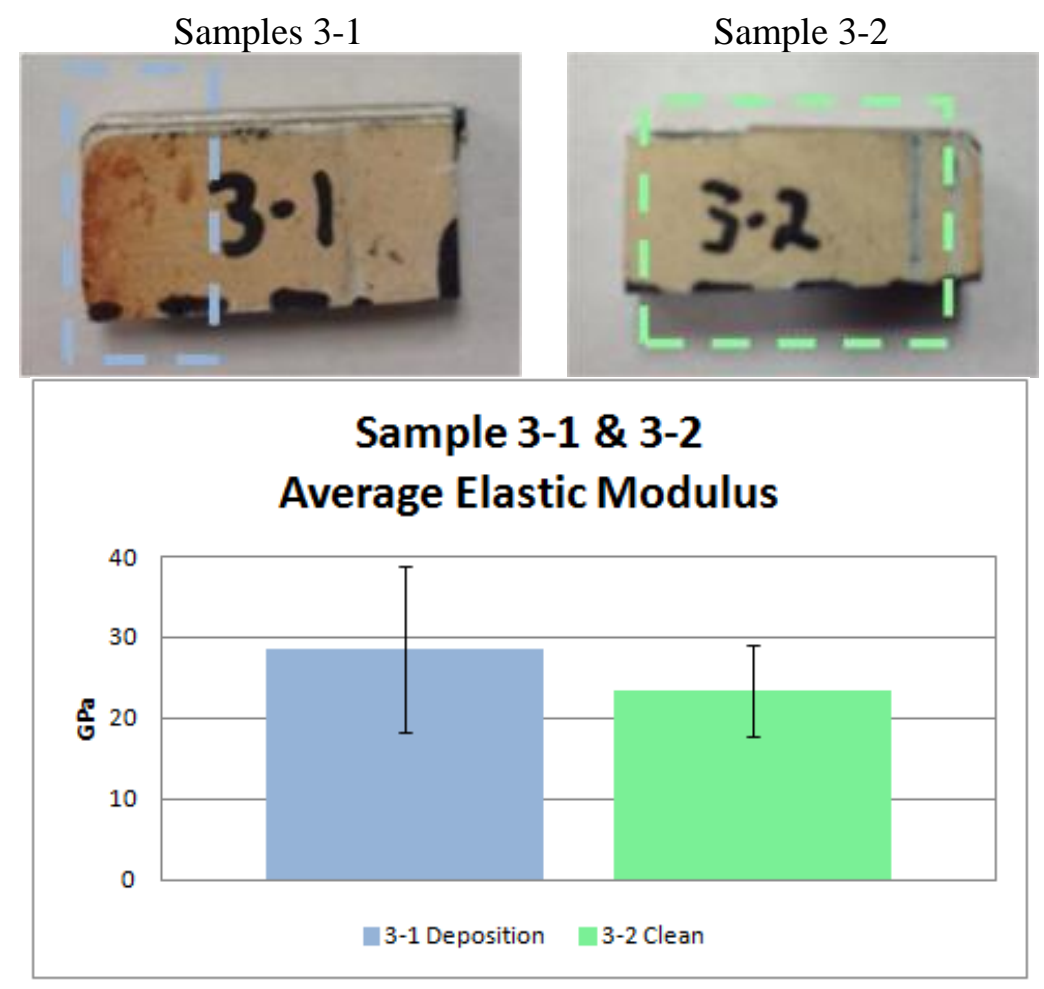

Figure 36: Image of samples 3-1 and 3-2 and their values for averaged TBC modulus elasticity 
Table 7: Summary of micro-indentation testing

\begin{tabular}{|c|c|c|c|}
\hline Sample & $\begin{array}{c}\text { Amount of Deposition } \\
\text { (High, Med, Low, Unexposed) }\end{array}$ & Modulus of Elasticity & Uncertainty \\
& & $(\mathbf{G P a})$ & $(\mathbf{G P a})$ \\
\hline $1-1$ & High & 27.14 & \pm 4.44 \\
\hline $1-1$ & Low & 20.58 & \pm 3.15 \\
\hline $1-2$ & Low & 19.09 & \pm 3.48 \\
\hline $1-3$ & High & 29.55 & \pm 2.96 \\
\hline $1-3$ & Low & 20.63 & \pm 3.79 \\
\hline $1-4$ & Low & 22.45 & \pm 6.65 \\
\hline $2-3$ & Unexposed & 21.59 & \pm 5.48 \\
\hline $2-4$ & Unexposed & 28.52 & \pm 3.97 \\
\hline $3-1$ & Med & 23.34 & \pm 10.22 \\
\hline $3-2$ & Low & & \pm 5.61 \\
\hline
\end{tabular}

In order to develop a trend for the molten fly deposits effects on the strain tolerance of the TBC, the modulus of elasticity with respect to the length across the TBC pressure surface face was plotted. In order to normalize the length scale, the width of the top face of all the TBC coated articles is measured at roughly 2 inches (see Figure 34).

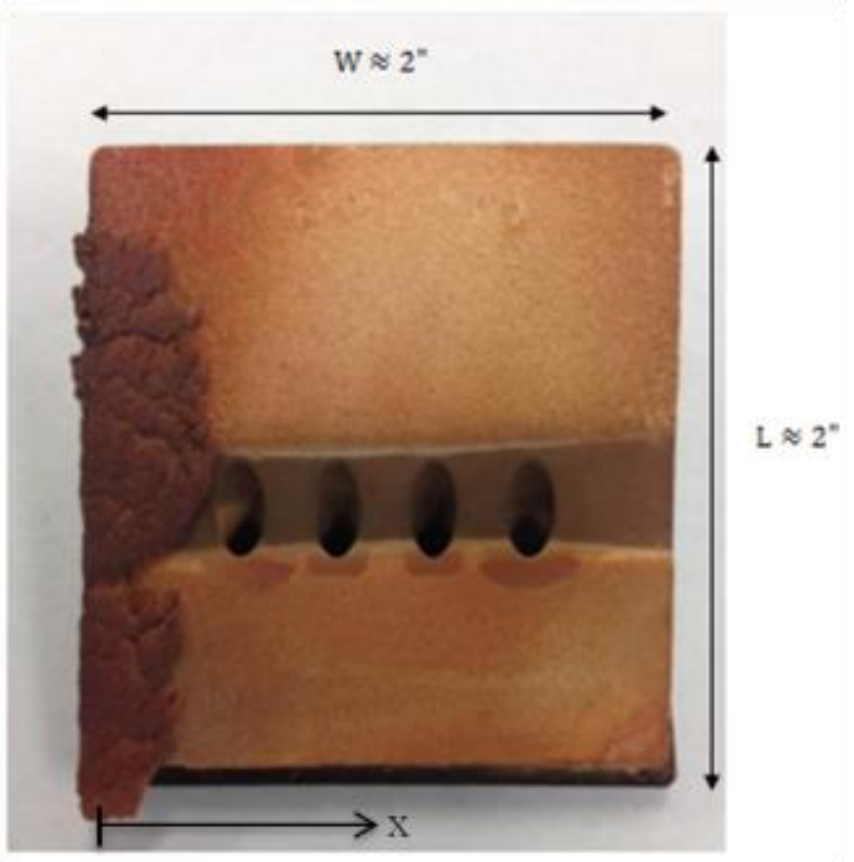

Figure 37: Dimensions of the test article faces 
Individual indenter results for Sample 1-1 and 1-2 are plotted in Figure 38 as normalized Young's modulus values $\left(\mathrm{E}_{\mathrm{i}} / \mathrm{E}_{\text {unexposed }}\right)$ vs. normalized distance $(\mathrm{x} / \mathrm{W})$. The normalized unexposed modulus is included on the plot by the dashed red line. A power series trendline is included to show the difference in surface stiffness between the $\mathrm{x} \approx 0$ edge, where deposition is abundant, to $\mathrm{x} \approx 2$ ", where the surface is relatively clear of deposition. In fact, the majority of the deposition is within 0.2 inches of the $x=0$ edge. Uncertainty is not plotted for the individual results in an effort to prevent cluttering of the plot. Only measurement errors were applicable, and the errors were in the range of $0.5 \%$. The same type of plots are constructed for sample 1-3 and 1-4 (see Figure 39) and 3-1 and 3-2 (see Figure 40).

\section{Sample 1-1 \& 1-2: Normalized Elastic Modulus}

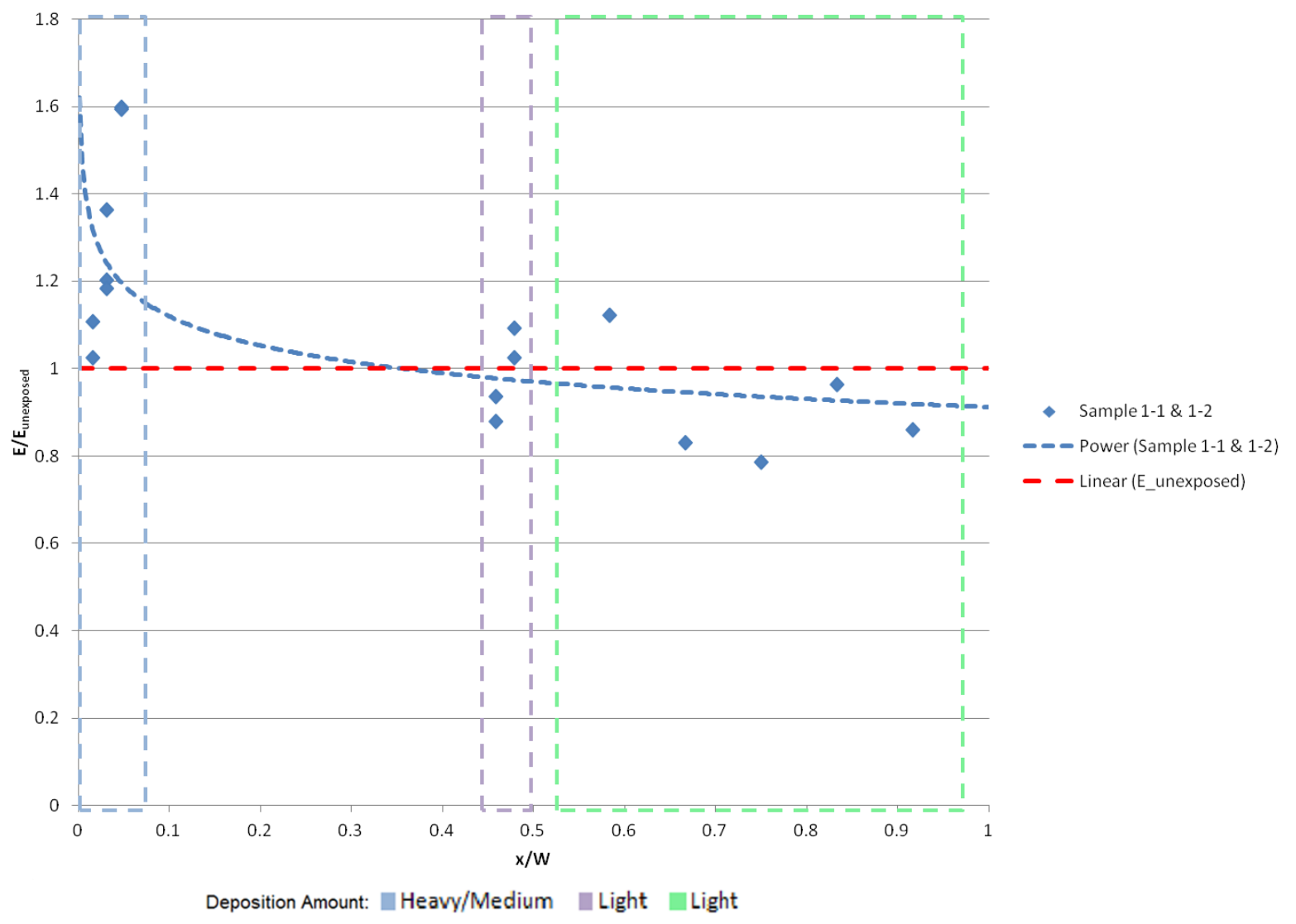

Figure 38: Normalized elastic modulus trend for Sample 1-1 \& 1-2 
Sample 1-3 \& 1-4: Normalized Elastic Modulus

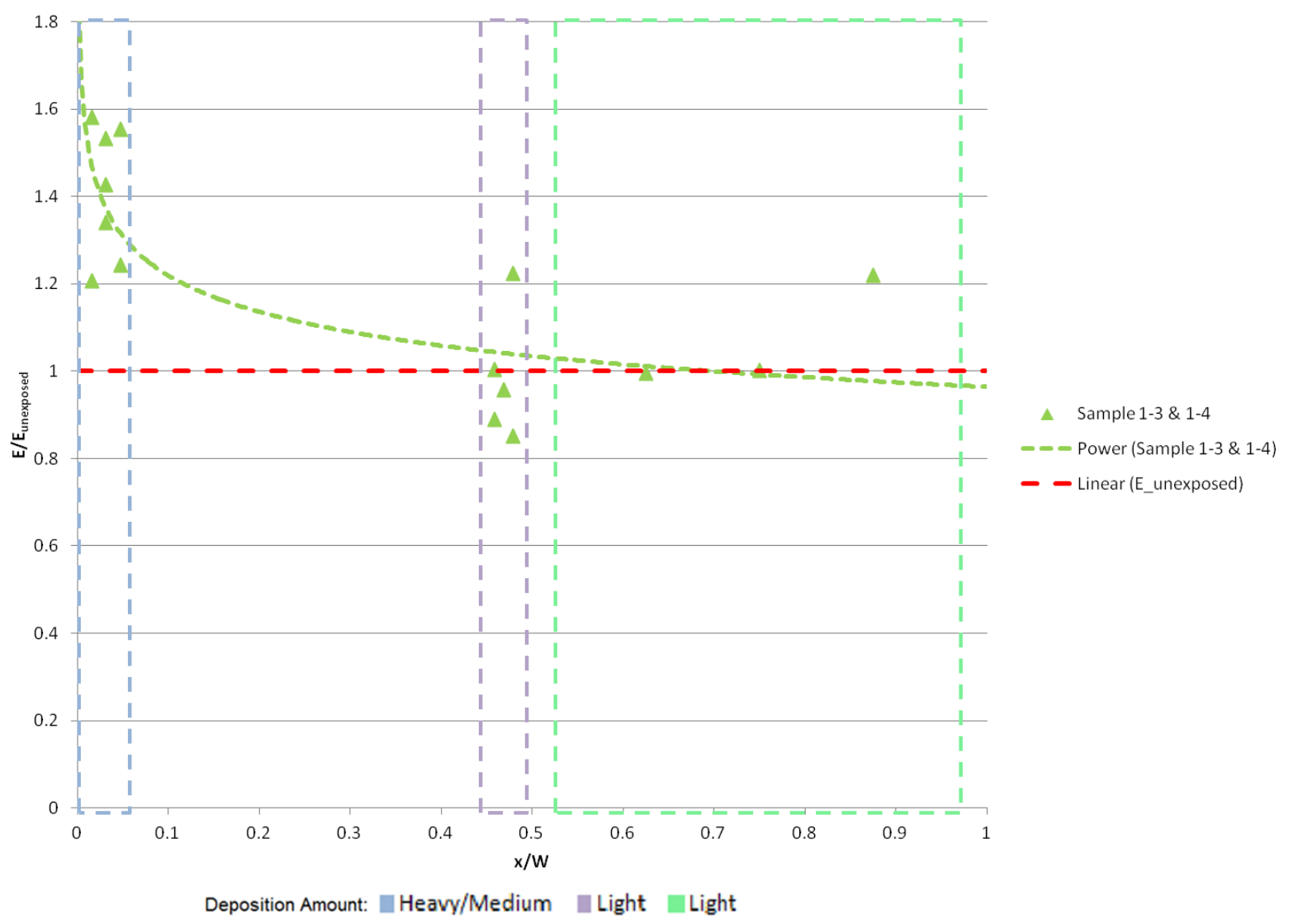

Figure 39: Normalized elastic modulus trend for Sample 1-3 \& 1-4 


\section{Sample 3-1 \& 3-2: Normalized Elastic Modulus}

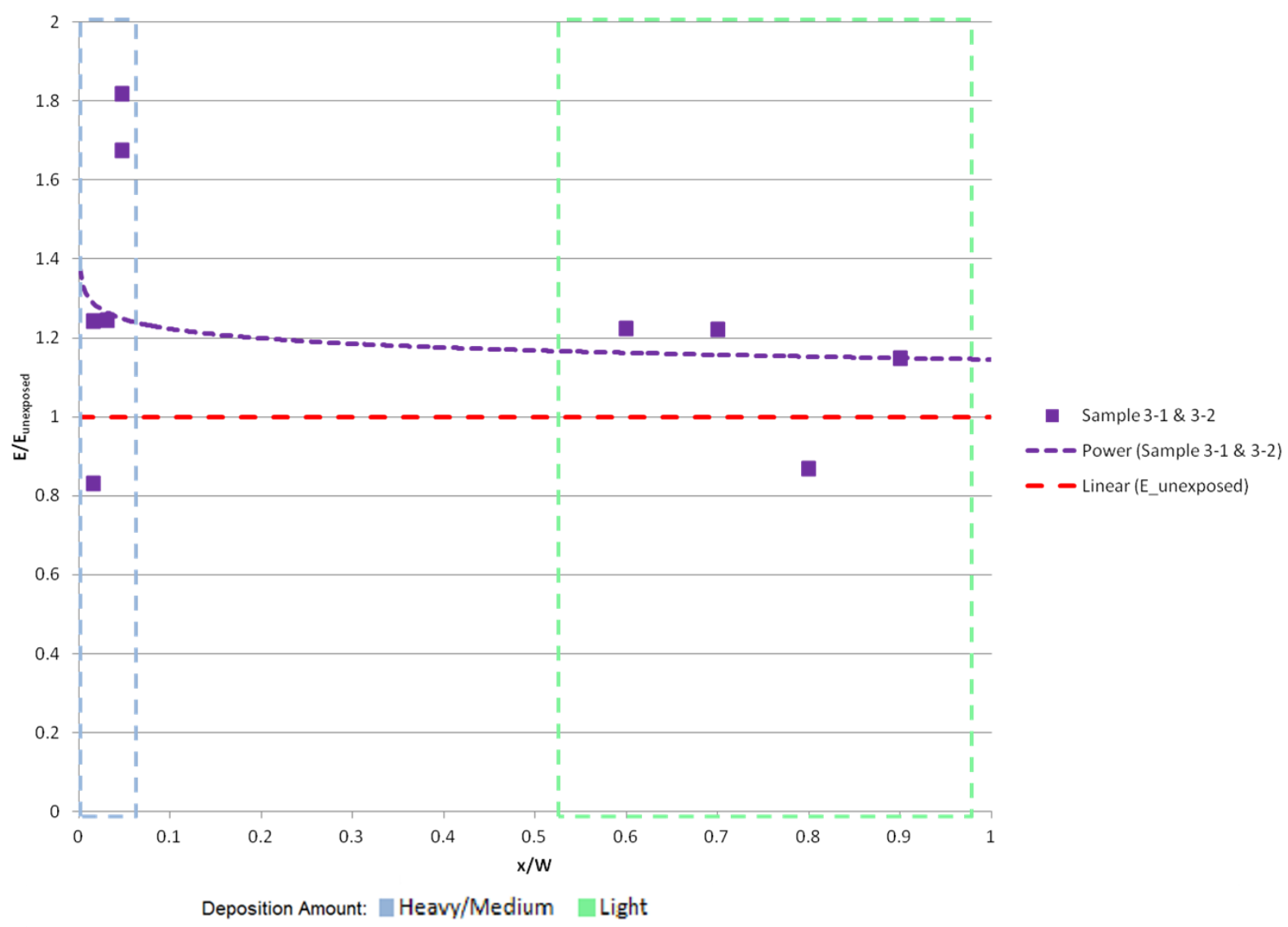

Figure 40: Normalized elastic modulus trend for Sample 3-1 \& 3-2

The individual micro-indentation elastic modulus values for YSZ coating areas with deposition $(\mathrm{x} / \mathrm{W} \approx 0)$ are higher than test areas without significant deposition $(\mathrm{x} / \mathrm{W} \approx 0.45-1)$. Areas with a low amount of deposition approach the surface stiffness value of the unexposed test article. In order to compare Figure 35, 36, 37, all the normalized individual micro-indentation indentation results were plotted in Figure 38. The trendlines in Figure 41 show that the samples produced from test article $1\left(20^{\circ}\right.$ angled) have a higher increase in the Young's modulus from the deposition than the samples from test article $3\left(10^{\circ}\right.$ angled). The level of modulus of elasticity increase can be attributed to a higher level of fly ash deposition adherence and infiltration. 


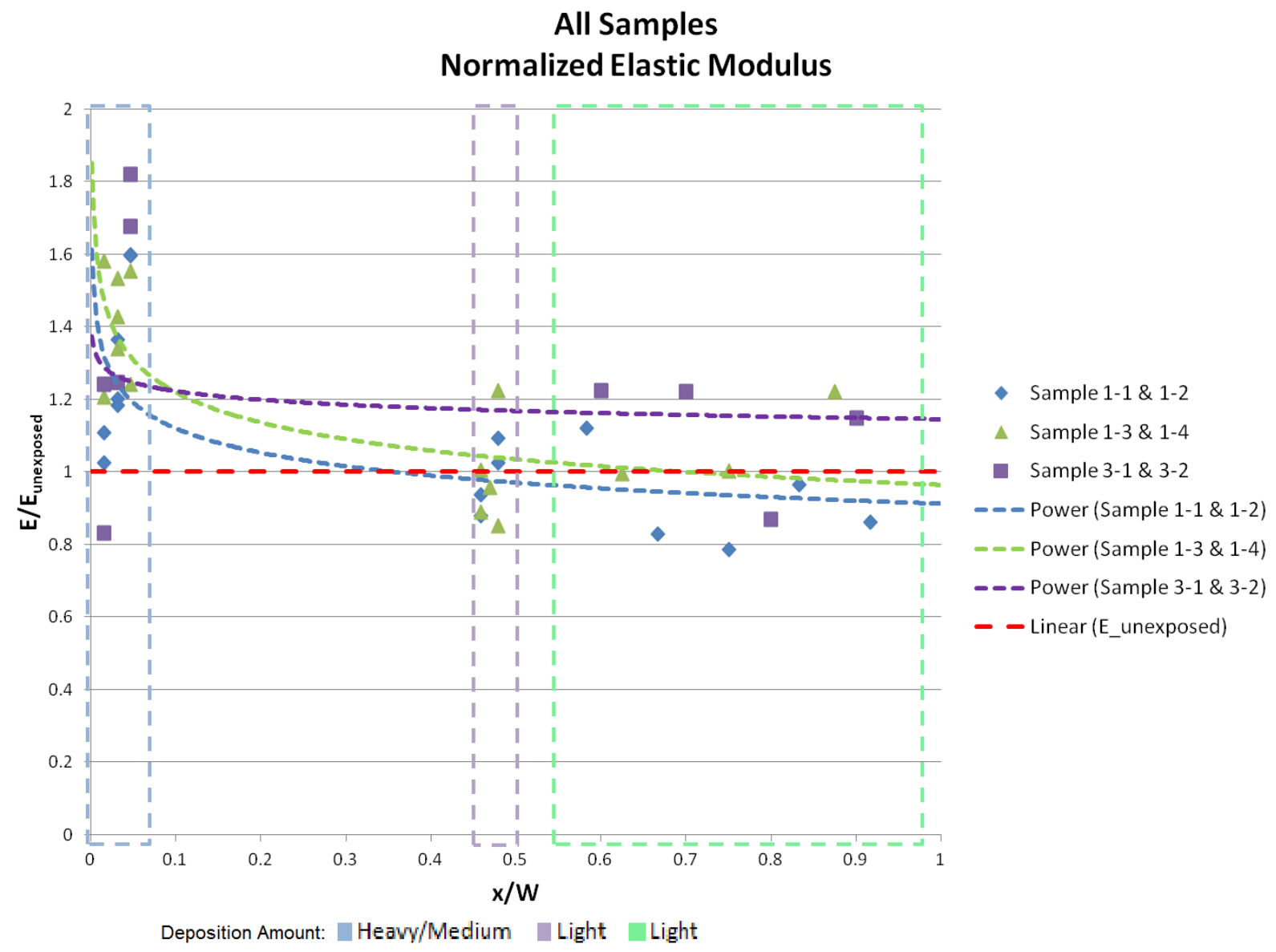

Figure 41: Normalized elastic modulus trends for samples 1-1, 1-2, 1-3, 1-4, 3-1, and 3-2

The results from the micro-indentation testing show that the deposition does increase the Young's modulus of the 7YSZ coatings of the TBC by stiffening the columnar structure near the top of the ceramic top coat. This increase in surface stiffness allows for early detection of failure (spallation) within the ceramic top coat. In addition, the amount of deposition adherence and infiltration does affect the increase in the modulus of elasticity. The high level of deposition on the samples of test article 1 does increase the Young's modulus of the TBC more than the medium amount deposition on the samples from test article 3. The micro-indentation procedure allowed for the study to quantitatively show that the molten deposits from the coal-derived syngas penetrated the columnar structure of the DVD TBC and stiffened the ceramic top coat as the deposits were cooled. 


\section{CHAPTER 8: MICROSTRUCTURE ANALYSIS}

Once the test samples have completed the micro-indentation testing, scanning electron microscopy (SEM) and energy dispersive X-ray spectroscopy (EDS) examinations were performed. Several samples were sent to Metallurgical Technologies, Inc to be placed in a conductive mounting media which aids in SEM examinations and polished to achieve a smooth reflective surface. Once the samples are returned, metallurgical testing was performed using a JEOL JSM-7600F Scanning Electron Microscope or Hitachi S-4700 Field Emission Scanning Electron Microscope.

\section{1: Scanning Electron Microscopy (SEM) views of TBC}

Figure 42 contains SEM micrographs of the cross-sections of unexposed sample 2-3 and deposition exposed sample 1-3. The TBC layers can be seen in both images, and the columnar structure of the DVD YSZ can be seen in both cross-sections of the samples. The DVD ceramic top coat used in this study exhibited a higher density than the EB-PVD coatings used in the CMAS studies of Wellman and Nicholls [63] and Peng et al. [69]. Due to shallow deposition infiltration depths, shown later using EDS mapping, the only difference between the TBCs in the figures at a magnification of 250x was the growth of the TGO thickness $(\sim 5 \mu \mathrm{m})$ and the intercolumnar and internal pores from sintering. The TGO and pores develop as part of operation within the aerothermal facility. 


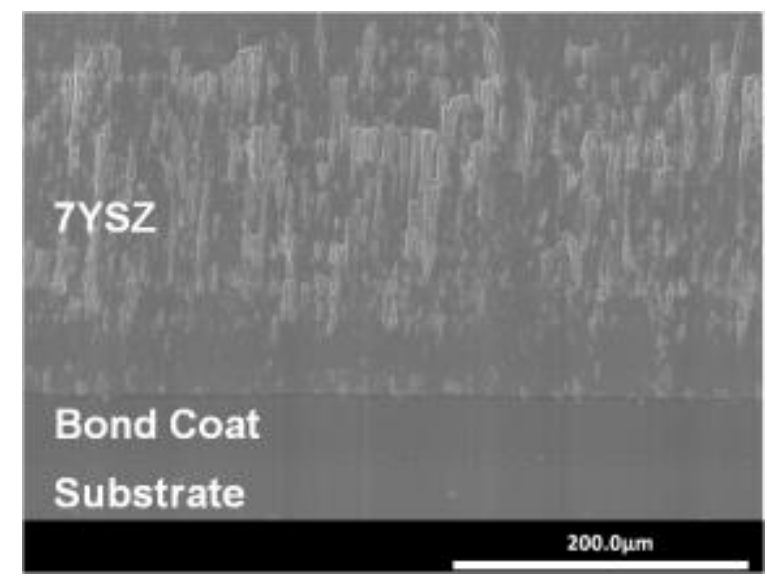

(a)

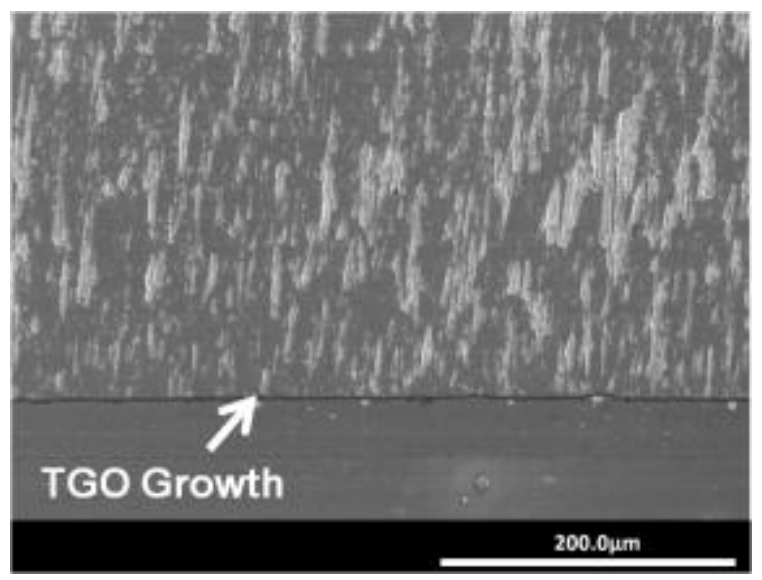

(b)

Figure 42: Cross-sectional SEM micrographs of a) samples 2-3 (unexposed) and b) samples 1-3 (deposition)

The top view of the unexposed and exposed YSZ coatings are seen in the SEM micrographs in Figure 43. The top view of the unexposed sample 2-1 in Figure 43a shows the inter-columnar gaps of the YSZ coating. The columnar structure of the YSZ coating is typical for an EB-PVD or DVD application process and improves the lateral strain compliance of the coating. The top view of the fly ash deposition on sample 1-5 can be viewed in Figure 43b. The ash deposition forms a hardened and glass-like layer on top of the columns of the YSZ coating.

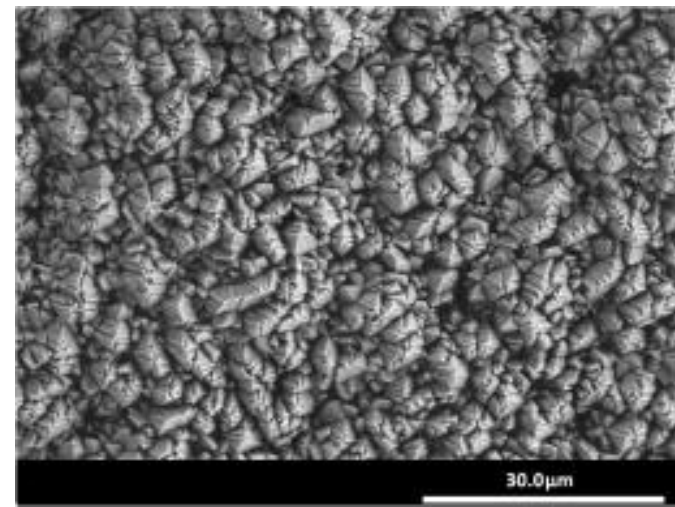

Sample 2-1 (Unexposed)

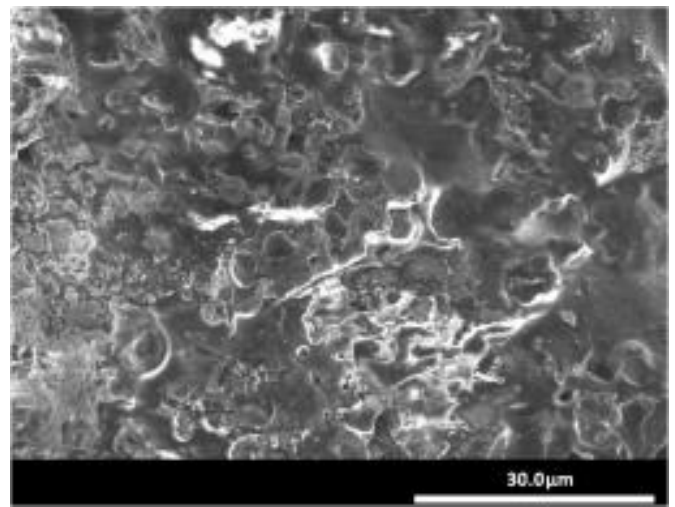

Sample 1-5 (Deposition Exposed)

(a)

(b)

Figure 43: Top view SEM micrographs of a) samples 2-1 (unexposed) and b) samples 1-5 (deposition) 
By having the hardened fly ash adhering onto the top surface of the ceramic top coat, the lateral strain compliance of the coating was reduced. This was the biggest contribution to the increase in surface stiffness throughout the micro-indentation tests.

\section{2: Degradation of TBC from Fly Ash Deposition}

Several degradation mechanisms were found with the SEM and EDS analysis. The mechanisms recorded are broken down into delamination, yttria migration from the YSZ columnar tips to the fly ash deposition, and a dissolution-reprecipitation mechanism of the columnar tips embedded in deposition.

Delamination and spallation of the YSZ coating is a very common failure mechanism in TBC systems. Deposition from foreign objects can infiltrate the coatings and make the TBC more susceptible to delamination, and the fly ash deposition in this study is no different. After the sectioning of the test articles, a large diagonal crack, seen in Figure 44, developed in sample 1-7. During sample preparation procedures, the crack caused spallation of the top coat on the sample. Figure 45 shows delamination of roughly $100 \mu \mathrm{m}$ of the YSZ coating from the edge of sample 1-3. A high concentration of deposition was present in the area.

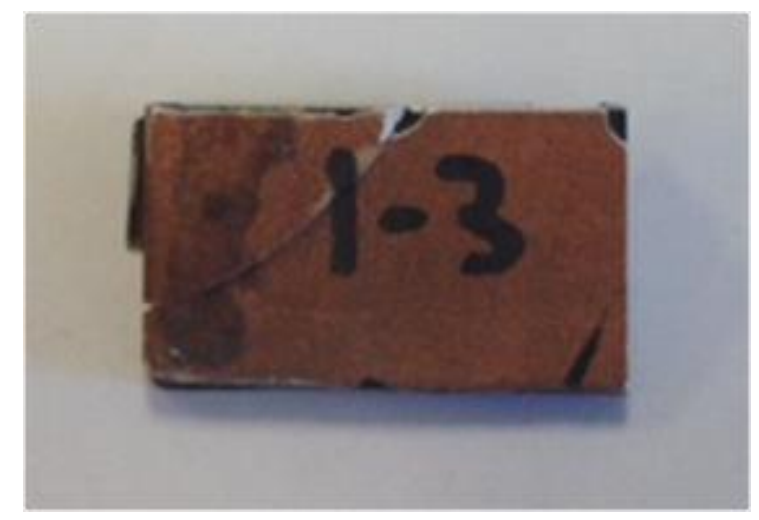

Figure 44: Top view image of sample 1-7 with a large diagonal crack 


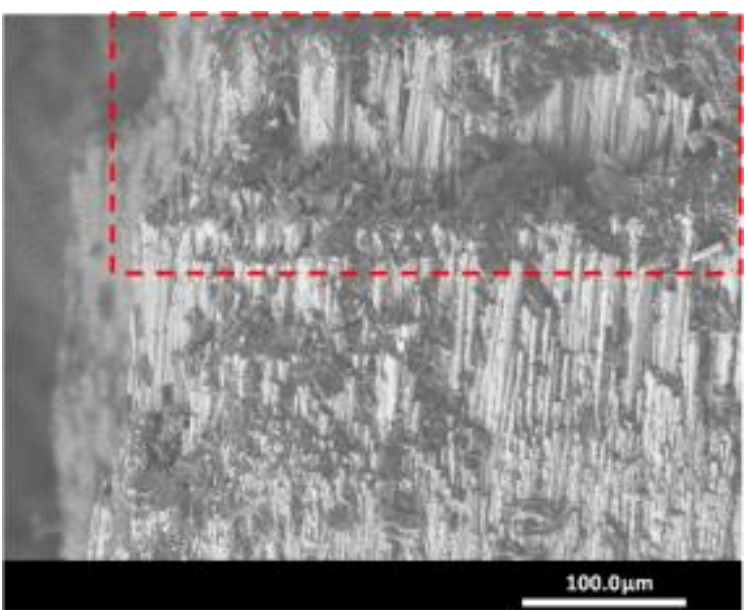

Post-sectioning

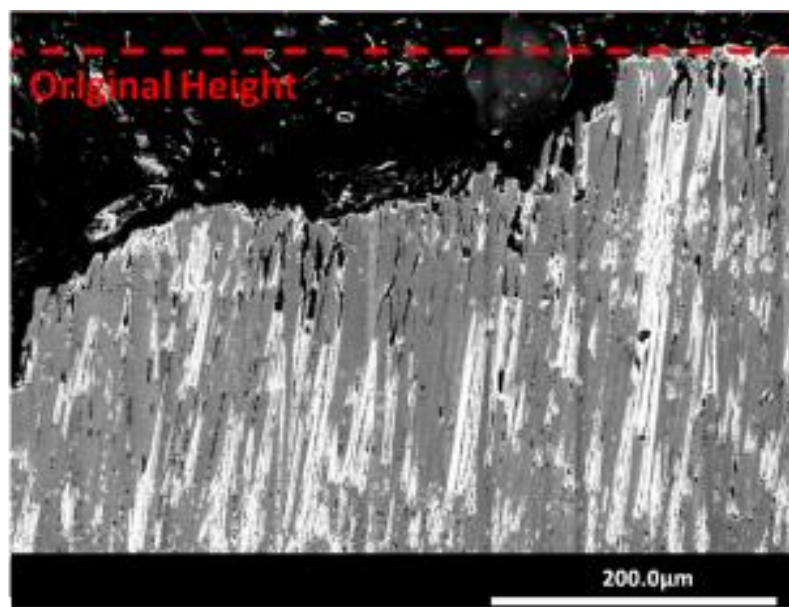

Mounted in conductive media

(a)

(b)

Figure 45: Delamination in sample 1-3 YSZ coating a) after sectioning and b) after mounting and polishing

In deposition adhered, but delamination-free YSZ coating areas, the fly ash deposition did not infiltrate deeply into the top coating. The infiltration of the deposition into the TBC of sample 1-3 can be seen in Figure 46. Figure 46a shows the cross-sectional micrograph of the YSZ coating on sample 1-3. The dashed red line denotes the original top surface of the top coating. Figure 46b-d shows the EDS elemental maps of $\mathrm{Zr}, \mathrm{Si}$, and $\mathrm{Al}$ from the micrograph in 46a, respectively. Silicon and aluminum are chosen to map the deposition since they have the two highest elemental weight percentages in the molten fly ash deposition. Figure 43a-d show that even the most fly ash deposited test article only experiences an infiltration depth into the YSZ coating of $10-20 \mu \mathrm{m}$. 


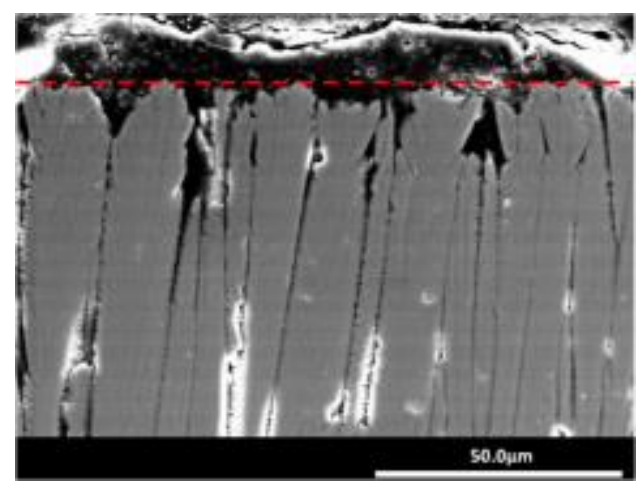

(a)

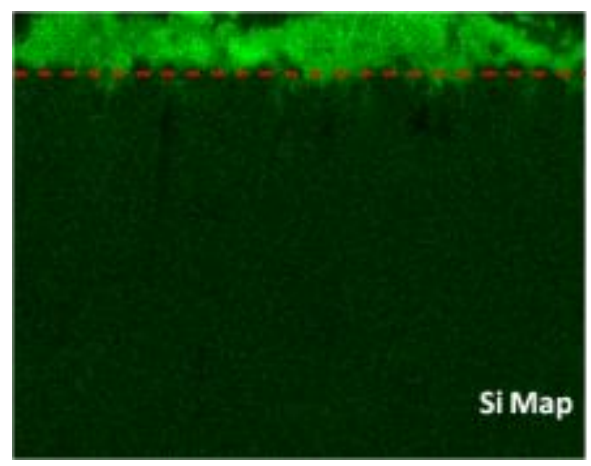

(c)

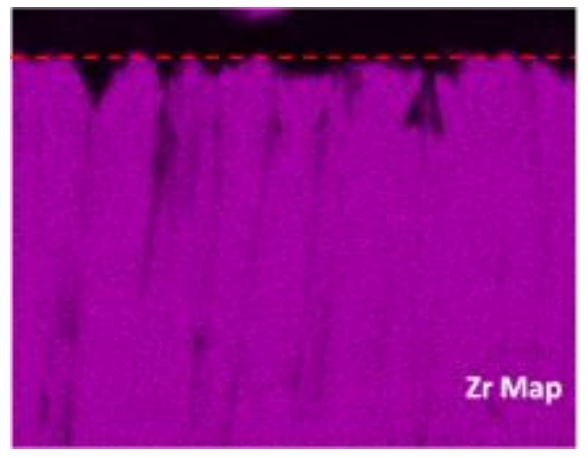

(b)

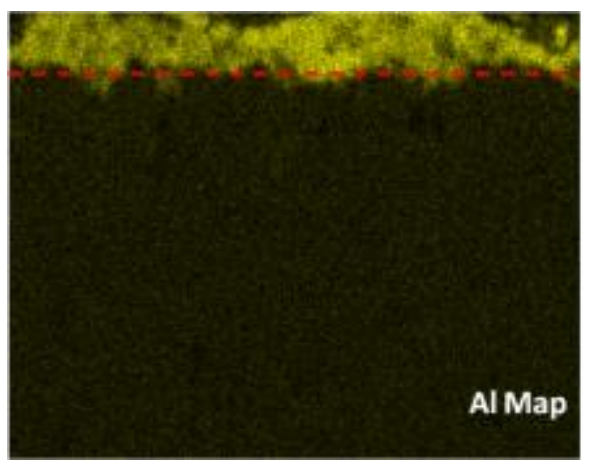

(d)

Figure 46: a) Cross-sectional SEM micrograph of sample 1-3 with molten fly ash interaction and their corresponding elemental maps: b) $\mathrm{Zr}$, c) $\mathrm{Si}$, and d) $\mathrm{Al}$. The horizontal red line show the original top surface of the TBC

To show yttria migration from the YSZ coating into the deposition, an EDS chemical spectrum analysis is completed for various zones within the fly ash and TBC system. Cross-sectional SEM micrographs of sample 1-3 with heavy deposition are shown in Figure 47. The SEM micrograph in Figure 47a is divided into four regions: epoxy, molten deposits, an interaction zone, and unaffected YSZ coating. Table 7 contains the distributions of the elements based on weight percentage of the latter three regions. The numbers from the table are populated by averaging the EDS "Point\&ID" spectrum results at the columnar centers and infiltration depth locations. The interaction zone region was labeled as Zone 1 and Zone 2 in Figure 47b. Zone 3 represents an YSZ area which was relatively unaffected by the fly ash infiltration depth. Zirconia and yttria are chosen to characterize the YSZ coating, and silicon, aluminum, 
and iron are chosen to show deposition infiltration into the top coating layer. The molten deposits that lie on top have a comparable elemental distribution as the processed fly ash. A similar change in weight percentage between the fly ash and the molten deposits can be found in a study by Bons et al. [7]. However, the detection of yttria and zirconia in the molten deposition layers indicates that some of the YSZ coating has migrated into the fly ash deposition. Zone 1 data was recorded at the tips of the YSZ coatings and shows that although zirconia was the predominant element in the zone, molten deposits presence was found. The yttria weight percentage level was roughly 5\%, which is lower than the typical 7-8 \% normally found in 7YSZ or 8YSZ. Zone 2 and Zone 3 data is taken at $10 \mu \mathrm{m}$ and $20 \mu \mathrm{m}$ from the columnar tips respectively. The level of fly ash deposition influence decreases as the depth gets deeper. Table 7 results agree with the infiltration depth from the EDS maps in Figure 46. A study by Peng et al. completed a similar type of EDS analysis comparing CMAS infiltration depth and the elemental distribution within the EB-PVD coating [69]. Even though the CMAS penetrated roughly all of the 80$120 \mu \mathrm{m}$ YSZ, which is as much as 12 times the infiltration depth of our top coat, both studies show yttria migration from the YSZ columnar tips into the molten deposits. This migration causes a destabilization within the ceramic top coating. By having a 5 YSZ instead of a 7YSZ or 8YSZ, the top coating will have a higher tendency to change into one of the less desirable crystal phases (the monoclinic phase) during startup and shutdown. 


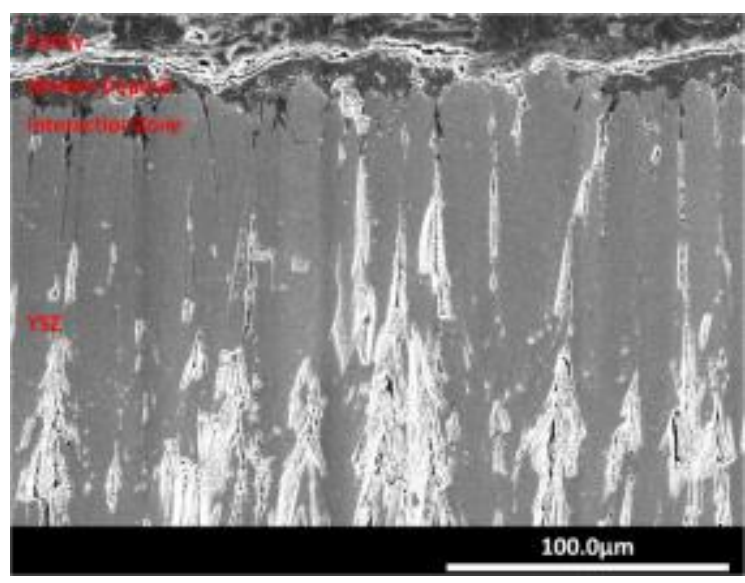

(a)

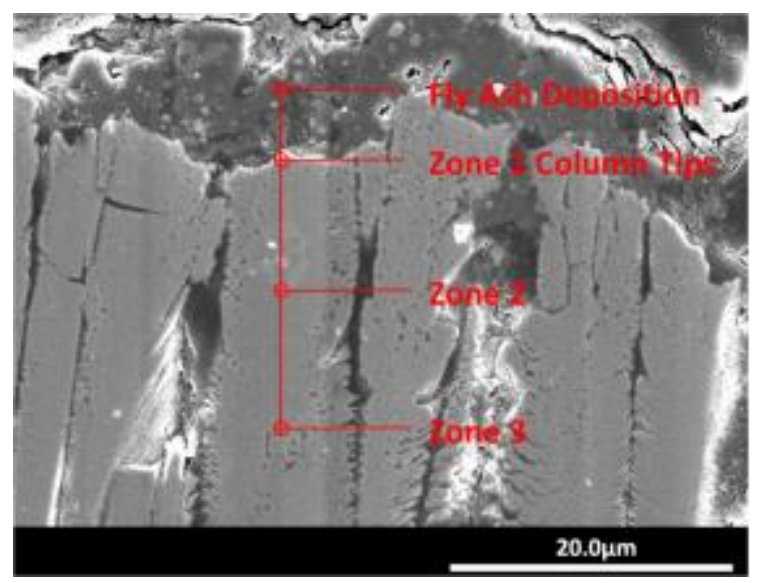

(b)

Figure 47: Cross-sectional views of a) top coating on sample 1-3 with molten deposits with their region label, and b) locations of EDS spectrum analysis

Table 8: Chemical composition (excluding oxygen) of the fly ash deposition and Zones 1-3 in Figure 44b

\begin{tabular}{|lccccc|}
\hline Constituent/wt \% & $\mathrm{Si}$ & $\mathrm{Al}$ & $\mathrm{Fe}$ & $\mathrm{Y}$ & $\mathrm{Zr}$ \\
\hline Original Fly Ash & 28.09 & 14.98 & 6.93 & - & - \\
Molten deposit & 23.23 & 12.98 & 5.76 & 1.35 & 9.54 \\
$1($ Column Tips) & 5.77 & 4.44 & 1.83 & 5.24 & 56.87 \\
$2(10 \mu \mathrm{m})$ & 0.66 & 0.03 & 0.35 & 6.74 & 75.32 \\
$3(20 \mu \mathrm{m})$ & 0.53 & 0.01 & 0.21 & 7.31 & 77.04 \\
\hline
\end{tabular}

The last degradation mechanism found in this study is the dissolution-reprecipitation mechanism of the yttria-stabilized zirconia and is associated with the yttria migration. The tips of the unexposed YSZ coating are shown in Figure 48. The tops of the 7YSZ coating have thin columns with jagged tips. Figure 49 is an illustration from a study by Levi et al. [24] that shows the dissolution-reprecipitation mechanism of YSZ in CMAS. The ceramic coating material dissolves in the molten glass and reprecipitates as one of the modified YSZ crystalline phases. The SEM micrographs in Figure 50 show the columnar tips on sample 1-3 that have reprecipitated in the molten fly ash deposition. The YSZ columnar tips have lost their identity and have similar degradation as YSZ coating tips in CMAS. The reprecipitated YSZ columnar tips were due to the de-stabilizing of the YSZ from yttria migration into the molten deposits, 
and the crystalline phase change may have attributed to a portion of the reduction in the strain tolerance of the deposition infiltrated YSZ coating found in the study.

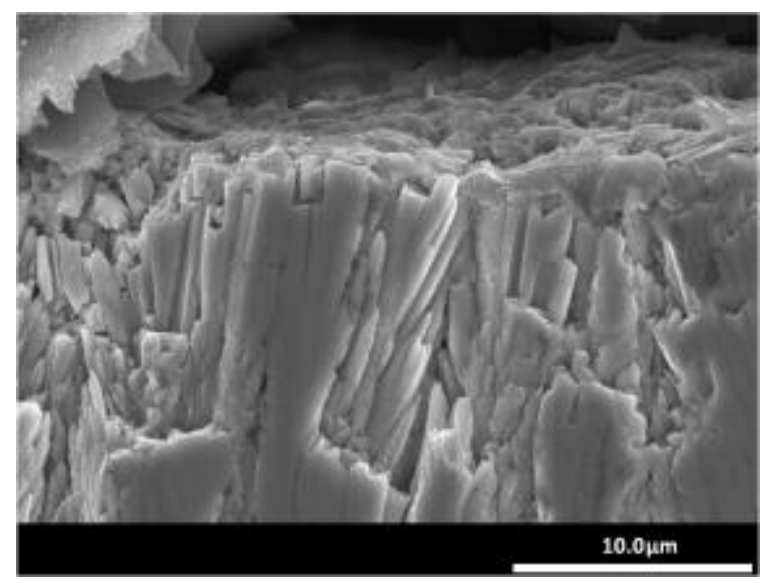

(a)

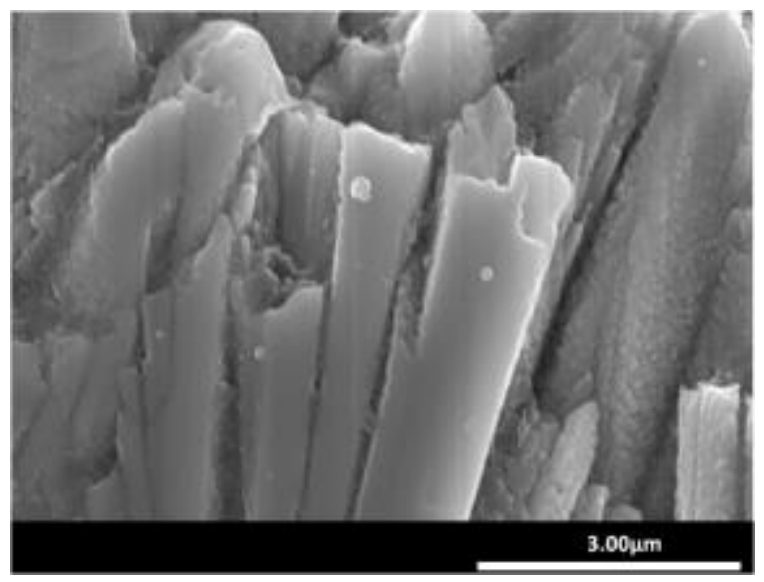

(b)

Figure 48: Unexposed columnar tips of sample 2-3 at a) 4000x magnification and b) 15000x magnification

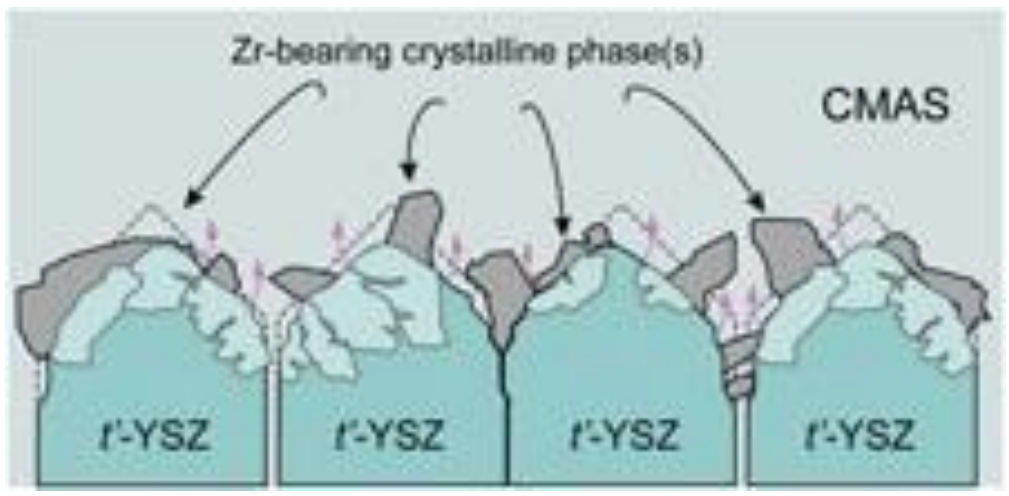

Figure 49: Schematic illustration of the dissolution-reprecipitation mechanism in YSZ due to CMAS [24] 


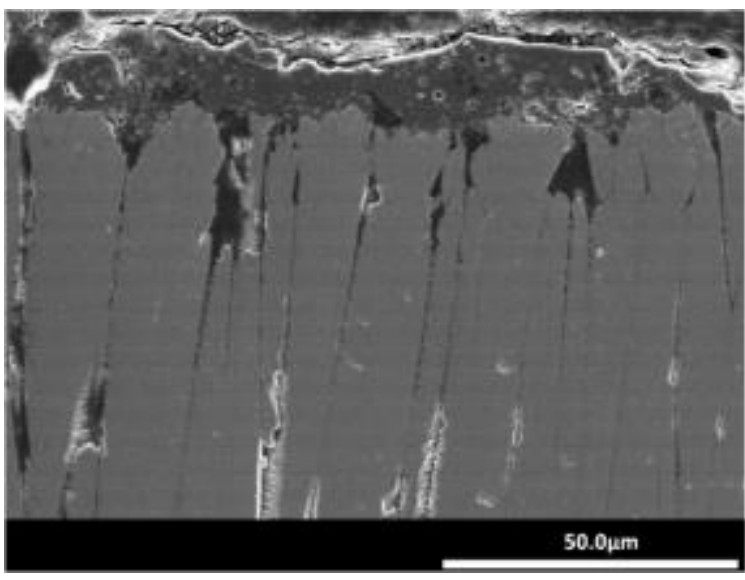

(a)

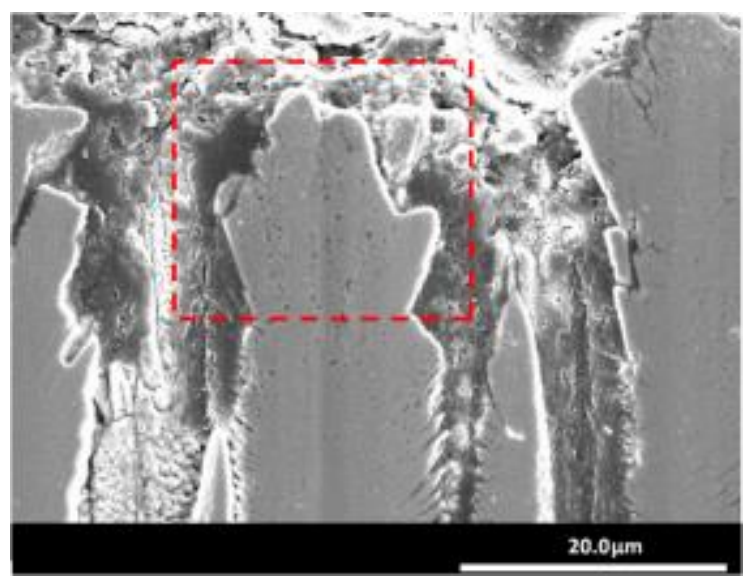

(b)

Figure 50: SEM micrographs of the reprecipitated YSZ columnar tips of sample 1-3 at a) 1000x magnification and b) 2500x magnification

The DVD 7YSZ coatings in the current study had a higher density than most of the EB-PVD coatings used in other molten deposition experiments. Most studies with forms of molten deposit show full penetration of the ceramic top coating, the TBC in this study exhibited a maximum infiltration of only 4-5\% of the YSZ. The high densities of the DVD coatings limited the infiltration of the deposition during the experiment, even though the lack of deposit penetration is desired during actual engine operation. If the samples had experienced a further infiltration depth, the results may have been similar to those found in a study by Krämer et al. [70]. Their study applied a CMAS layer with a thickness of $150 \mu \mathrm{m}$ on an EBPVD TBC for 4 hours at $1300{ }^{\circ} \mathrm{C}$. Figure 51 contains a cross-sectional SEM micrograph of the exposed EB-PVD TBC [70]. Figure 51a shows the severe attacking of the CMAS, which includes the appearance of globular particles near the top surface. Figure 51b shows the relatively unaffected EB-PVD TBC microstructure near the substrate. The columnar tips of the current study, such as those in Figure 50, would be expected to change into the globular particles in 51a with further penetration and dissolution and reprecipitation. Also from the study by Krämer et al. [70], a highly magnified view of the conglomerate of globular particles embedded in CMAS can be seen in Figure 52. 

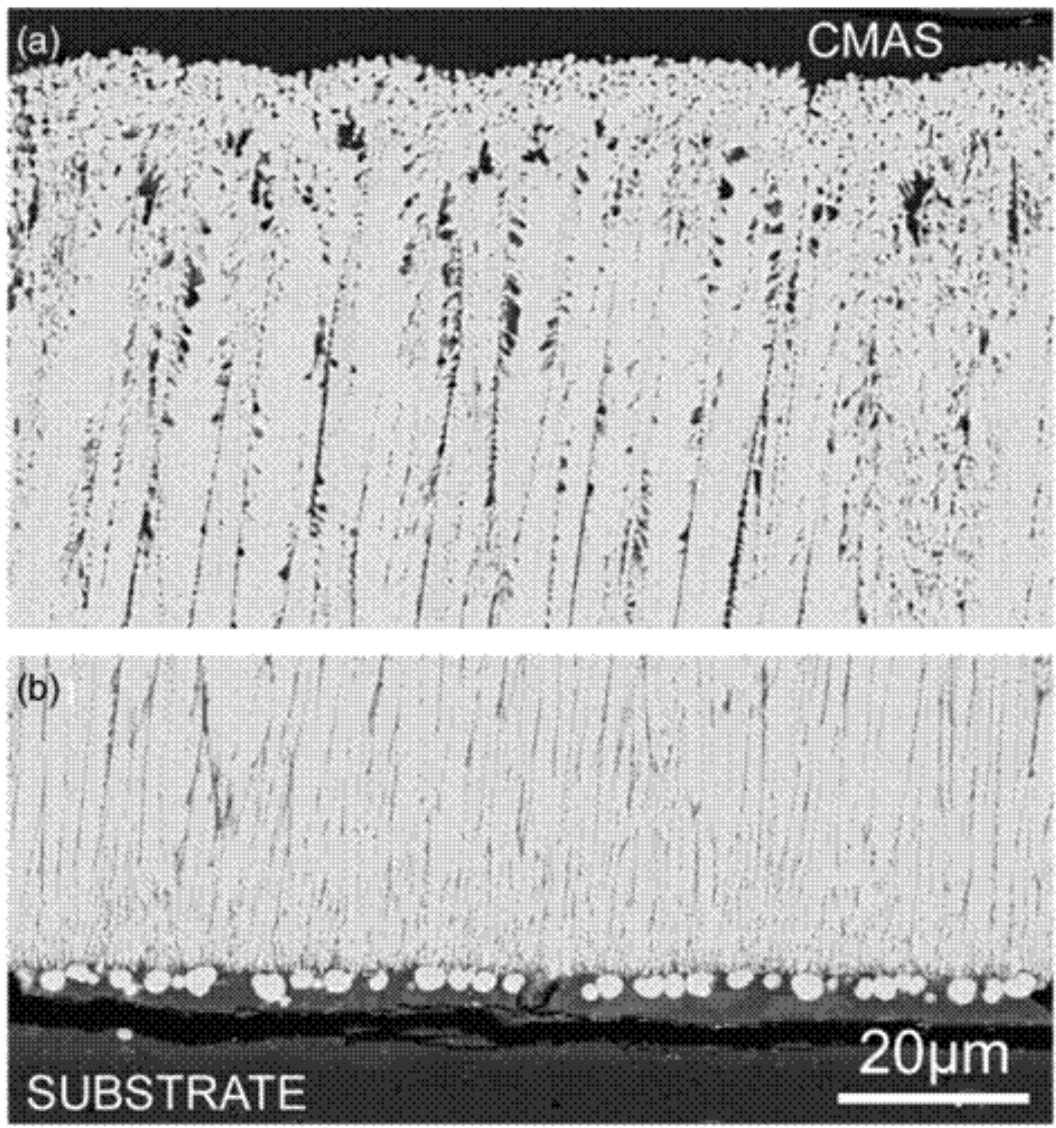

Figure 51: Cross-sectional SEM micrograph of TBC with exposure to CMAS a) near the outer surface of the TBC (severe attack) and b) at the TBC/substrate interface [70]

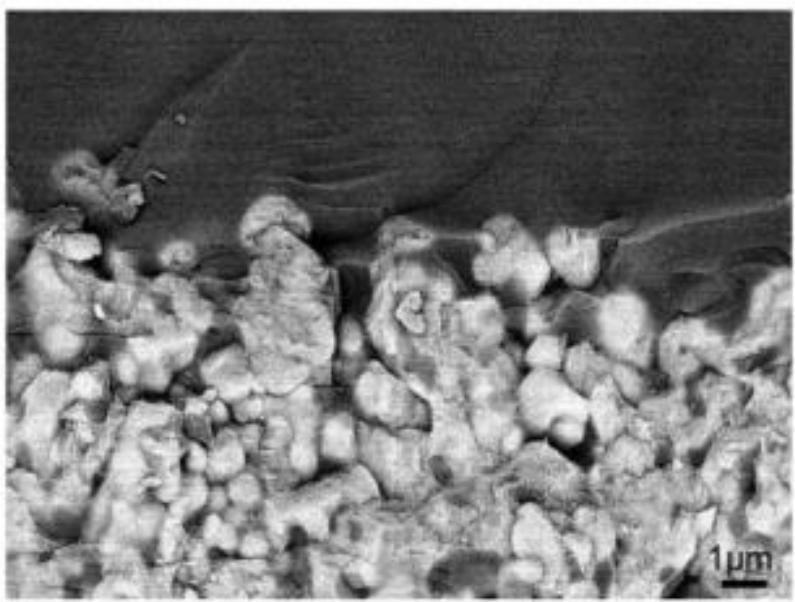

Figure 52: TBC columns that have lost their identity and have formed a conglomerate of globular particles [70] 


\section{CHAPTER 9: CONCLUSIONS AND FUTURE WORK RECOMMENDATIONS}

\section{1: Summary}

The purpose of the study was to analyze the effects of the syngas particulate molten deposits on the TBC coating systems on gas turbine first stage vane. The material analysis of the TBC was completed following the study by Murphy [10] on the effects of gas turbine vane film cooling parameters on the adherence of particulate deposition on first stage vane components. Molten fly ash adhered and infiltrated the YSZ coatings on simulated TBC coated film cooled test articles in Murphy's study. The approximate infiltration depth was $20 \mu \mathrm{m}$. Degradation of the TBC was found using a load-based multiple-partial unloading micro-indentation system to evaluate the mechanical properties of the YSZ and scanning electron microscopy (SEM) and energy dispersive X-ray spectroscopy (EDS) to characterize the microstructure of the TBC system.

The results from the micro-indentation testing found an increase in the modulus of elasticity in the DVD YSZ coating due to the deposition, and subsequently a reduction in the strain tolerance. Several studies have listed a loss of strain tolerance in the YSZ top coating as a result of foreign object molten deposits, however not many studies were able to quantitatively show this. Selected areas of varying deposition quantities were tested to evaluate the surface stiffness response. These areas included areas with heavy deposition, light deposition, and unexposed. The indentation results of the areas with heavy deposition infiltration and adherence experienced higher Young's modulus values than the unexposed YSZ and YSZ on the same test samples but with a very low level of deposition. The higher modulus of elasticity values are due to the fly ash deposits cooling within the 7YSZ and causing a "stiffening" of the columnar microstructure. In terms of the loss of strain tolerance, the stiffening of the microstructure limits the lateral movement of the columns, thus reducing the strain compliance of the coating. The increase was found to be by as much as almost of $9 \mathrm{GPa}$ in sample 1-3, which would be an increase of $43 \%$ in that particular case. The higher surface stiffness values make the YSZ coating more likely to spall off. 
With the use of an SEM, mechanical and microstructure degradation could be seen in the YSZ top coating. Delamination in the YSZ of an area that had heavy deposition was observed on a sample produced from test article 1. In addition, a dissolution-reprecipitation mechanism could be detected in the molten deposit interaction zone. The YSZ columnar tips embedded in the fly ash deposition were reprecipitated and lost their identity. The reprecipitation of the YSZ is part of a phase change within the ceramic top coating material. This physical change can be associated with the yttria migration found by the EDS.

The EDS feature in the scanning electron microscopes allowed for chemical characterization and mapping of the TBC. The molten deposits on the test articles were found to match the processed fly ash of from Murphy's study. In addition, the mapping feature found the infiltration depth of the most heavily fly ash deposited test articles. The highest infiltration depth of the fly ash was found to be roughly 10-20 $\mu \mathrm{m}$. Lastly, EDS was used to find the yttria migration in the reprecipitated YSZ columnar tips. The fly ash absorption of the stabilizing yttria can cause phase change within the YSZ. This yttria migration is the leading factor to the dissolution-reprecipitation mechanism described in the SEM work. A phase transformation can change the thermochemical and thermomechanical properties of the ceramic top coating.

To summarize the work in the study, a micro-indentation procedure and microscopic examinations found several TBC degradation mechanisms associated with the adherence and infiltration of the syngas fly ash deposition. The load-based multiple-partial unloading micro-indentation system allowed the study to evaluate the "loss of strain tolerance" of the YSZ associated with molten deposits that many studies have found. The increase in the YSZ modulus of elasticity from molten fly ash deposition is due to the stiffening of the DVD 7YSZ columnar structure and can detect where delamination and spallation may occur in the future. Through microscopic SEM and EDS examinations, the work found mechanisms that have been associated with molten deposits from CMAS, volcanic ash, 
and lignite fly. These mechanisms include delamination, yttria migration, and the dissolutionreprecipitation that accompanies the yttria migration.

\section{2: Recommendations for Future Work}

Further study is needed in the fabrication of more test samples with fly ash deposition and cyclic thermal loading testing. The unique geometry of the simulated film cooled test articles made generating test samples quite difficult. Although the purpose of the original combined study was to look at the film cooling and syngas particulates, additional fly ash application to TBC coated 1" diameter samples would allow for further and alternative materials testing due to its more accepted geometry for research. Cyclic thermal loading was desired in the original scope of the study, however a lack of additional heavily fly ash infiltrated test samples prevented the thermal study. The cyclic thermal loading would simulate transient engine conditions of a gas turbine. The mechanical and microstructural properties could be evaluated versus the number of cycles the samples experienced before failure from spallation.

Future work could be completed on the same type of study with a different processed particulate injected in the high pressure high temperature facility. Performing the same tests using CMAS or volcanic ash would allow for another comprehensive study on molten deposition, film cooling, and material analyses of gas turbine components. 


\section{CHAPTER 10: REFERENCES}

[1] R. G. Murphy, A. C. Nix, S. A. Lawson, D. Straub and S. K. Beer, "Preliminary Experimental Investigation of the Effects of Particulate Deposition on IGCC Turbine Film-Cooling in a HighPressure Combustion Facility," ASME Turbo Expo 2012: Turbine Technical Conference and Exposition, pp. 979-986, 2012.

[2] B. S. Kang, C. Feng, J. M. Tannenbaum and M. A. Alvin, "A Load-based Micro-indentation Technique for Mechanical Property and NDE Evaluation," National Energy Technology LaboratoryIn-house Research, 2009.

[3] C. A. Johnson, J. A. Ruud, R. Bruce and D. Wortman, "Relationships Between Residual Stress, Microstructure and Mechanical Properties of Electron Beam-Physical Vapor Deposition Thermal Barrier Coatings," Surface and Coatings Technology, vol. 108, pp. 80-85, 1998.

[4] M. P. Boyce, Gas Turbine Engineering Handbook, Elsevier, 2012.

[5] Siampilot.com, "How Aircraft Fly \& Aircraft Engines," Siampilot, [Online]. Available: http://www.siampilot.com/How\%20Aircraft\%20Fly\%20\&\%20Aircraft\%20Engines.htm. [Accessed $16092014]$.

[6] N. P. Padture, M. Gell and E. H. Jordan, "Thermal Barrier Coatings for Gas-Turbine Engine Applications," Science, vol. 296, no. 5566, pp. 280-284, 2002.

[7] J. P. Bons, T. H. Fletcher, J. Crosby, J. E. Wammack and B. I. Bentley, "High-Pressure Turbine Deposition in Land-Based Gas Turbines from Various Synfuels," Journal of Engineering for Gas Turbines and Power, vol. 129, no. 1, pp. 135-143, 2007. 
[8] A. Hamed, W. C. Tabakoff and R. V. Wenglarz, "Erosion and Deposition in Turbomachinery," Journdal of Propulsion and Power, vol. 22, no. 2, pp. 350-360, 2006.

[9] N. P. Padture, A. Krause, S. Sampath and R. Subramanian, Advanced Thermal Barrier Coatings for Next Generation Gas-Turbine Engines Fueled by Coal-Derived Syngas, DoE NETL University Coal Research Program, 2014.

[10] R. G. Murphy, "Experimental Investigation of Particulate Deposition on a Simulated Film-Cooled Turbine Vane Pressure Surface in a High Pressure Combustion Facility," West Virginia University, Morgantown, WV, 2012.

[11] J. Yan, Aspects of Instrumented Indentation with Applications to Thermal Barrier Coatings, Proquest, 2007.

[12] H. Herman, "Plasma-Sprayed Coatings," Scientific American, vol. 259, no. 3, 1988.

[13] U. Schulz, C. Leyans, K. Fritscher, M. Peters, B. Saruhan-Brings, O. Lavigne, J.-M. Dorvaux, M. Poulain, R. Mévrel and M. Caliez, "Some Recent Trends in Research and Technology of Advanced Thermal Barrier Coatings," Aerospace Science and Technology, vol. 7, no. 1, pp. 73-80, 2003.

[14] J. T. DeMasi-Marcin and D. K. Gupta, "Protective Coatings in the Gas Turbine Engine," Surface and Coatings Technology, vol. 68, pp. 1-9, 1994.

[15] D. A. Otunyo, "Mechanical Property Evaluation of Thermal Barrier Coating Systems at Elevated Temperatures by use of Spherical Micro-Indentation Method," West Virginia University, Morgantown, WV, 2012.

[16] M. Hu, S. Guo, T. Tomimatsu, Y. Ikuhara and Y. Kagawa, "TEM Study on Microstructure of Thermally Grown Oxide in EB-PVD Thermal Barrier Coatings," Surface and Coatings Technology, 
vol. 200, no. 20, pp. 6130-6136, 2006.

[17] L. Lelait, S. Alperine and R. Mevrel, "Alumina Scale Growth at Zirconia- MCrAlY Interfaces: A Microstructural Study," Journal of Material Science, vol. 27, no. 1, pp. 5-12, 1992.

[18] A. G. Evans, D. R. Clarke and C. G. Levi, "The Influence of Oxides on the Performance of Advanced Gas Turbines," Journal of the European Ceramic Society, vol. 28, no. 7, pp. 1405-1419, 2008.

[19] V. K. Tolpygo and D. R. Clarke, "Surface Rumpling of a (Ni, Pt)Al Bond Coat Induced by Cyclic Oxidation," Acta Materialia, vol. 48, no. 13, pp. 3283-3293, 2000.

[20] S. Dalkilic and A. A. Tanatmis, "Damage Evaluation of Thermal Barrier Coatings Under High Temperature Low Cycle Fatigue Conditions," in Aerospace Sciences \& Aviation Technology, Cairo, Egypt, 2009.

[21] J. R. Nicholls and R. G. Wellman, "Erosion and Foreign Object Damage of Thermal Barrier Coatings," in RTO AVt Specialists, Williamsburg, 2003.

[22] R. G. Logan, G. A. Richards, C. T. Meyer and R. J. Anderson, "A Study of Techniques for Reducing Ash Deposition in Coal-Fired Gas Turbines," Progress in Energy and Combustion Science, vol. 16, no. 4, pp. 221-233, 1990.

[23] R. Wellman, G. Whitman and J. R. Nicholls, "CMAS Corrosion of EB PVD TBCs: Identifying the Minimum Level to Initiate Damage," International Journal of Refractory Metals and Hard Materials, vol. 28, no. 1, pp. 124-132, 2010.

[24] C. G. Levi, J. W. Hutchinson, M.-H. Vidal-Sétif and C. A. Johnson, "Environmental Degradation of 
Thermal-Barrier Coatings by Molten Deposits," MRS Bulletin, vol. 37, no. 10, pp. 932-941, 2012.

[25] G. Whitman and R. Wellman, The Effect of Calcium-Magnesium-Aluminosilicate Attack on Thermal Barrier Coatings, Cranfield University, 2008.

[26] J. M. Drexler, A. D. Gledhill, K. Shinoda, A. L. Vasiliev, K. M. Reddy, S. Sampath and N. P. Padture, "Jet Engine Coatings for Resisting Volcanic Ash," Advanced Materials, vol. 23, no. 21, pp. 2419-2424, 2011.

[27] N. P. Padture, "Degradation of Thermal Barrier Coatings from Deposits and Its Mitigation," USDOE, 2011.

[28] X. Zhao and P. Xiao, "Residual Stresses in Thermal Barrier Coatings Measured by Photoluminescence Piezospectroscopy and Indentation Technique," Surface and Coatings Technology, vol. 201, no. 3, pp. 1124-1131, 2006.

[29] J. M. Tannenbaum, "Progression in Non-Destructive Spallation Prediction and Elevated Temperature Mechanical Property Evaluation of Thermal Barrier Coating System by Use of a Spherical MicroIndentation Method," West Virginia University, Morgantown, WV, 2011.

[30] B. S.-J. Kang, C. Feng, J. M. Tannenbaum and M. A. Alvin, "A Load-Based Depth-Sensing Indentation Technique for Damage Assessment of Thermal Barrier Coatings," in ASME Turbo Expo 2009: Power for Land, Sea, and Air, Orlando, FL, 2009.

[31] Haynes International, "HAYNES 230 Alloy," Haynes International, Inc, 2007.

[32] D. Hass, "Thermal Barrier Coating Environmental Durability Enhancement (CMAS)," NAVAIR Public Release, 2012. 
[33] Directed Vapor Technologies International, "Directed Vapor Technologies International," Directed Vapor Technologies International, 2011. [Online]. Available: www.directedvapor.com. [Accessed 04 09 2011].

[34] B. Gleeson, W. Wang, S. Hayashi and D. J. Sordelet, "Effects of Platinum on the Interdiffusion and Oxidation Behavior of Ni-Al-Based Alloys," in Materials Science Forum, 2004.

[35] Y. Lu, H. Nasir and S. V. Ekkad, "Film Cooling From a Row of Holes Embedded in Transverse Slots," ASME Turbo Expo 2005: Power for Land, Sea, and Air, pp. 585-592, 2005.

[36] D. D. Hass, P. A. Parrish and H. N. Wadley, "Electron Beam Directed Vapor Deposition of Thermal Barrier Coatings," Journal of Vacuum Science \& Technology A, vol. 16, no. 6, pp. 3396-3401, 1998.

[37] D. D. Hass, A. J. Slifka and H. G. Wadley, "Low Thermal Conductivity Vapor Deposited Zirconia Microstructures," Acta Materialia, vol. 49, no. 6, pp. 973-983, 2001.

[38] R. G. Murphy, A. C. Nix, S. A. Lawson, D. Straub and S. K. Beer, "Investigation of Factors that Contribute to Deposition Formation on Turbine Components in a High-Pressure Combustion Facility," in ASME Turbo Expo 2013: Power for Land, Sea, and Air, San Antonio, Texas, 2013.

[39] C. Smith, B. Barker, C. Clum and J. Bons, "Deposition in a Turbine Cascade with Combusting Flow," in ASME Turbo Expo 2010: Power for Land, Sea and Air, Glasgow, 2010.

[40] S. A. Lawson and K. A. Thole, "The Effects of Simulated Particle Deposition on Film Cooling," Journal of Turbomachinery, vol. 133, no. 2, pp. 021009-1 - 021009-10, 2011.

[41] R. A. Dennis, W. W. Shelton and P. Le, "Development of Baseline Performance Values for Turbines in Existing IGCC Applications," in ASME Turbo Expo 2007: Power for Land, Sea, and Air, 2007. 
[42] J. Bons, A. Ameri and T. Fletcher, "Designing Turbine Endwalls for Deposition Resistance with 1400C Combustor Exit Temperatures and Syngas Water Vapor Levels," The Ohio State University, 2012.

[43] J. W. Jensen, S. W. Squire, J. P. Bons and T. H. Fletcher, "Simulated Land Based Turbine Deposits Generated in an Accelerated Deposition Facility," Journal of Turbomachinery, vol. 127, no. 3, pp. 462-470, 2005.

[44] G. Moskal, B. Witala and A. Rozmyslowska, "Metallographic Preparation of Conventional and New TBC Layers," Archives of Materials Science and Engineering, vol. 39, no. 1, pp. 53-60, 2009.

[45] A. C. Fischer-Cripps and I. Mustafaev, Introduction to Contact Mechanics, New York, New York: Springer, 2000.

[46] K. L. Johnson, K. Kendall and A. D. Roberts, "Surface Energy and Contact Mechanics of Elastic Solids," Proceedings of the Royal Society of London. A. Mathematical and Physical Sciences, vol. 324, no. 1558, pp. 301-313, 1971.

[47] H. Hertz, "On the Contact of Elastic Solids," J. Reine Angew. Math, vol. 92, no. 156-171, p. 110, 1881.

[48] A. I. Lur'e, Three-Dimensional Problems in the Theory of Elasticity, New York, New York: Interscience Publishers, 1964.

[49] ASTM Standard, "Standard Practice for Instrumented Indentation Testing," in ASTM International, West Conshohocken, PA, 2007.

[50] A. C. Fischer-Cripps, Nanoindentation, New York, New York: Springer, 2004. 
[51] J. M. Tannenbaum, "The Development of an Instrumented Indentation System," West Virginia University, Morgantown, WV, 2008.

[52] G. Feng and A. H. W. Ngan, "Effects of Creep and Thermal Drift on Modulus Measurement using Depth-Sensing Indentation," Journal of Materials Research, vol. 17, no. 3, pp. 660-668, 2002.

[53] J. H. Underwood, "Residual-Stress Measurement using Surface Displacements around an Indentation," Experimental Mechanics, vol. 13, no. 9, pp. 373-380, 1973.

[54] T. Y. Tsui, W. C. Oliver and G. M. Pharr, "Influences of Stress on the Measurement of Mechanical Properties Using Nanoindentation: Part I. Experimental Studies in an Aluminum Alloy," Journal of Materials Research, vol. 11, no. 3, pp. 752-759, 1996.

[55] K. L. Johnson, Contact Mechanics, New York, New York: Cambridge University Press, 1987.

[56] S. J. Kline and F. A. McClintock, "Describing Uncertainties in Single-Sample Experiments," Mechanical Engineering, vol. 75, no. 1, pp. 3-8, 1953.

[57] R. J. Moffat, "Describing the Uncertainties in Experimental Results," Experimental Thermal and Fluid Science, vol. 1, no. 1, pp. 3-17, 1988.

[58] Physik Instrumente (PI), "P-2x5 Piezo Actuator," Physik Instrumente (PI), Karlsruhe, Germany, 2013.

[59] Keyence Corporartion, "Units \& Tolerance," Keyence Corporartion, 2014. [Online]. Available: http://www.sensorcentral.com/worldsupport/standards14.php. [Accessed 2014].

[60] G. G. Carette and V. M. Malhotra, "Characterization of Canadian Fly Ashes and Their Relative Performance of Concrete," Canadian Journal of Civil Engineering, vol. 14, no. 5, pp. 667-682, 1987. 
[61] T. R. Naik and B. W. Ramme, "Setting and Hardening of High Fly Ash Content Concrete," in American Coal Ash Association 8th International Coal Ash Utilization Symposium, Washington, D.C., 1987.

[62] C. Eberl, D. S. Gianola, X. Wang, M. Y. He, A. G. Evans and K. J. Hemker, "A Method for In Situ Measurement of Elastic Behavior of a Columnar Thermal Barrier Coating," Acta Materialia, vol. 59, no. 9 , pp. 3612-3620, 2011.

[63] R. G. Wellman and J. R. Nicholls, "Some Observation on Erosion Mechanisms of EB PVD TBCs," Wear, vol. 242, no. 1-2, pp. 89-96, 2000.

[64] A. M. Karlsson, T. Xu and A. G. Evans, "The Effect of the Thermal Barrier Coating on the Displacement Instability in Thermal Barrier Systems," Acta Materialia, vol. 50, no. 5, pp. 1211$1218,2002$.

[65] R. Vaßen, G. Kerkhoff and D. Stöver, "Development of a Micromechanical Life Prediction Model for Plasma Sprayed Thermal Barrier Coatings," Material Science Engineering: A, vol. 303, no. 1, pp. 100-109, 2001.

[66] M. Z. Alam, D. K. Das and S. V. Kamat, "Tensile Behavior of Free-Standing Pt-aluminide (PtAl) Bond Coats," Acta Materialia, vol. 61, no. 4, pp. 1093-1105, 2013.

[67] G. M. Newaz, S. Q. Nusier and Z. A. Chaudhury, "Damage Accumulation Mechanisms in Thermal Barrier Coatings," Journal of Engineering Materials and Technology, vol. 120, no. 2, pp. 149-153, 1998.

[68] HAYNES, "Haynes 230 (2.4733, N06230, NiCr22W14Mo)," MakeItFrom.com, 2009-2013. [Online]. Available: http://www.makeitfrom.com/material-data/?for=Haynes-230-2.4733-N06230- 
NiCr22W14Mo. [Accessed 2014].

[69] H. Peng, L. Wang, L. Guo, W. Miao, H. Guo and S. Gong, "Degradation of EB-PVD Thermal Barrier Coatings Casued by CMAS Deposits," Progress in Natural Science: Materials International, vol. 22, no. 5, pp. 461-467, 2012.

[70] S. Krämer, J. Yang, C. G. Levi and C. A. Johnson, "Thermochemical Interaction of Thermal Barrier Coatings with Molten $\mathrm{CaO}-\mathrm{MgO}-\mathrm{Al} 2 \mathrm{O} 3-\mathrm{SiO} 2$ (CMAS) Deposits," Journal of the American Ceramic Society, vol. 89, no. 10, pp. 3167-3175, 2006. 


\section{APPENDIX}

\section{A. Supporting Data}

Sample 2-3

AVERAGE ELASTIC MODULUS

$\mathrm{R}_{\mathrm{o}}$

TEST 1

TEST 2

TEST 3

TEST 4

TEST 5

TEST 6

AVERAGE

Average $\sigma b$

Average $\sigma b$

\begin{tabular}{|l|r|}
\hline Number of data points (n) & 5 \\
\hline Std dev of data (sigma-hat) & 4.416529 \\
\hline Mean of data (mu-hat) & 20.27147 \\
\hline
\end{tabular}

\begin{tabular}{|l|c|}
\hline \multicolumn{2}{|c|}{ Individual estimates } \\
\hline Estimate of true mean & 25.75531 \\
\hline Estimate of true stdev & 2.867675 \\
\hline
\end{tabular}

$\delta \mathrm{Xi}=\mathrm{tS}(\mathrm{N}) / \sqrt{ } \mathrm{N}$

5.483845

$\mathrm{GPa}$

Total Uncertainty

5.484722 GPa
Sample 2-4

AVERAGE ELASTIC MODULUS

$\mathrm{R}_{\mathrm{o}}$

TEST 1

26.57446

TEST 2

19.6067

TEST 3

18.58666

TEST 4

22.81101

TEST 5

20.35378

TEST 6

\section{AVERAGE}

$21.58652 \mathrm{GPa}$

Average $\sigma b$

$0.104695 \mathrm{GPa}$

Average $\sigma b$

$0.48 \%$

\begin{tabular}{|l|r|}
\hline Number of data points (n) & 5 \\
\hline Std dev of data (sigma-hat) & 3.194429 \\
\hline Mean of data (mu-hat) & 21.58652 \\
\hline
\end{tabular}

\begin{tabular}{|l|c|}
\hline \multicolumn{2}{|c|}{ Individual estimates } \\
\hline Estimate of true mean & 25.55293 \\
\hline Estimate of true stdev & 2.074159 \\
\hline
\end{tabular}

$\delta \mathrm{Xi}=\mathrm{tS}(\mathrm{N}) / \sqrt{ } \mathrm{N}$

$3.966408 \mathrm{GPa}$

3.967789 GPa

Eunexposed 20.92899 GPa 
1-1 Deposition

AVERAGE ELASTIC

MODULUS

TEST 1

TEST 2

TEST 3

TEST 4

TEST 5

TEST 6

CONFIRMATION

AVERAGE

Average $\sigma b$

Average $\sigma b$

\begin{tabular}{|l|r|}
\hline Number of data points (n) & 7 \\
\hline & 4.80174097 \\
Std dev of data (sigma-hat) & 6 \\
\hline Mean of data (mu-hat) & 27.1378540 \\
\hline
\end{tabular}

\begin{tabular}{|l|r|}
\hline \multicolumn{2}{|c|}{ Individual estimates } \\
\hline & 31.5787237 \\
Estimate of true mean & 9 \\
\hline & 3.31462280 \\
Estimate of true stdev & 9 \\
\hline
\end{tabular}

4.44086971

$\delta \mathrm{Xi}=\mathrm{tS}(\mathrm{N}) / \sqrt{ } \mathrm{N}$

$7 \mathrm{GPa}$

4.44319855

Total Uncertainty

33.4723331

33.3790769

27.1378540

0.1438

$0.49 \%$

GPa
E/E0

1.02559

1.10827

6

1.20217

4
1.18292

4

1.36346

9

1.59932

8
1.59487

3

$\mathrm{GPa}$

TEST 2

TEST 3

TEST 4

TEST 5

TEST 6

TEST 7

AVERAGE

Average $\sigma b$

Average $\sigma b$

$\begin{array}{lr}\text { Ro } & \text { E/E0 } \\ 18.3975 & 0.87904 \\ 9 & 8 \\ 19.5886 & 0.93595 \\ 1 & 6 \\ 21.4727 & \\ 2 & 1.02598 \\ 22.8656 & 1.09253 \\ 7 & 6\end{array}$

20.5811

$5 \mathrm{GPa}$

$0.0995 \mathrm{GPa}$

$0.48 \%$

\begin{tabular}{|l|r|}
\hline Number of data points (n) & 4 \\
\hline & 1.98048 \\
Std dev of data (sigma-hat) & 9 \\
\hline & 20.5811 \\
Mean of data (mu-hat) & 5 \\
\hline
\end{tabular}

\begin{tabular}{|l|r|}
\hline \multicolumn{2}{|c|}{ Individual estimates } \\
\hline \multicolumn{2}{|c|}{} \\
Estimate of true mean & 23.7325 \\
\hline & 5 \\
\hline Estimate of true stdev & 1.22708 \\
\hline
\end{tabular}

$\delta \mathrm{Xi}=\mathrm{tS}(\mathrm{N}) / \sqrt{ } \mathrm{N}$

$3.1514 \mathrm{GPa}$

Total Uncertainty

3.15297 GPa 
1-2 Clean

AVERAGE ELASTIC MODULUS

$\begin{array}{lcl} & \text { Ro } & \text { E/E0 } \\ \text { TEST 1 } & 23.47638 & 1.121716 \\ \text { TEST 2 } & 17.35857 & 0.829403 \\ \text { TEST 3 } & 16.46073 & 0.786503 \\ \text { TEST 4 } & 20.17531 & 0.963989 \\ \text { TEST 5 } & 18.01579 & 0.860805\end{array}$

TEST 6

AVERAGE

$19.09736 \mathrm{GPa}$

Average $\sigma \mathrm{b}$

$0.0982 \mathrm{GPa}$

Average $\sigma b$

$0.48 \%$

\begin{tabular}{|l|r|}
\hline Number of data points (n) & 5 \\
\hline Std dev of data (sigma-hat) & 2.80548 \\
\hline Mean of data (mu-hat) & 19.09736 \\
\hline
\end{tabular}

\begin{tabular}{|l|c|}
\hline \multicolumn{2}{|c|}{ Individual estimates } \\
\hline Estimate of true mean & 22.58082 \\
\hline Estimate of true stdev & 1.821612 \\
\hline
\end{tabular}

$\delta \mathrm{Xi}=\mathrm{tS}(\mathrm{N}) / \sqrt{ } \mathrm{N} \quad 3.483463 \quad \mathrm{GPa}$

Total Uncertainty

3.484848 GPa 
1-3 Deposition

AVERAGE ELASTIC MODULUS

\begin{tabular}{lrr} 
& \multicolumn{1}{c}{ Ro } & \multicolumn{1}{l}{ E/E0 } \\
TEST 1 & 33.1006 & 1.581567 \\
TEST 2 & 25.24518 & 1.20623 \\
TEST 3 & 28.04463 & 1.339989 \\
TEST 4 & 29.86901 & 1.42716 \\
TEST 5 & 32.08709 & 1.533141 \\
CONFIRMATION 1 & 25.99598 & 1.242104 \\
CONFIRMATION 2 & 32.53369 & 1.554479 \\
AVERAGE & 29.55374 & $\mathrm{GPa}$ \\
Average $\sigma \mathrm{b}$ & 0.1464 & $\mathrm{GPa}$ \\
Average $\sigma \mathrm{b}$ & $0.49 \%$ &
\end{tabular}

1-3 Clean

AVERAGE ELASTIC MODULUS

\begin{tabular}{lrr} 
& \multicolumn{1}{l}{ Ro } & \\
TEST 1 & 21.02251 & 1.004468 \\
TEST 2 & 18.6252 & 0.889923 \\
TEST 3 & 20.04873 & 0.95794 \\
TEST 4 & 17.83375 & 0.852107 \\
TEST 5 & 25.6154 & 1.22392 \\
& & \\
& & \\
AVERAGE & 20.62912 & $\mathrm{GPa}$ \\
Average $\sigma \mathrm{b}$ & 0.0998 & $\mathrm{GPa}$ \\
Average $\sigma \mathrm{b}$ & $0.48 \%$ &
\end{tabular}

\begin{tabular}{|l|l|}
\hline \multicolumn{2}{|c|}{ Individual estimates } \\
\hline Estimate of true mean & 32.51412 \\
\hline Estimate of true stdev & 2.209601 \\
\hline
\end{tabular}

\begin{tabular}{|l|l|}
\hline \multicolumn{2}{|c|}{ Individual estimates } \\
\hline Estimate of true mean & 24.41489 \\
\hline Estimate of true stdev & 1.979701 \\
\hline
\end{tabular}

$\delta \mathrm{Xi}=\mathrm{tS}(\mathrm{N}) / \sqrt{ } \mathrm{N} \quad 2.960382 \mathrm{GPa}$
$\delta \mathrm{Xi}=\mathrm{tS}(\mathrm{N}) / \sqrt{ } \mathrm{N}$
$3.785775 \mathrm{GPa}$

Total Uncertainty

2.963999 GPa

Total Uncertainty

3.78709 GPa 
1-4 Clean

AVERAGE ELASTIC MODULUS

Ro

$\begin{array}{lll}\text { TEST } 1 & 20.8317 & 0.995351\end{array}$

$\begin{array}{lll}\text { TEST } 2 & 20.97138 & 1.002025\end{array}$

$\begin{array}{lll}\text { TEST } 3 & 25.53539 & 1.220096\end{array}$

TEST 4

TEST 5

TEST 6

$\begin{array}{lrl}\text { AVERAGE } & 22.44616 & \mathrm{GPa} \\ \text { Average } \sigma \mathrm{b} & 0.1091 & \mathrm{GPa} \\ \text { Average } \sigma \mathrm{b} & 0.49 \% & \end{array}$

\begin{tabular}{|l|r|}
\hline Number of data points (n) & 3 \\
\hline Std dev of data (sigma-hat) & 2.676265 \\
\hline Mean of data (mu-hat) & 22.44616 \\
\hline
\end{tabular}

\begin{tabular}{|l|c|}
\hline \multicolumn{2}{|c|}{ Individual estimates } \\
\hline Estimate of true mean & 29.09437 \\
\hline Estimate of true stdev & 1.546242 \\
\hline
\end{tabular}

$\delta \mathrm{Xi}=\mathrm{tS}(\mathrm{N}) / \sqrt{ } \mathrm{N} \quad 6.64821 \quad \mathrm{GPa}$

Total Uncertainty

6.649105 GPa 
3-1 Deposition

AVERAGE ELASTIC MODULUS

Ro

TEST 1

TEST 2

TEST 3

TEST 4

TEST 5

TEST 6

AVERAGE

Average $\sigma b$

Average $\sigma \mathrm{b}$

\begin{tabular}{|l|r|}
\hline Number of data points (n) & 5 \\
\hline Std dev of data (sigma-hat) & 8.226238 \\
\hline Mean of data (mu-hat) & 28.51741 \\
\hline
\end{tabular}

\begin{tabular}{|l|c|}
\hline \multicolumn{2}{|c|}{ Individual estimates } \\
\hline Estimate of true mean & 38.73164 \\
\hline Estimate of true stdev & 5.341339 \\
\hline
\end{tabular}

25.99424
3-2 Clean

AVERAGE ELASTIC MODULUS

1.242021

$17.38056 \quad 0.830454$

$26.0658 \quad 1.24544 \quad$ TEST 3

TEST 1

TEST 2

TEST 4

TEST 5

TEST 6

AVERAGE

23.34043 GPa

Average $\sigma b$

$0.1231 \mathrm{GPa}$

Average $\sigma b$

$0.49 \%$

\begin{tabular}{|l|r|}
\hline Number of data points (n) & 4 \\
\hline Std dev of data (sigma-hat) & 3.527594 \\
\hline Mean of data (mu-hat) & 23.34043 \\
\hline
\end{tabular}

\begin{tabular}{|l|c|}
\hline \multicolumn{2}{|c|}{ Individual estimates } \\
\hline Estimate of true mean & 28.95362 \\
\hline Estimate of true stdev & 2.185659 \\
\hline
\end{tabular}

$\delta \mathrm{Xi}=\mathrm{tS}(\mathrm{N}) / \sqrt{ } \mathrm{N}$

$5.613189 \mathrm{GPa}$

Total Uncertainty

5.614539 GPa 


\title{
KEVIN LUO
}

Mechanical and Aerospace Engineering Department, West Virginia University

Center for Alternative Fuels, Engines and Emissions

Tel: (304) 282-2845

Engineering Sciences Building

Email: kluo1@mix.wvu.edu

Morgantown, WV 26506

kevin9015us@yahoo.com

\section{EDUCATION}

Master of Science in Mechanical Engineering, Mechanical and Aerospace Engineering

Department, Benjamin M. Statler College of Engineering and Mineral Resources,

West Virginia University, Morgantown, West Virginia

Thesis: Degradation of Thermal Barrier Coatings on an Integrated Gasification Combined Cycle

(IGCC) Simulated Film-Cooled Turbine Vane Pressure Surface due to Particulate Fly Ash

Deposition

Chair: Dr. Andrew C. Nix, October 2014

Bachelor of Science in Mechanical Engineering, Mechanical and Aerospace Engineering Department, College of Engineering and Mineral Resources, West Virginia University, Morgantown, West Virginia.

\author{
AWARDS \\ 2013 University Turbine Systems Research Fellowship, Coatings and NDE Group, General \\ Electric Power \& Water, Schenectady, NY \\ Mentor: Joshua Margolies
}

\section{PUBLICATIONS}

Luo, K., Nix, A.C., Kang, B.S., Otunyo, D.A., 2014 “Effects of Syngas Particulate Fly Ash Deposition on the Mechanical Properties of Thermal Barrier Coatings on Simulated Film-Cooled Turbine Vane Components," International Journal of Clean Coal Energy, vol. 3, pp. 54-64, 2014.

Luo, K., Nix, A.C., Sabolsky, E.M., 2014 "Microstructural Degradation of Thermal Barrier Coatings on an Integrated Combined Cycle (IGCC) Simulated Film-Cooled Turbine Vane Pressure Surface due to Particulate Fly Ash Deposition," International Journal of Clean Coal Energy, (Accepted for the February 2015 issue of IJCCE) [Final Draft] 


\section{Journal Papers}

1. Luo, K., Nix, A.C., Kang, B.S., Otunyo, D.A., 2014 “ Effects of Syngas Particulate Fly Ash Deposition on the Mechanical Properties of Thermal Barrier Coatings on Simulated Film-Cooled Turbine Vane Components," International Journal of Clean Coal Energy, vol. 3, pp. 54-64, 2014.

\section{(PUBLISHED)}

2. Luo, K., Nix, A.C., Sabolsky, E.M., 2014 "Microstructural Degradation of Thermal Barrier Coatings on an Integrated Combined Cycle (IGCC) Simulated Film-Cooled Turbine Vane Pressure Surface due to Particulate Fly Ash Deposition," International Journal of Clean Coal Energy, (Accepted for the February 2015 issue of IJCCE)

(FINAL DRAFT; IN PUBLICATION) 


\title{
Effects of Syngas Particulate Fly Ash Deposition on the Mechanical Properties of Thermal Barrier Coatings on Simulated Film-Cooled Turbine Vane Components
}

\author{
Kevin Luo ${ }^{1}$, Andrew C. Nixx ${ }^{1}$, Bruce S. Kangz, Dumbì A. Otunyo ${ }^{2}$ \\ ${ }^{1}$ Center for Alternative Fuels, Engines and Emissions, Department of Mechanical and Aerospace Engineering, \\ Morgantown, USA \\ 'Department of Mechanical and Aerospace Engineering, Morgantown, USA \\ Email: kluo1@mix.wy.edu, andrew.nix@mail.wy.edu
}

Received 7 September 2014; revised 17 October 2014 ; accepted 13 November 2014

Copyright (c) 2014 by authors and Scientific Research Publishing inc.

This work is licensed under the Creative Commons Attribution International License (CC BY).

htto:/creativecommons.org/licenses/by/4.0/

(c) () Open Access

\begin{abstract}
Research is being conducted to study the effects of particulate deposition from contaminants in coal synthesis gas (syngas) on the mechanical properties of thermal barrier coatings (TBC) employed on integrated gasification combined cycle (IGCC) turbine hot section airfoils. West Virginia University (WVU) had been working with US Department of Energy, National Energy Technology Laboratory (NETL) to simulate deposition on the pressure side of an IGCC turbine first stage vane. To model the deposition, coal fly ash was injected into the flow of a combustor facility and deposited onto TBC coated, angled film-cooled test articles in a high pressure (approximately $4 \mathrm{~atm}$ ) and a high temperature $(1560 \mathrm{~K})$ environment. To investigate the interaction between the deposition and the TBC, a load-based multiple-partial unloading micro-indentation technique was used to quantitatively evaluate the mechanical properties of materials. The indentation results showed the Young's Modulus of the ceramic top coat was higher in areas with deposition formation due to the penetration of the fly ash. This corresponds with the reduction of strain tolerance of the $7 \%$ yttria-stabilized zirconia (7YSZ) coatings.
\end{abstract}

Keywords

IGCC Gas Turbine Thermal Barrier Coatings, Coal Syngas, Fly Ash Deposition, Micro-Indentation, Strain Tolerance

How to cite this paper: Luo, K., Nix, A.C., Kang, B.S. and Otunyo, D.A. (2014) Effects of Syngas Particulate Fly Ash Deposition on the Mechanical Properties of Thermal Barrier Coatings on Simulated Film-Cooled Turbine Vane Components. International Journal of Clean Coal and Energy, 3, 54-64. http://dx.doi.org/10.4236/iicce.2014.34006 


\section{Introduction}

Development and analysis of gas turbine coating systems are being driven worldwide in an effort to produce higher efficiency and more durable turbine systems. Thermal barrier coatings (TBCs) are designed to withstand high temperatures and protect the component substrate below the coatings. The top layer of a TBC system typically contains the ceramic top coat comprised of $\mathrm{Y} \mathrm{SZ}$ (Zirconia, $\mathrm{ZrO}_{2}$ partially stabilized by yttria $7-8$ wt\% $\mathrm{Y}_{2} \mathrm{O}_{3}$ ) [1]. The purpose of the layer is to extend the life of the metallic substrate components below the YSZ coatings by insulating them at turbine operating temperatures, and lowering the surface temperature of the metallic substrate. Two common methods for TBC application are air plasma sprayed (APS) and electron-beam physical-vapor deposition (EB-PVD). An EB-PVD coating is typically preferred for its strain tolerance provided by its columnar grain microstructure [2]. A metallic bond coat (BC) is applied to the substrate in order to adhere the top coat to the substrate and to provide an aluminum reservoir for alumina, $\alpha-\mathrm{Al}_{2} \mathrm{O}_{3}$, formation in the thermally grown oxide (TGO). TGO develops between the bond coat and ceramic top coat of the system under thermal operating conditions. The low thermal conductivity $(k)$ of the TBC relative to the substrate allows for the gas turbine system to run at higher gas temperatures than the melting point of the substrate. The gas turbine efriciency will subsequently be higher.

Several TBC durability issues arise from the higher operating temperatures. One particular issue is the effects of molten deposits that adhere on top of the YSZ coatings. Molten deposits in the gas turbines are due to impurities that enter through the inlet air or the upstream combustion of particulate laden alternative fuels such as coalderived synthesis gas (syngas). Sand or volcanic ash ingestion is among the most common impurities found in aero engines. These deposits can degrade the components within the turbine system or inhibit performance of cooling designs.

Calcium-magnesium-alumino-silicate (CMAS) attacks form the most common molten deposits on TBCs. The deposits from CMAS develop as siliceous debris is introduced through the intake air and melt and adhere on top of the TBC once the temperatures exceed $1150^{\circ} \mathrm{C}$. Wellman and Nicholls [3] found that CMAS causes severe damage to the column morphology from dissolution of the YSZ which reduces the TBCs insulating properties and strain tolerance, changes in the YSZ crystal structure from tetragonal to monoclinic from depletion in ytria, and an increase in the erosion rate on EB-PVD TBCs. Levi, Hutchinson, Vidal-Setif, and Johnson [4] found that CMAS deposits infiltrated the intercolumnar gaps of the EB-PVD top coat towards the TGO and de-stabilized the non-transformable, metastable tetragonal $t^{*}$-YSZ top coat along the way. The infiltration can lower the strain tolerance after the CMAS salt cools within the TBC due to the stress mismatch from coefficient of thermal expansion differences.

Volcanic ash can also form molten deposits onto the TBC. An eruption of the Eyjafjallajökull volcano in Iceland in 2010 sent volcanic ash clouds in which a jet aircraft can inadvertently fly through. The ash from Eyjafjallajökull was found to form a glass at roughly $1160^{\circ} \mathrm{C}$. Drexler et al. [5] found that the molten ash infiltrates the pores and cracks of the APS top coat causes similar degradation as the molten CMAS.

The purpose of the current study is to understand the effects of particulate deposition due to coal syngas combustion in a high-pressure, high-temperature environment on the mechanical properties of TBCs of gas turbine components. The National Energy Technology Laboratory (NETL) Aerothermal Test Facility was the site where the modeling of fly ash and simulation of deposition for 10,000 operating hours in a 6-hour test on angled test articles was conducted [6]. The accelerated deposition process takes place at a pressure of approximately $4 \mathrm{~atm}$ and a gas temperature of $1560 \mathrm{~K}$. The processed fly ash had its Stokes number and particulate loading matched between the laboratory and engine conditions.

Understanding of the effects of particulate deposition on the TBCs can improve the gas turbine durability and efficiency. The current study examines the influence of the fly ash deposition on the mechanical properties, specifically the Young's modulus, of the ceramic top coat. Eberl et al. found that a typical EB-PVD YSZ coating has an elastic modulus of $15-30 \mathrm{GPa}[7]$. To determine the Young's modulus values of the areas of TBC with varying amount of deposition, a table top load-based multiple-partial unloading micro-indentation system is used. Studies by Tannenbaum [8] and Otunyo [9] have used the micro-indentation systems at WVU to measure the Young's modulus of the TBC systems. Their studies were able to predict future spallation locations in areas of theYSZ coatings that exhibited increases in surface stifrness. With the use of the micro-indentation system, the modulus of elasticity can be evaluated for unexposed and deposition infiltrated portions of the simulated test articles. 


\section{Test Articles and Experimental Methods}

In the current study, the test articles were designed to simulate the pressure side of a first stage turbine vane with incline angles of $10^{\circ}$ and $20^{\circ}$. The substrate material of the test articles is HAYNES 230 (HA230) alloy due to its excellent high-temperature strength, resistance to oxidizing environments, and lower thermal expansion characteristics compared to most high-temperature alloys. The test article has four round cooling holes, each with a 3.9 $\mathrm{mm}$ diameter placed on the face at an angle $30^{\circ}$ to the surface. Using Reynolds similarity, the cooling holes were scaled to $8 \times$ the size of an actual gas turbine cooling hole. Cooling air is delivered to the face with a hollowed out backside from a connected high pressure air system.

The thermal barrier coatings were applied to each test article using a directed vapor deposition (DVD) process [10]. The DVD process produces coatings similar to those of the EB-PVD but has a more efficient deposition process. It features non line-of-sight deposition and controlled intermixing during multiple source evaporation which allows for novel coating architectures and deposition on complex engine components. Approximately 400 $\mu \mathrm{m}$ of ceramic top coat layer was applied as $7 \%$ Ytrium Stabilized Zirconia (7YSZ). A $Y-\Upsilon^{n}$ platinum aluminide (PtAl) bond coat, developed by Brian Gleeson at the University of Pittsburgh [11], was applied with an approximate thickness of $15-20 \mu \mathrm{m}$. The cooling holes were masked during the coating process, which created a shallow trench, a configuration used in modern gas turbine components [12]. Figure 1 contains images of two angled test articles after TBC application [6].

To simulate the syngas contaminants, fly ash was processed by drying, grinding, and filtering and injected in to the high-pressure combustion facility. After filtration, the mean particle size of the processed fly ash was measured by a LS Particle Size Analyzer to be approximately $13 \mu \mathrm{m}$. Table 1 displays the composition of the bituminous fly ash in the current study [6]. To scale the particle inertial characteristics and set the desired mean particle diameter, the Stokes number was matched between engine conditions and laboratory [13]. The Stokes numbers were calculated for fly ash particles that range from $0.5 \mu \mathrm{m}$ to $47 \mu \mathrm{m}$ for the engine and laboratory conditions based on mainstream temperature, fly ash density, hole diameter, mainstream viscosity, mainstream velocity, and particle size [6]. Lastly, fly ash particulate was injected into the high pressure combustion rig using a PS-20 Scitek pressurized particle seeder. Particulate loading (ppmw-hr) was matched for loadings that exist in actual gas turbine engines that operate over a period of 10,000 hours. The particulate concentration (ppmw) was increased to reduce the required hours in the laboratory. The particulate loading comparison is shown in Table 2 $[6]$.

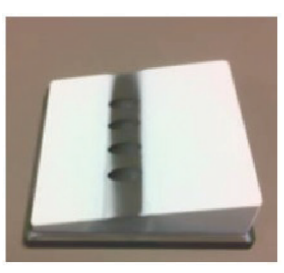

(a)

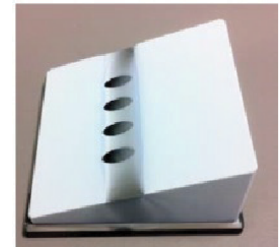

(b)

Figure 1. Photographs of the (a) $10^{\circ}$ and (b) $20^{\circ}$ test articles with TBC before deposition testing.

Table 1. Bituminous coal ash composition [6].
\begin{tabular}{ccccccc}
\hline Oxides & $\mathrm{SiO}_{2}$ & $\mathrm{CaO}$ & $\mathrm{Fe}_{2} \mathrm{O}_{3}$ & $\mathrm{Al}_{2} \mathrm{O}_{3}$ & $\mathrm{SO}_{3}$ & $\mathrm{~K}_{2} \mathrm{O}$ \\
\hline $\mathrm{H} 4 \%$ & 53.8 & 4.39 & 8.87 & 25.35 & 1.15 & 2.23
\end{tabular}

\begin{tabular}{ccc} 
Table 2. Particulate loading comparison [6]. & \\
\hline & Engine & Laboratory \\
\hline Particulate Concentration (ppmw) & 0.02 & 33.3 \\
Operation Duration (tr) & 10000 & 6 \\
Particulate Loading (ppmw-hr) & $\mathbf{2 0 0}$ & $\mathbf{2 0 0}$ \\
\hline
\end{tabular}


The study by Murphy, Nix, Lawson, Straub, and Beer [6] found that deposition formed on only one side of the test articles. The one sided deposit formation was due to a large deposit structure forming on the transition piece of the test section. Figure 2 shows the transition piece with a deposit structure on the left side of the piece [14] [15]. The structure on the test section transition piece created a swirl effect leading to an uneven distribution of fly ash into the test section. This limited the areas of heavy deposition and created a "stratified" amount of deposition on the test articles. The swirl effect would be unrealistic in an actual gas turbine first stage vane flow.

The test articles used in this study are labeled and shown in Figure 3 . Heavy deposition can be observed on the left side of the face on test article 1 (see Figure 3(a)). The roughness results were computed for the deposition on test article 1 using an Olympus LEXT OLS 3100 laser confocal microscope [14]. A detalled view of the roughness characteristics is shown in Figure 4(a) [14]. The blue line represents the mean average roughness of the article when unexposed to testing. The measurements to the peaks and valleys are represented by $y_{\text {, }}$ which is used to calculate the centerline averaged roughness $\left(\mathrm{SR}_{\mathrm{a}}\right)$ and the root-mean-square (RMS) roughness $\left(\mathrm{SR}_{\mathrm{f}}\right)$. $\mathrm{SR}_{\mathrm{p}}$ and $\mathrm{SR}_{\mathrm{y}}$ are defined as highest peak and lowest valley measure by $\mathrm{y}_{\mathrm{y}}$ respectively. Adding $\mathrm{SR}_{\mathrm{p}}$ and $\mathrm{SR}_{\mathrm{w}}$ gives the maximum peak-to-valley distance value, $S R_{z}$. Figure $4(b)$ contains the image of where the surface roughness scan of the deposition was taken on test article 1 . The roughness values for test article 1 prior to sectioning are given in Table 3 [14].

In order to perform micro-indentation and SEM analysis, the test articles required prepping which included sectioning and trimming of the angle. The location of angle trimming can be seen in Figure 3(a). Flat samples were required to produce accurate results from the micro-indentation procedure. The samples have a substrate thickness of $1 / 4$ inches after the angle cut. Once the angle was removed, a grid for further sectioning was created to produce the test samples from flat test articles. Figure 5 details the sample labels for each test sample. The

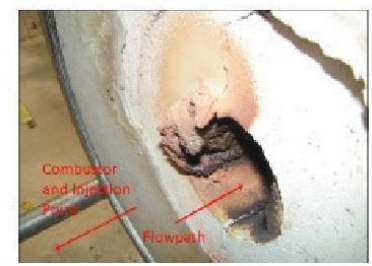

Figure 2. Image of large deposit formation on the left size of the transition piece [12].

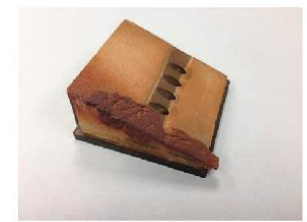

(a)

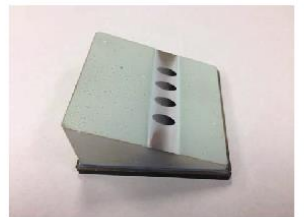

(b)

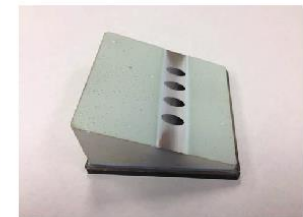

(c)

Figure 3. Labels of (a) Test Article $1^{\circ}-20^{\circ}$ with deposition; (b) unexposed Test Article $2^{\circ}-20^{\circ}$; and (c) Test Article $3^{\circ}-$ $10^{\circ}$ with deposition. (a) Test Article 1; (b) Test Article 2; (c) Test Article 3.

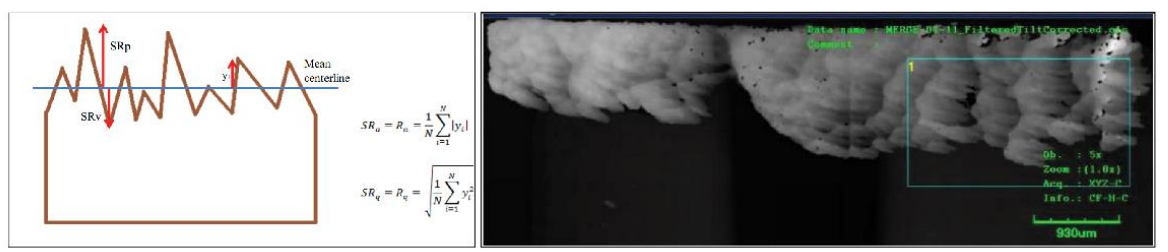

(a)

(b)

Figure 4. (a) Schematic of roughness values and (b) selected area for the roughness scan [12]. 


Table 3. Roughness characteristics for test article 1 [12].
\begin{tabular}{ccc}
\hline Parameter & Deseription of Roughness Parameters & Height $(\boldsymbol{\mu m})$ \\
\hline $\mathrm{SR}_{\mathrm{p}}$ & Maximum Peak Height & 399 \\
$\mathrm{SR}_{z}$ & Maximum Valley Depth & 367 \\
$\mathrm{SR}_{z}$ & Maximum Distance & 766 \\
$\mathrm{SR}_{2}$ & Roughness Average & 79 \\
$\mathrm{SR}_{\mathrm{q}}$ & Root Mean Square Average & 100 \\
\hline
\end{tabular}

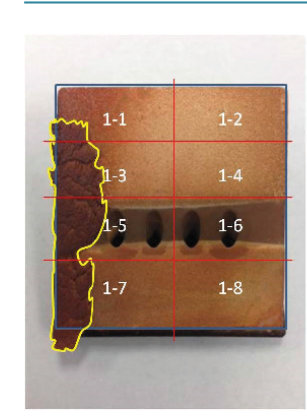

(a)

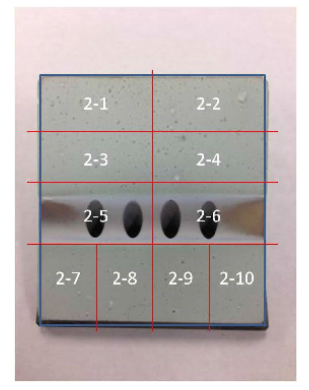

(b)

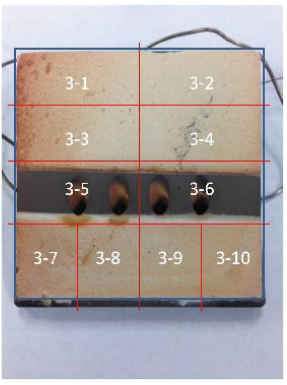

(c)

Figure 5. Cut list for (a) Test Article 1; (b) Test Article 2; and (c) Test Article 3.

heavy deposition on test article 1 in Figure 3 (a) is outlined in Figure 5(a). Most of the deposition falls off during the sectioning, leaving only strongly adhered deposition that has reacted with the YSZ coating. After completion of the sectioning, samples devoid of defects (delamination, cracking, etc.) were used for micro-indentation tests on selected areas of varying deposition quantity.

For the micro-indentation test, a table top system was used for the multiple partial unloading procedure to determine the elastic modulus of the desired areas of the TBC samples at room temperature. The table top indentation system is comprised of a spherical tungsten carbide (WC) indenter having a radius of $793.5 \mu \mathrm{m}$, combined with a piezoelectric actuator (3.6 nm Resolution, Physik Instrumente, P-239.9S, $180 \mu \mathrm{m}$ ) and a high accuracy $( \pm 0.15 \%$ Accuracy, Honeywell, Model 31, $100 \mathrm{lb}$.) load cell [9]. The shallow indentation depth (50 $\mu \mathrm{m}$ into the YSZ coating in the current study) allowed the test to be considered a non-destructive evaluation (NDE). The system is illustrated below in Figure 6 [9].

In order to perform a normalized elastic modulus analysis, the Young's modulus was determined for the unexposed Test Article 2 ( $E_{\text {unexposed }}$ ) using sections of Samples 2-3 and 2-4. Neither sample had been subjected to deposition testing. The samples were secured in a holder and underwent the multiple partial loading and unloading procedure. Indenter loading and unloading was performed throughout each of the top surfaces of the samples" top coat. An uncertainty analysis was performed on the strain tolerance results in order to show the effect of measurement uncertainties on the accuracy of the elastic moduli results. A root-sum-square (RSS) combination was used to incorporate the uncertainties from the multiple-sample data and pertubated measurement/ system errors associated with the table top system [16].

Scanning electron microscopy (SEM) was used to provide high resolution images of cross sections of the samples and the top surface of the YSZ coating, and energy dispersive X-ray spectroscopy (EDS) was completed to determine of the elemental composition of regions of interest (Hitachi S-4700 or JEOL JSM-7600F).

\section{Results and Discussion}

Prior to any micro-indentation, confirmation that the molten deposit on top of the TBC ceramic top coat agreed with the elemental composition of fly ash injected into the combustion facility (Table 2) was examined. Figure 7 shows a SEM micrograph of a cross-section of Sample 3-1 near the columnar tips of the YSZ coating. An $\mathrm{X}$-ray spectrum was acquired at a single point within the deposition layer (circled in Figure 7). 


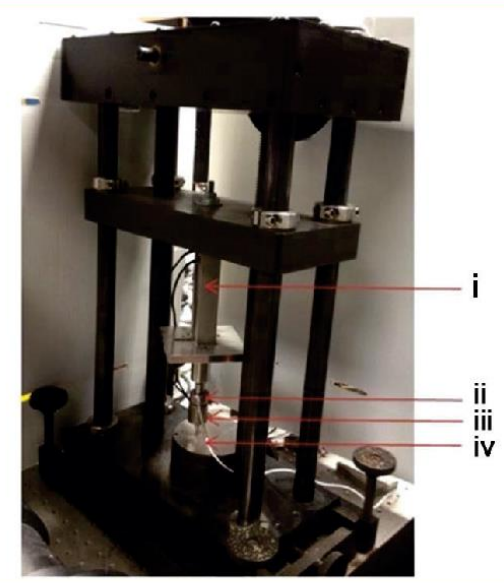

Figure 6. Table top micro-indentation setup: (i) $3.6 \mathrm{~nm}$ Resolution, Physik Instrumente, P-239.9S, $180 \mu \mathrm{m}$ piezoelectric actuator; (ii) $\pm 0.15 \%$ Accuracy, Honeywell, Model $31,100 \mathrm{lb}$. load cell; (iii) spherical tungsten carbide (WC) $793.5 \mu \mathrm{m}$ radius indenter; and (iv) sample stage [8].

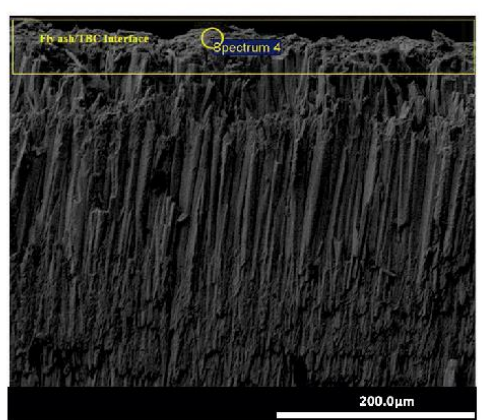

Figure 7. Point \& ID location on Sample 3-1 for acquisition of spectrum results in Table 4.

Table 4 has the comparison between original processed fly ash and the results obtained from the spectrum analysis by weight percentage. Silicon, aluminum, and oxygen were chosen as elements of interest since they have the highest weight percentage in Table 1. Based on the elemental distribution content, Table 4 confirmed that the adhering deposits were molten and cooled processed fly ash.

Figure 8 (a) shows the top view of as-deposited YSZ coating that has been unexposed to any combustion facility testing. The columnar structure with inter-columnar gaps improved the lateral strain compliance of the coatings. The top view of the YSZ top coat with molten fly ash are shown in Figure 8(b). Once molten and cooled, the deposits formed a thin, hardened, and almost glass-like ash layer on top of the columns of the YSZ coating. This subsequently reduced to the stain tolerance of the YSZ coating.

As the molten deposits infiltrated top coat, the YSZ coating became more susceptible to delamination. Upon sectioning, a portion of Sample 1-7 developed a diagonal crack along the top surface of top coat which later led to delamination (see Figure 9(a)). Figures 9(b)-(c) show that Sample 1-3 lost roughly $100 \mu \mathrm{m}$ of YSZ coating near the edge where deposition was abundant. Spallation of the TBC layers is considered the final failure of the insulating system. 
Table 4. Comparison between processed fly ash and molten deposits by weight percentage.

\begin{tabular}{cccc}
\hline Constituent/wt\% & Si & Al & O \\
\hline Original Fly Ash & 28.09 & 14.98 & 51.74 \\
Molten Deposit & 19.51 & 13.61 & 53.40 \\
\hline
\end{tabular}

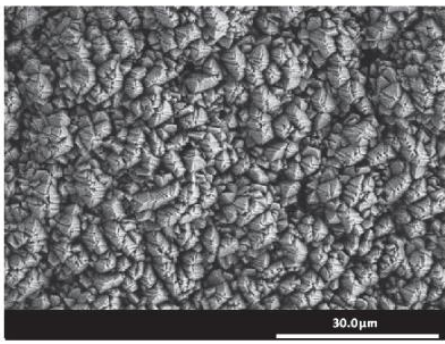

(a)

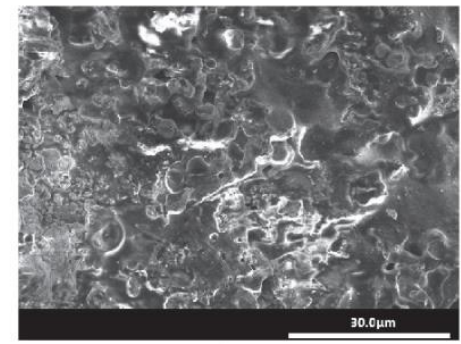

(b)

Figure 8. Top view of (a) unexposed Samples 2-1 and (b) molten deposition on Sample 1-5.

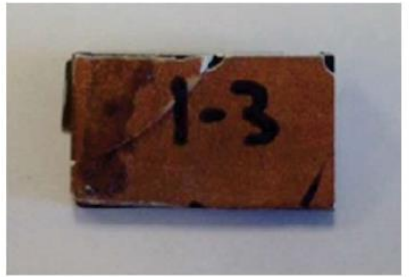

(a)

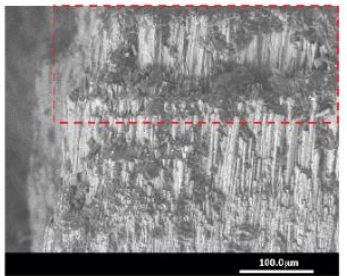

(b)

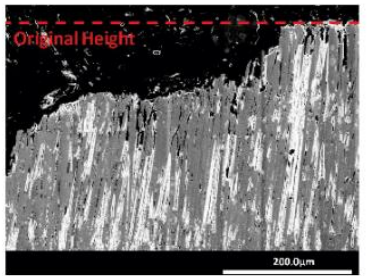

(c)

Figure 9. (a) Top view of Sample 1-7 and cross-section micrographs of delamination in Sample 1-3 top coating (b) after sectioning and (c) after mounting and polishing. (a) Sample 1-7: Top coat cracking; (b) Post-sectioning/Pre-polishing; (c) Mounted in a conductive mounting media.

Figure 10 below contains an image of the two unexposed samples, 2-3 and 2-4, and their averaged elastic modulus are recorded below in test sample images. The error bars in on the results denoted the uncertainty for each sample. An average of all the individual tests on both samples was used to obtain a value for the baseline elastic modulus ( $E_{\text {zuexposed }}$ ) of $20.93 \mathrm{GPa}$. The uncertainty was measured as a combination of the number of indentations on each sample and the tolerance of the table top system.

Once the value of $E_{\text {unexposed }}$ was obtained, multiple partial unloading was performed on Samples 1-1, 1-2, 1-3, 1-4, 3-1, and 3-2. Figure 11(a) contains the images and results for Samples 1-1 and 1-2. The colored dashed boxes in the images of the samples correspond with the averaged elastic modulus value in the lower chart of Figure 11(a). The portion of Sample 1-1 bordered with the blue dashed box contained an area where molten deposits had adhered onto the TBC prior to the sectioning. The infiltrated area exhibited a higher modulus of elasticity than those of the unexposed articles or areas along the same sample or same plane without any significant deposition adherence. The same increase in Young's modulus can be observed for Samples 1-3 and 1-4 (Figure 11(b)) and Samples 3-1 and 3-2 (Figure 11(c)). The elastic modulus for Sample 3-1 was recorded for the area with deposition only due to sample compliance issues.

In order to develop a trend for the molten deposits effects on the $\mathrm{TBC}$, the modulus of elasticity with respect to the length across the TBC top face was plotted. The width of the top face, which is used for a length scale, of all the TBC coated articles is roughly 2 inches (see Figure 12).

Individual indenter results for all samples were plotted in Figure 13. The graph contains the normalized distance $(x / W)$ versus normalized Young's modulus values $\left(E_{i} / E_{\text {nnexposed }}\right)$. A power series trendline was included for 


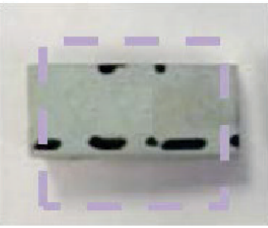

Samples 2-3

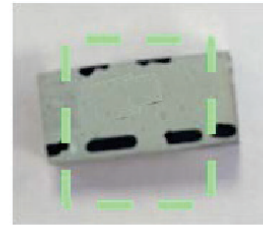

Sample $2-4$

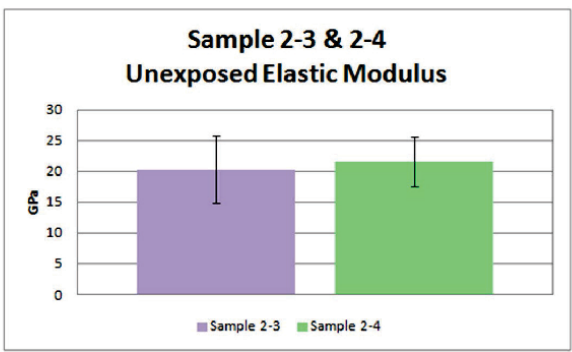

Figure 10. Images of unexposed Samples 2-3 and 2-4 and their average values for TBC modulus of elasticity.

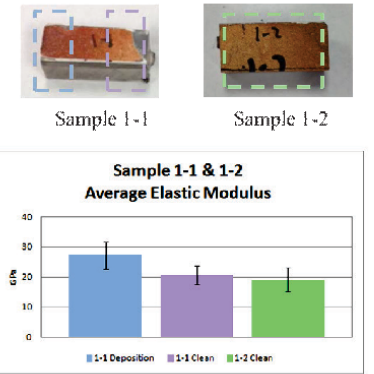

(a)

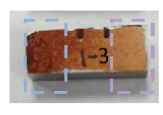

Sample $1-3$

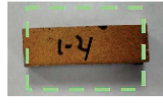

Sample 1.4

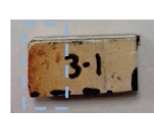

Sample 3.1

Sample $3 \times 2$

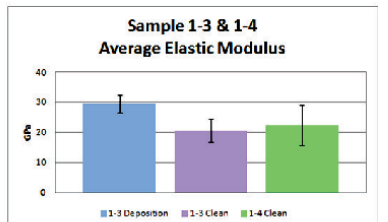

(b)

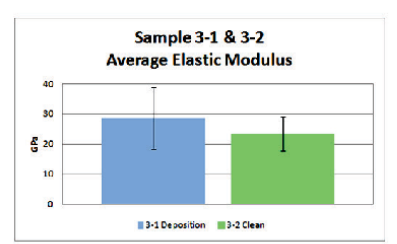

(c)

Figure 11. Image of samples and their values for averaged TBC modulus of elasticity for (a) Samples $1-1$ and $1-2$; (b) Samples 1-3 and 1-4; and (c) Samples 3-1 and 3-2.

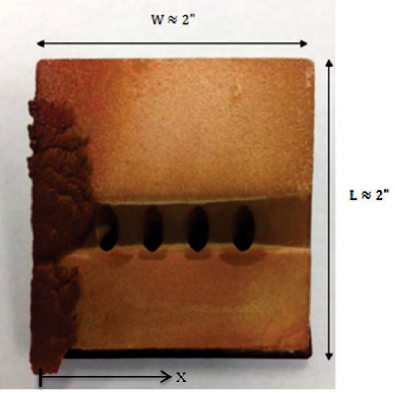

Figure 12. Dimensions of the test article faces. 
All Samples

Normalized Elastic Modulus

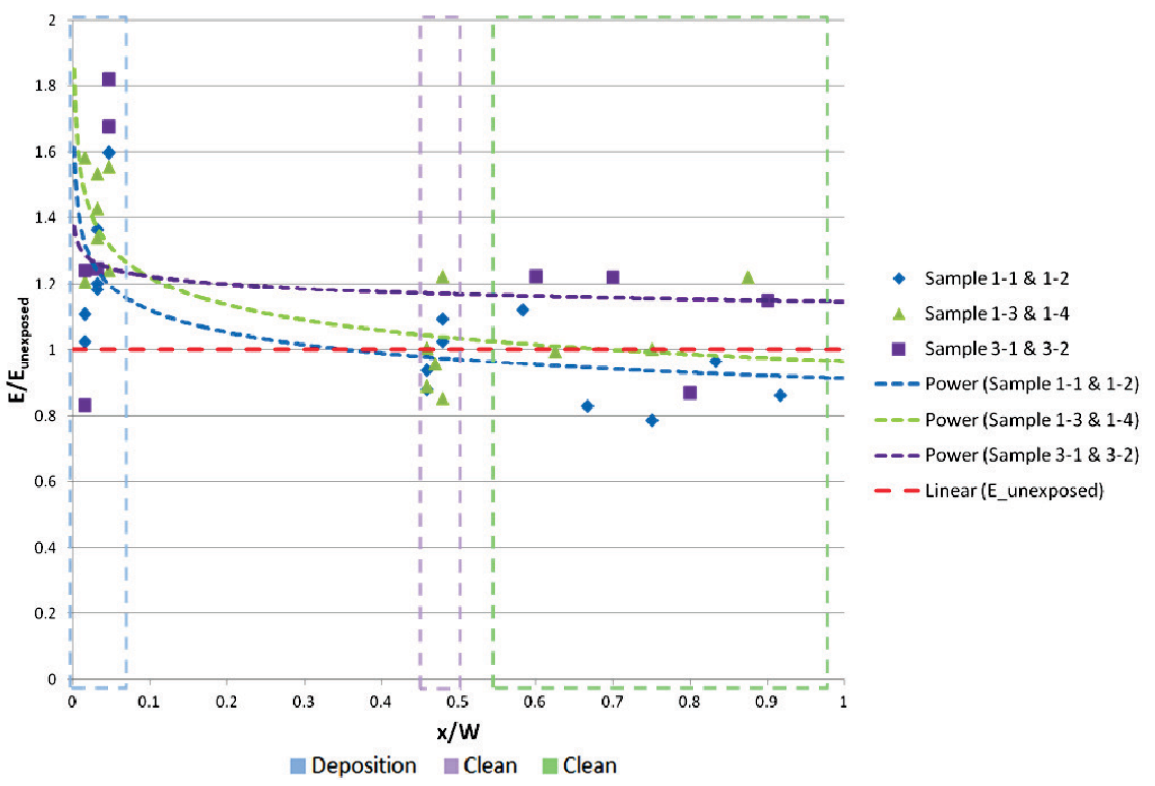

Figure 13. Normalized elastic modulus trends for all samples.

each sample set to show the relationship between the surface stiffness from near the $\mathrm{x} / \mathrm{W} \approx 0$ edge to the right side of the test article face. The error was not plotted in Figure $13 \mathrm{in}$ an attempt to not clutter the plot and was already shown in Figure 11. The trend for Samples 1-1 \& 1-2 and Samples 1-3 \& 1-4 show that there was a reduction in the strain tolerance of the YSZ coating in an area of depositi on infiltration, and that the modulus of elasticity approaches the baseline Young's modulus of the unexposed test articles as $\mathrm{x}$ approaches 2 inches where there was significantly less deposition. The two aforementioned power series lines share a similar trend since the samples were from the same test articles. The difference in modulus of elasticity was less between for Samples 3-1 and 3-2, which was most likely due to less molten fly ash contaminants.

\section{Conclusions}

This purpose of the current study was to analyze the effects on the mechanical properties of TBC coating systems from syngas particulate molten deposits after Murphy, Nix, Lawson, Straub, and Beer completed work on the effects of the particulate deposition on gas turbine vane film cooling [6]. The molten deposits from the fly ash were found to adhere onto the YSZ top coatings and penetrate the YSZ coating to a maximum distance of 20 $\mu \mathrm{m}$. With the use of a micro-indentation technique, the modulus of elasticity was recorded for unexposed TBC, lightly exposed TBC, and deposition-infiltrated TBC.

The molten deposits lead to an increase in the Young's modulus and thus, degradation of the strain tolerance of the DVD YSZ coating. Once the deposits were cooled on the top coat, the YSZ layer had a higher tendency to delaminate. A micro-indentation method was used to quantify the elastic modulus of the layer, and it was found that areas with molten deposit infiltration experienced an increase in the surface stiffness. This increase corresponds with a reduction in the strain tolerance of the top coat. The stress mismatch between exposed and unexposed TBC from the interaction between the fly ash deposition and YSZ coating will result in spallation of the ceramic top coat. 


\section{Acknowledgements}

The authors would like to acknowledge the support of the Department of Energy, Office of Science, Experimental Program to Stimulate Competitive Research (EPSCoR) under grant/contract number DE-FG02-09ER46615 , monitored by Dr. Tim Fitzsimmons. In addition, the project was partially funded by the US Department of Energy, National Energy Technology Laboratory through a cooperative agreement with EPSCoR. There are several people that deserve acknowledgments for their contributions to this project. The authors would like to thank Dr. Keith Kruger of Haynes, International for donating the Haynes 230 test article material. Dr. Derek Hass and Balvinder Gogia of Directed Vapor Technologies International, Inc. (DVTI) cost shared the thermal barrier coatings and bond coat applied to the test articles. Westmoreland Mechanical Testing \& Research, Inc. sectioned the angled test articles into the test samples. Mounting and polishing of the samples were completed by Metallurgical Technologies, Inc. Gratitude also goes out to the Shared Research Facilities and the Chemical Engineering Department at West Virginia University for the cleanroom access and training for the use of the SEM and other microscopy preparation techniques.

\section{References}

[1] Padture, N.P., Gell, M. and Jordan, Ex. (2002) Themal Barrier Coatings for Gas-Turbine Engine Applications, Science AAAS, 296, 280-284. http:/dx,doi,org/10,1126/science, 1068609

[2] Schulz, U., Leyans, C., Fritscher, K., Peters, Ms, Saruhan-Brings, M., Lavigne, O., Dorvaux, J.-M., Poulain, M., Mévrel, R. and Caliez, M. (2003) Some Recent Trends in Research and Technology of Advanced Thermal Barrier Coatings.

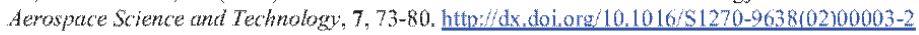

[3] Wellman, R.G. and Nicholls, J.R. (2000) Some Observation on Erosion Mechanisms of EB PVD TBCs. Wear, 242, 89-96. http/dx.doi.org $10.1016 / 50043-1648(00) 00391-4$

[4] Levi, C.G., Hutchinson, J.W., Vidal-Sétif, M.-H. and Johnson, C.A. (2012) Environmental Degradation of Thermal-

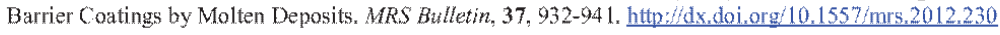

[5] Drexler, J.M., Gledhill, A.D., Shinoda, K., Vasiliev, A.L., Reddy, K.M., Sampath, S. and Padture, N.P. (2011) Jet Engine Coatings for Resisting Volcanic Ash. Artwancel Materials, 23, 2419-2424. http:/dx.doi,org/10,1002/adma,201004783

[6] Murphy, $\mathrm{R}_{x} \mathrm{G}_{3}, \mathrm{Nix}, \mathrm{A}_{x} \mathrm{C}_{\mathrm{x}}$, Lawson, $\mathrm{S}_{x} \mathrm{~A}_{x}$, Straub, D, and Beer, $\mathrm{S}_{\mathrm{x}} \mathrm{K}_{x}$ (2012) Preliminary Experimental Investigation of the Effects of Particulate Deposition on IGCC Turbine Film-Cooling in a High-Pressure Combustion Facility. ASME Turbo Expo 2012, Turbine Technical Conference ant Exposition, 4, 979-986. http:/dx.doi.org/10.1115/GT2012-68806

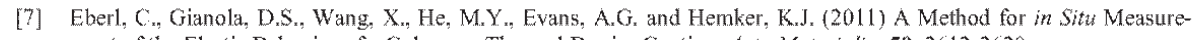
ment of the Elastic Behavior of a Columnar Thermal Barrier Coating. Acta Materialia, 59, 3612-3620. httr:/dx.doi,org $10,1016 /$ actamat,2011,02,034

[8] Tannenbaum, J.M. (2011) Progression in Non-Destructive Spallation Prediction and Elevated Temperature Mechanical Property Evaluation of Thermal Barrier Coating Systems by Use of a Spherical Micro-Indentation Method. Ph.D. Dissertation, West Virginia University, Morgantown.

[9] Otunyo, D.A. (2012) Mechanical Property Evaluation of Thermal Barrier Coating Systems at Elevated Temperatures by Use of Spherical Micro-Indentation Method. M.S. Thesis, West Virginia University, Morgantown.

[10] Hass, D. (2012) Thermal Barrier Coating Environmental Durability Enhancement (CMAS). NAVAIR, N06-032.

[11] Gleeson, B., Wang, W., Hayashi, S. and Sordelet, D.J. (2004) Effects of Platinum on the Interdiffusion and Oxidation Behavior of Ni-Al-Based Alloys, Material Science Fortim, 461, 213-222. http:/dx,doi,org $10,4028 /$ ww. scientific, net/MSF, $461-464,213$

[12] Dorrington, $J_{*} R_{x}$, Bogard, $D_{x} G_{x}$ and Bunker, $R_{x} S_{*}$ (2007) Film Effectiveness Performance for Coolant Holes Imbedded in Various Shallow Trench and Crater Depressions. ASME Turbo Expo 2007, Power for Land, Sea, and Air, 4, 749-758. http:/dx.doi.org $10 \times 1115 /$ GT2007-27992

[13] Lawson, S.A. and Thole, K.A. (2011) Effects of Simulated Particle Deposition on Film Cooling. Journal of Turbomachinery, 133, 021009-1-021009-10. http/dx,doi,org/10.1115/1.4000571

[14] Murphy, R.G. (2012) Experimental Investigation of Particulate Deposition on a Simulated Film-Cooled Turbine Vane Pressure Surface in a High Pressure Combustion Facility. M.S. Thesis, West Virginia University, Morgantown.

[15] Murphy, R.G., Nix, A.C., Lawson, S.A., Straub, D. and Beer, S.K. (2013) Investigation of Factors that Contribute to Deposition Formation on Turbine Components in a High-Pressure Combustion Facility . ASME Turbo Expo 2013; Tur 
bine Techical Conference and Exposition, 3B, V03BT13A027-V03BT13A027.

[16] Moffat, R.J. (1998) Describing the Uncertainties in Experimental Results. Experimental Thermal and Fluid Science, 1 ,

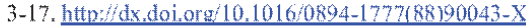

\section{Nomenclature}

E: Young's modulus

k: Thermal conductivity

SR: Surface roughness

W: Width of the test article face

$\mathrm{x}$ : Distance along the test article face

$y$ : Distance from the mean centerline for surface roughness measurement

Subscripts

a: Averaged surface roughness

p: Peak of surface roughness

q: Root-mean-square surface roughness

unexposed: Unexposed test article index

$v$ : Valley of surface roughness

$z$ : Distance from peak to valley 


\title{
Microstructural Degradation of Thermal Barrier Coatings on an Integrated Gasifica- tion Combined Cycle (IGCC) Simulated Film-Cooled Turbine Vane Pressure Surface due to Particulate Fly Ash Deposition
}

\author{
Kevin Luo, Andrew C. Nix
}

Center for Alternative Fuels, Engines and Emissions, Department of Mechanical and Aerospace Engineering, Morgantown, WV, USA

Email: kluo1@mix.wvu.edu, andrew.nix@mix.wvu.edu

Edward M. Sabolsky

Department of Mechanical and Aerospace Engineering, Morgantown, WV, USA

Received *****2014

Copyright (C 2014 by author(s) and Scientific Research Publishing Inc.

This work is licensed under the Creative Commons Attribution International License (CC BY).

http://creativecommons.org/licenses/by/4.0/

\section{(c) (1) Open Access}

\begin{abstract}
Research is being conducted to study the degradation of thermal barrier coatings (TBC) employed on IGCC turbine hot section airfoils due to particulate deposition from contaminants in coal synthesis gas (syngas). West Virginia University (WVU) had been working with U.S. Department of Energy, National Energy Technology Laboratory (NETL) to simulate deposition on the pressure side of an IGCC turbine first stage vane. To simulate the contaminant deposition, several TBC coated, angled film-cooled test articles were subjected to accelerated coal fly ash, which was injected into the flow of a combustor facility with a high pressure (approximately $4 \mathrm{~atm}$ ) and a high temperature (1560K) environment.
\end{abstract}

To investigate the degradation of the TBCs due to particulate deposition, non-destructive tests were performed using scanning electron microscopy (SEM) evaluation and energy dispersive $\mathrm{X}$-ray spectroscopy (EDS) examinations. The SEM evaluation was used to display the microstructure change within the layers of the TBC system directly related to the fly ash deposition. The SEM micrographs showed that deposition-TBC interaction made the YSZ coating more susceptible to delamination and promoted a dissolution-reprecipitation mechanism that

How to cite this paper: Luo, K., Nix, A.C., Sabolsky, E.M. (2014) Microstructural Degradation of Thermal Barrier Coatings on an Integrated Gasification Combined Cycle (IGCC) Simulated Film-Cooled Turbine Vane Pressure Surface due to Particulate Fly Ash Deposition. International Journal of Clean Coal and Energy, *, **_**. http://dx.doi.org/10.4236/ijcce.2014.***** 
changes the YSZ morphology and composition. The EDS examination provided elemental maps of the shallow infiltration depth of the fly ash and chemical composition spectrum results which showed yttria migration from the YSZ into the deposition.

\author{
Keywords
}

Thermal Barrier Coatings; Coal Syngas; IGCC Gas Turbine; Fly Ash Deposition; Microstructure

\title{
1. Introduction
}

In an effort to improve the efficiency and durability of gas turbines, research and development of TBC coating systems are being conducted worldwide. Thermal barrier coatings (TBCs) are applied onto gas turbine components and are designed to withstand high operating temperatures. The main function of the TBC is to extend the life of the gas turbine components while allowing for higher operating temperatures. The top layer of a TBC system typically contains the ceramic top coat comprised of partially stabilized zirconia, $\mathrm{ZrO}_{2}$, with yttria (7 8 $\mathrm{wt} \% \mathrm{Y}_{2} \mathrm{O}_{3}$ ). The composition is typically termed as $\mathrm{YSZ}$ [1]. The two typical TBC application methods are air plasma sprayed (APS) and electron-beam physical-vapor deposition (EB-PVD). Although an APS coating has a lower thermal conductivity $(k)$ value, an EB-PVD coating is typically preferred for its strain tolerance [2]. The 7 YSZ phase constitution is the non-transformable, metastable tetragonal $\left(t^{\prime}\right)$ phase, which provides stability at the high operating temperatures. For the as-deposited TBC coatings, a metallic bond coat (BC) is applied to the super alloy substrate prior to the application of the ceramic top coat. This BC coat is responsible for the adhesion between the top coat and the substrate and for providing an aluminum reservoir for the formation of alumina, $\alpha-\mathrm{Al}_{2} \mathrm{O}_{3}$, in the thermally grown oxide (TGO). TGO grows between the bond coat and the ceramic top coat during thermal operation. Due to the TBC's low thermal $k$ relative the substrate, it provides thermal insulation for the gas turbine components, allowing the turbine to operate at much higher gas temperatures than the melting point of the substrate material. This consequentially increases the gas turbine efficiency.

The increase in the turbine operating temperatures has resulted in several issues for the TBC. One issue is the degradation of TBCs from contaminants that become molten. The molten deposits can degrade the components in the turbines or inhibit external cooling designs. The deposits in the gas turbines are due to impurities that enter through the inlet air or the upstream combustion of particulate laden alternative duels such as coal-derived synthesis gas (syngas)

One common form of molten deposit that can degrade TBC systems is known as calcium-magnesium-alumino-silicate (CMAS). The deposits from CMAS are from siliceous debris (sand) that enter through the air intake. Once the temperatures exceed $1150^{\circ} \mathrm{C}$, the ingested particles and debris melt and adhere onto the surface of the ceramic top coat. Levi, Hutchinson, Vidal-Sétif, and Johnson [3] found that CMAS deposits de-stabilized the non-transformable, metastable tetragonal t'-YSZ top coat of an electron beam-physical vapor deposition (EB-PVD) TBC and infiltrated the intercolumnar gaps of the top coat towards the TGO. As the CMAS infiltrates and cools, the stress mismatch between the glassy deposits and the YSZ can lead to spallation of the TBC. In a separate CMAS study, Wellman and Nicholls [4] found that CMAS can cause severe damage to the EB-PVD YSZ column morphology from dissolution, change the YSZ crystal structure from tetragonal to monoclinic from depletion in yttria, and erode the TBC system. The morphology change can cause a reduction in the insulating properties and strain tolerance of the TBC.

Another form of deposit which can degrade TBCs is derived from the intake of volcanic ash. Drexler et al. [5] found that volcanic ash ingested by jet engines was found to damage conventional APS YSZ thermal barrier coatings. The eruption of Eyjafjallajökull volcano in Iceland in 2010 created volcanic ash clouds in which a jet aircraft inadvertently can fly through. The ash from Eyjafjallajökull was found to form a glass at roughly $1160^{\circ} \mathrm{C}$. The nature of the damage was similar to degradation caused by molten CMAS, where the molten ash was able to infiltrate the pores and cracks of the top coat causing enhanced microstructural change and final spallation.

The purpose of the current study is to understand the effects of particulate deposition due to coal syngas combustion in a high-pressure, high-temperature environment on the microstructure of thermal barrier coatings on film-cooled gas turbine components. To model the fly ash particulate, deposition experiments were conduct- 
ed in the National Energy Technology Laboratory (NETL) Aerothermal Test Facility to simulate 10,000 operating hours of syngas contaminant intake on first stage vane components. This was performed using a 6-hour test on angled test articles [6]. The accelerated deposition process takes place at a pressure of approximately 4 atm and a gas temperature of $1560 \mathrm{~K}$. Processed fly ash was injected into the test section using a high pressure particulate seeding system in which the Stokes number and particulate loading is matched between the laboratory and engine conditions.

Improving the gas turbine durability and efficiency requires an understanding of the effects of particulate deposition on the thermal barrier coatings. The current study examines the influence of the fly ash deposition on the microstructure of the TBC layers using scanning electron microscopy (SEM) and energy dispersive X-ray spectroscopy (EDS).

\section{Test Articles and Experimental Methods}

In the current study, the test articles were designed to simulate the pressure side of a first stage turbine vane at incline angles of $10^{\circ}$ and $20^{\circ}$. The design of the test articles are described in the work by Murphy, Nix, Lawson, Straub, and Beer [6]. Each test article is fabricated out of HAYNES 230 (HA230) alloy and has four 3.9mm diameter cooling holes placed on the face at a $30^{\circ}$ to the surface. The cooling holes are scaled to $8 \mathrm{X}$ the size of an actual turbine vane cooling hole using Reynolds similarity. The cooling holes are connected to a high pressure air system which delivers cold air to the face of the test articles.

Each test article has a TBC applied using a directed vapor deposition (DVD) process [7]. A 7\% Yttrium Stabilized Zirconia (7YSZ) coating with an approximate thickness of $400 \mu \mathrm{m}$ is applied as the ceramic top coat of the TBC. The bond coat of the TBC system was $\Upsilon-\Upsilon^{\prime}$ platinum aluminide (PtAl) with an approximate thickness of $15-20 \mu \mathrm{m}$. The $\Upsilon-\Upsilon^{\prime}$ PtAl bond coat closely matches the phase properties of the nickel-based superalloy and was developed by Brian Gleeson at the University of Pittsburgh [8]. A shallow trench, a configuration commonly used in modern gas turbine components, is created by masking the cooling holes during the coating process [9]. Figure 1 displays the two angled test articles after the TBC was applied [6].

The fly ash processing is described in a study by Murphy, Nix, Lawson, Straub, and Beer [6]. The processed fly ash has a mean particle size of $13 \mu \mathrm{m}$ and the composition of the bituminous fly ash is given in Table 1 [6]. Unlike previous molten deposit and TBC studies where the molten deposit was formed by applying a paste onto the TBC and heat treated, the ash particulate was injected into a high pressure and high temperature facility and impacted onto the TBC coated test articles. Bons, Ameri, and Fletcher found that bituminous fly ash that is injected in a similar fashion experiences a volumetric decrease when it becomes molten and from sintering [10]. Lawson and Thole [11] used a Stokes number analysis between the laboratory and engine conditions given by Dennis, Shelton, and Le [12] to scale the particle inertial characteristics and set the desired mean particle diameter. Lastly, the particulate loading is matched at 200 ppmw-hr to simulate 10,000 hours of particulate deposition into an engine in a 6-hour laboratory experiment [6].

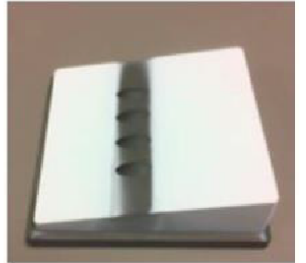

(a)

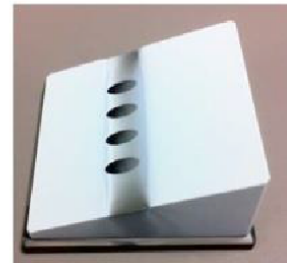

(b)

Figure 1. Photographs of the (a) $10^{\circ}$ and (b) $20^{\circ}$ test articles with TBC before the deposition testing [7]

\begin{tabular}{l}
\multicolumn{7}{l}{ Table 1. Bituminous Coal Ash Composition [7] } \\
\begin{tabular}{ccccccc}
\hline Oxides: & $\mathrm{SiO}_{2}$ & $\mathrm{CaO}$ & $\mathrm{Fe}_{2} \mathrm{O}_{3}$ & $\mathrm{Al}_{2} \mathrm{O}_{3}$ & $\mathrm{SO}_{3}$ & $\mathrm{~K}_{2} \mathrm{O}$ \\
\hline w. \% & 53.8 & 4.39 & 8.87 & 25.35 & 1.15 & 2.23 \\
\hline
\end{tabular}
\end{tabular}


The results from the study found that deposition formed on only one side of the test articles. Deposit formation on only one side of the test articles was due to a large deposit structure forming on the transition piece of the test section upstream of the test articles [13, 14]. The deposit structure on the test section transition piece created a swirl effect. This promoted an uneven distribution of fly ash into the test section and would be unrealistic in a first stage vane flow of an actual gas turbine.

The test articles used in this study are labeled and shown in Figure 2 [15]. The test article most heavily infiltrated was the 20-degree angled test article 1 (see Figure 2a). Figure 2b-c contains images of the unexposed 20 -degree angled test article 2 and the exposed 10-degree angled test article 3 respectively. To determine the effect of the fly ash deposition on the cross-sectional microstructure of the TBC, the test articles were sectioned into materials testing samples. The sectioning job produced flat test samples with an approximate thickness of $1 / 4$ inches. Figure 3 details the sample labels for each test article [15]. The heavy deposition on test article 1 is outlined in Figure 3a.

Prior to any SEM and EDS work, the samples undergo a micro-indentation procedure on the ceramic top coat to evaluate the effects on the mechanical properties from the fly ash deposition. The study found that the modulus of elasticity increases in areas where the molten deposition had cooled and adhered onto the top coating [15]. The increase in the surface stiffness can be directly related to the reduction in strain tolerance of the YSZ coating. Once micro-indentation was completed, SEM micrographs of the top view of the YSZ coatings (unexposed and deposition exposed) were taken, and then the samples were mounted, polished, and underwent microstructural analysis through scanning electron microscopy (SEM) examinations to provide high resolution images of the cross sections of the samples. Following SEM evaluation, energy dispersive X-ray spectroscopy (EDS) examinations of the ceramic top coat were conducted for determination of the elemental composition and mapping of the regions of interest (Hitachi S-4700)

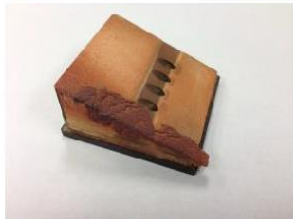

Test Article 1

(a)

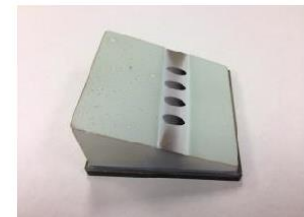

Test Article 2

(b)

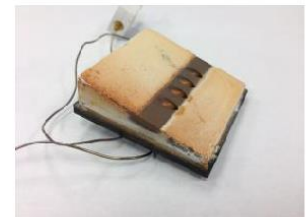

Test Article 3

(c)

Figure 2. Labels of a) Test Article $1-20^{\circ}$ with deposition, b) unexposed Test Article $2-20^{\circ}$, and c) Test Article $3-10^{\circ}$ with deposition [15]

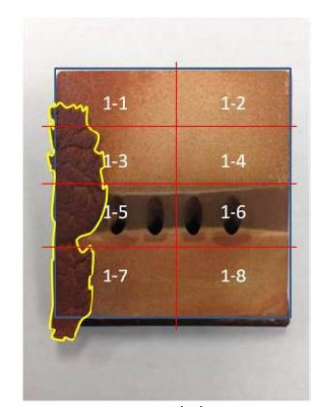

Test Article 1

(a)

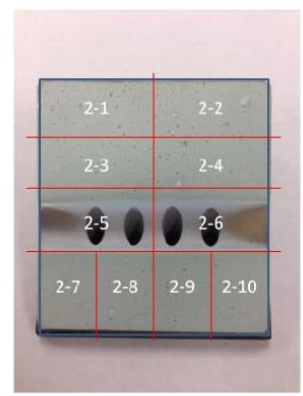

Test Article 2

(b)

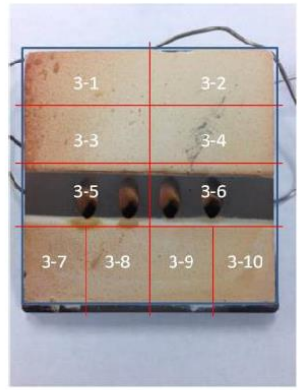

Test Article 3

(c)

Figure 3. Sectioning diagrams and sample labels for a) Test Article 1, b) Test Article 2, and c) Test Article 3 [15] 


\section{Results and Discussion}

\subsection{SEM and EDS Results}

Microstructural characterization examinations commenced after the micro-indentation work was completed. Figure 4 contains images of unexposed test sample 2-3 and deposition exposed test sample 1-3 and their corresponding cross-sectional SEM micrograph of the TBC layers. The columnar structure of the DVD YSZ can be seen in both cross-sectional views of the samples. The DVD ceramic coating exhibited a higher density than the EB-PVD YSZ found in CMAS studies by Wellman and Nicholls [4] and Peng et al. [16]. The only difference between the unexposed cross-sectional area in Figures 4a and the cross-section of the deposition exposed sample in Figure $4 \mathrm{~b}$ at $250 \times$ magnification is the growth of TGO thickness $(\sim 5 \mu \mathrm{m})$ and intercolumnar and internal pores due to sintering. The lack of significant microstructural changes away from the top of the YSZ coating meant the deposition had a shallow infiltration depth.

SEM micrographs of the top view of unexposed and exposed YSZ coatings are shown in Figure 5 [15]. Figure 5a shows the top view of an unexposed, as-deposited YSZ coating on test sample 2-1. The columnar structure produced by the DVD application process has inter-columnar gaps which improves the lateral strain compliance of the coatings. The top view of the molten deposits on the YSZ top coating of test sample 1-5 are shown in Figure 5b. The molten and cooled ash layer on top of the columns of the YSZ coating is thin, hardened, and almost glass-like.

A molten deposit infiltrated top coat has been found to be more susceptible to delamination, and spallation of the YSZ coating was found for the samples in the current study. A diagonal crack developed after sectioning along the top surface of top coat of sample 1-7 (s ee Figure 6a) [15]. The crack further propagated during sample preparation procedures and led to delamination of the TBC. Figure 6b-c show that Sample 1-3 lost roughly 100 $\mu \mathrm{m}$ of YSZ coating near the edge where deposition was abundant.

Sample 2-3 (Un exposed)
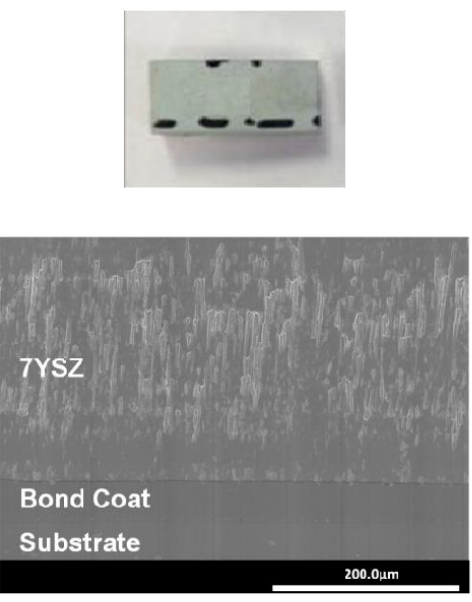

(a)
Sample 1-3 (Exposed)
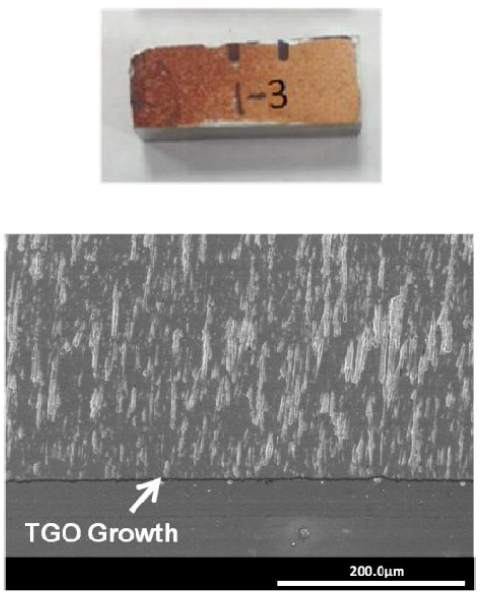

(b)

Figure 4. Cross-section SEM micrograph of the a) unexposed sample 2-3 and b) sample 1-3. 


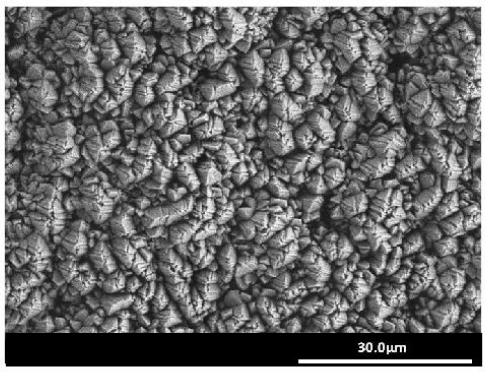

Sample 2-1 (Unexposed)

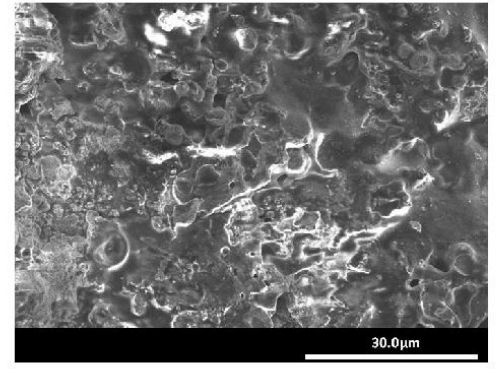

Sample 1-5 (Deposition Exposed)

(a)

(b)

Figure 5. Top view of a) unexposed Samples 2-1 and b) molten deposition on Sample 1-5 [15]

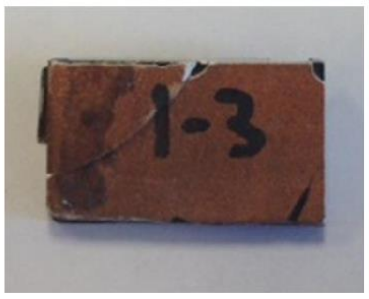

(a)

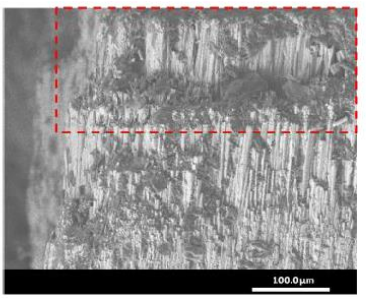

Post-sectioning

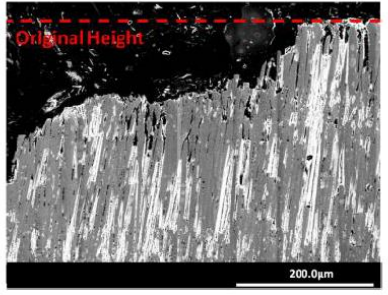

Mounted in a conductive mounting media

(b)

Figure 6. a) Top view of sample 1-7 and cross-section micrographs of delamination in Sample 1-3 top coating b) after sectioning and c) after mounting and polishing [15].

In areas where deposition adhered onto the top surface of the YSZ coatings but did not cause delamination, the fly ash deposition did not infiltrate deep into the top coat. Figure 7 shows the infiltration of the fly ash deposits into the TBC on sample 1-3. Figure 7a shows a cross-sectional micrograph of the top surface of sample $1-3$. The dashed red line shows the original top surface of the 7YSZ coating. Figure $7 \mathrm{~b}-\mathrm{d}$ shows corresponding $\mathrm{Zr}, \mathrm{Si}$, and Al EDS elemental maps, respectively. Silicon and aluminum are chosen for the elemental mapping since they contain the two highest elemental percentages that make up the composition of the fly ash. Figure 7a-d shows that even the most heavily deposited test article only sees an infiltration depth into the YSZ coating of $10-20 \mu \mathrm{m}$

A cross-section of sample 1-3 where a heavy amount of deposition is on top of the YSZ coating is shown in Figure 8. The image in Figure 8a is divided into four regions: epoxy, molten deposits, interaction zone, and unaffected YSZ. The elemental distributions of the latter three microstructural regions are listed in Table 2 . The results are the average of several EDS Point\&ID spectrum results at each columnar center and infiltration depth locations. The interaction zone is broken up into sub-regions Zone 1 and Zone 2 in Figure $8 \mathrm{~b}$. Zone 3 represents a YSZ depth relatively unaffected by the molten deposits. Silicon, aluminum, and iron comprise the three largest elements by percentage in the original processed fly ash. The molten deposits that lie on top have a comparable elemental distribution. The small change in the weight percentage between the processed fly ash and molten deposits was found in this study and was also found for the coal ash particulate in a study by Bons, Crosby, Wammack, Bentley, and Fletcher [17]. The detection of yttria and zirconia in the deposit layer indicates that 
some of the TBC has migrated into the molten fly ash deposit. Zone 1 is placed at the tips of the YSZ coatings, and although the spectrum results show that zirconia is the predominant element, there is still presence of the molten deposits on the column tips. The weight percentage level of yttria at roughly 5\% is lower than the $7-8 \%$ normally found in 7 YSZ. This agrees with the yttria migration into deposit layer found in the study by Peng et al. [16]. The study by Peng et al. completed the same type of EDS analysis using CMAS and an EB-PVD YSZ coating and showed yttria migration to the CMAS deposit. Zone 2 lies $10 \mu \mathrm{m}$ into the columnar tips and shows just a trace amount of deposit elements in the YSZ of the zone. Zone 3 is $20 \mu \mathrm{m}$ into the columnar tips and contains even less of the fly ash composition. The results in Table 2 agree with the EDS maps in Figure 7 for infiltration depth.

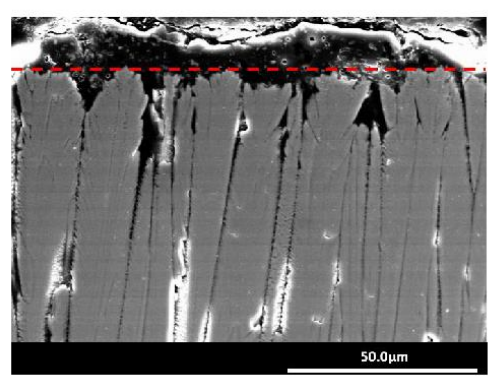

(a)

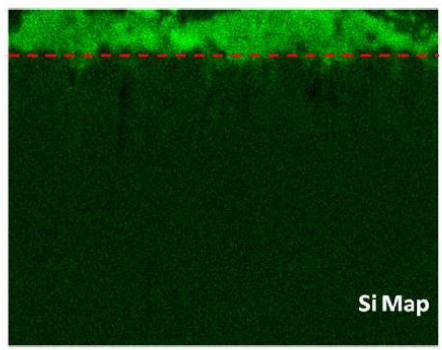

(c)

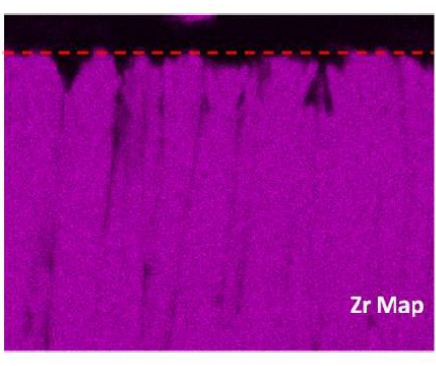

(b)

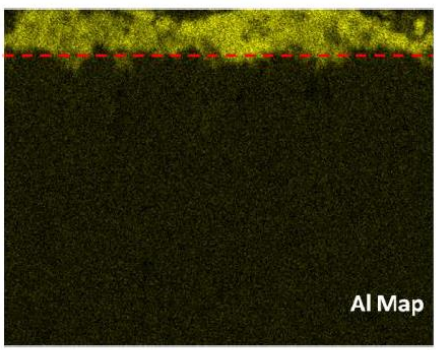

(d)

Figure 7. a) Cross-section SEM micrograph of Sample 1-3 that has interacted with molten fly ash and corresponding elemental maps: b) $\mathrm{Zr}, \mathrm{c}$ ) Si, and d) $\mathrm{Al}$. The horizontal dashed lines denote the original top surface of the TBC. 


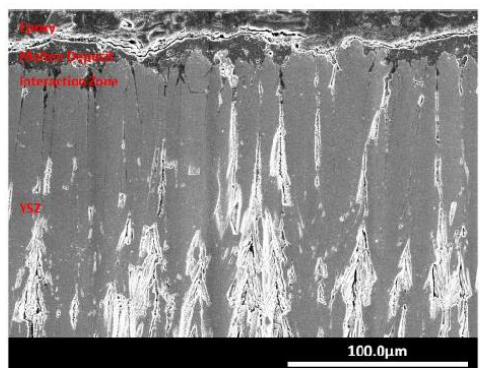

(a)

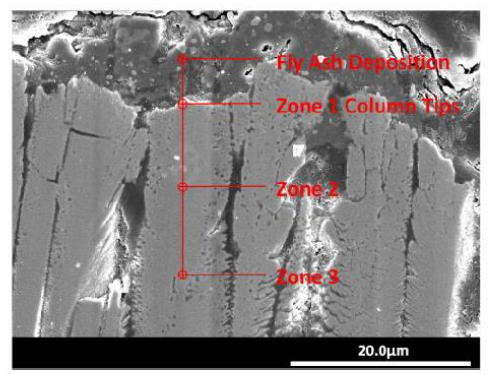

(b)

Figure 8. Cross-section views of a) TBC on sample 1-3 with molten deposits, their region description, and b) locations of EDS spectrum analysis.

Table 2. Elemental distribution (excluding oxygen) of the fly ash deposition and zones 1-3 in Figure 8b.
\begin{tabular}{|lcccccc|}
\hline Constituent/wt \% & $\mathrm{Si}$ & $\mathrm{Al}$ & $\mathrm{Fe}$ & $\mathrm{Y}$ & $\mathrm{Zr}$ \\
\hline Original Fly Ash & 28.09 & 14.98 & 6.93 & - & - \\
Molten deposit & 23.23 & 12.98 & 5.76 & 1.35 & 9.54 \\
1 (Column Tips) & 5.77 & 4.44 & 1.83 & 5.24 & 56.87 \\
$2(10 \mu \mathrm{m})$ & 0.66 & 0.03 & 0.35 & 6.74 & 75.32 \\
$3(20 \mu \mathrm{m})$ & 0.53 & 0.01 & 0.21 & 7.31 & 77.04 \\
\hline
\end{tabular}

Figure 9a contains an illustration from Levi et al. [3] that allows visualization of the dissolution-reprecipitation mechanism of yttria-stabilized zirconia in CMAS. The ceramic coating material dissolves within the molten glass and reprecipitates in one of the modified crystalline phases of the YSZ as the yttria is leeched out of the YSZ. Figure 9b contains a micrograph of a YSZ columnar tip in sample 1-3 that was reprecipitated in the molten fly ash deposit. The column tips have lost their identity. The molten fly ash does have similar degradation to the ceramic top coat tips as the molten glass from CMAS. The reprecipitated YSZ columnar tips, along with the stress mismatch caused by the molten deposit, may have attributed to the strain tolerance loss found in the study of the mechanical properties of the test samples [15]. Further penetration of the deposition and heat treatment can result in floating YSZ in the deposits leading to the appearance of globular particles found in studies by Levi et al. [3] and Peng et al. [16].

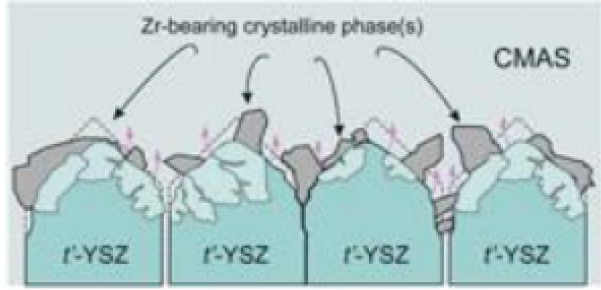

(a)

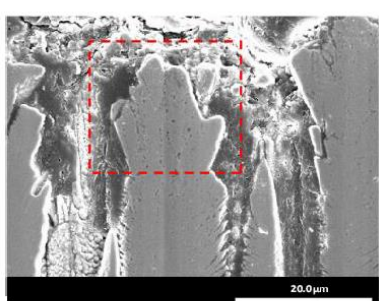

(b)

Figure 9. a) Schematic illustration of the dissolution-reprecipitation mechanism in YSZ [4] and b) SEM micrograph of a reprecipitated YSZ columnar tip of sample 1-3. 


\section{Conclusions}

This purpose of the current study was to analyze the microstructure of TBC coating systems on the test articles used in the Murphy, Nix, Lawson, Straub, and Beer study after 6-hour (accelerated to simulate of 10,000 hours) syngas particulate deposition. The articles were sectioned, mounted, and polished to study the microstructure of selected areas of varying quantities of deposition. Scanning electron microscopy and energy dispersive X-ray spectroscopy was used to characterize the TBC coatings at a microscopic level.

The molten deposits from the fly ash was found to penetrate the inter-columnar gaps of the YSZ a shallow depth of 10-20 $\mu \mathrm{m}$, but the deposits still lead to degradation of the DVD YSZ layer of TBC. Once the deposits were cooled on the top coat, the YSZ layer had a higher tendency to delaminate. SEM and EDS work showed that the deposit/YSZ interaction zone dissolved and reprecipitated the column tips of the top coating and made the tips lose their identity. During the dissolution-reprecipitation of the YSZ coating, the stabilizing yttria from the top coat column tips within the interaction zone is absorbed by the fly ash deposition, causing phase transformations within the YSZ. The phase transformation changes the mechanical and thermal properties in the YSZ coating.

\section{Acknowledgements}

The authors would like to acknowledge the support of the Department of Energy, Office of Science, Experimental Program to Stimulate Competitive Research (EPSCoR) under grant/contract number DE-FG02-09ER46615, monitored by Dr. Tim Fitzsimmons. In addition, with a cooperative agreement with EPSCoR, the project was partially funded by the US Department of Energy, National Energy Technology Laboratory. There are several people that deserve acknowledgments for their contributions to this project. The authors would like to thank Dr. Keith Kruger of Haynes, International for donating the Haynes 230 test article material. The thermal barrier coatings that were applied were cost shared by Dr. Derek Hass and Balvinder Gogia of Directed Vapor Technologies International, Inc. (DVTI). In addition, DVTI applied the bond coat to the test articles. Westmoreland Mechanical Testing \& Research, Inc. sectioned the angled test articles into the test samples. Mounting and polishing of the samples were completed by Metallurgical Technologies, Inc. Gratitude also goes out to the Shared Research Facilities and the Chemical Engineering Department at West Virginia University for the cleanroom access, training, and use of the SEM and other metallurgical preparation machines.

\section{References}

[1] Padture, N.P., Gell, M., and Jordan, E.H. (2002) Thermal Barrier Coatings for Gas-Turbine Engine Applications. Science AAAS, 296 (5566), 280-284. http://dx.doi.org/10.1126/science.1068609

[2] Schulz, U., Leyens, C., Fritscher, K., Peters, M., Saruhan-Brings, B., Lavigne, O., Dorvaux, J.-M., Poulain, M., Mévrel, R., and Caliez, M. (2003) Some Recent Trends in Research and Technology of Advanced Thermal Barrier Coatings. Aerospace and Technology, 7 (1), 73-80. http//dx.doi.org/10.1016/S12790-9638(02)00003-2

[3] Levi, C.G., Hutchinson, J.W., Vidal-Sétif, M.-H., and Johnson, C.A. (2012) Environmental Degradation of Thermal-Barrier Coatings by Molten Deposits. MRS Bulletin, 37 (10), 932-941. http://dx.doi.org $/ 10.1557 / \mathrm{mrs} .2012 .230$

[4] Wellman, R.G. and Nicholls, J.R. (2000) Some Observation on Erosion Mechanisms of EB PVD TBCs. Wear, 242 (1-2), 89-96. http://dx.doi.org/10.1016/S0043-1648(00)00391-4

[5] Drexler, J.M., Gledhill, A.D., Shinoda, K., Vasiliev, A.L., Reddy, K.M., Sampath, S., and Padture, N.P. (2011) Jet Engine Coatings for Resisting Volcanic Ash. Advanced Materials, 23 (21), 2419-2424. http://dx.doi.org/10.1002/adma.201004783

[6] Murphy, R.G., Nix, A.C., Lawson, S.A., Straub, D., and Beer, S.K. (2012) Preliminary Experimental Investigation of the Effects of Particulate Deposition on IGCC Turbine Film-Cooling in a High-Pressure Combustion Facility. ASME Turbo Expo 2012: Turbine Technical Conference and Exposition, 4, 979-986. http://dx.doi.org/10.1115/GT2012-68806

[7] Hass, D. (2012) Thermal Barrier Coating Environmental Durability Enhancement (CMAS). NAVAIR, N06-032.

[8] Gleeson, B., Wang, W., Hayashi, S., and Sordelet, D.J. (2004) Effects of Platinum on the Interdiffusion and Oxidation Behavior of Ni-Al-Based Alloys. Material Science Forum, 461, 213-222. 
http://dx.doi.org/10.4028/www.scientific.net/MSF.461-464.213

[9] Dorrington, J.R., Bogard, D.G., and Bunker, R.S. (2007) Film Effectiveness Performance for Coolant Holes Imbedded in Various Shallow Trench and Crater Depressions. ASME Turbo Expo 2007: Power for Land, Sea, and Air, 4 749-758. http://dx.doi.org/10.1115/GT2007-27992

[10] Bons, J., Ameri, A., Fletcher, T. (2012) Designing Turbine Endwalls for Deposition Resistance with $1400 \mathrm{C}$ Combustor Exit Temperatures and Syngas Water Vapor Levels. The Ohio State University.

[11] Lawson, S.A. and Thole, K.A. (2011) Effects of Simulated Particle Deposition on Film Cooling. Joumal of Turbomachinery, 133 (2), 021009-1-021009-10. http://dx.doi.org/10.1115/1.4000571

[12] Dennis, R.A., Shelton, W.W., and Le, P. (2007) Development of Baseline Performance Values for Turbines in Existing IGCC Applications. ASME Turbo Expo 2007: Power for Land, Sea, and Air, 2, 1017-1049. http://dx.doi.org/10.1115/GT2007-28096

[13] Murphy, R.G. (2012) Experimental Investigation of Particulate Deposition on a Simulated Film-Cooled Turbine Vane Pressure Surface in a High Pressure Combustion Facility. M.S. Thesis, West Virginia University, Morgantown, WV

[14] Murphy, R.G., Nix, A.C., Lawson, S.A., Straub, D., and Beer, S.K. (2013) Investigation of Factors that Contribute to Deposition Formation on Turbine Components in a High-Pressure Combustion Facility. ASME Turbo Expo 2013. Turbine Technical Conference and Exposition, 3B,V03BT13A027-V03BT13A027. http://dx.doi.org/10.1115/GT2012-94657

[15] Luo, K., Nix, A.C., Kang, B.S., Otunyo, D.A. (2014) Effects of Syngas Particulate Fly Ash Deposition on the Mechanical Properties of Thermal Barrier Coatings on Simulated Film-Cooled Turbine Vane Components. Intemational Joumal of Clean Coal and Energy, 3, 54-64. http://dx.doi.org/10.4236/ijcce.2014.34006

[16] Peng, H., Wang, L., Guo, L., Miao, W., Guo, H., and Gong, S. (2012) Degradation of EB-PVD Thermal Barrier Coatings Caused by CMAS Deposits, Progress in Natural Science: Materials International, 22 (5), 461-467. http://dx.doi.org/10.1016/j.pnsc.2012.06.007

[17] Bons, J.P., Crosby, J., Wammack, J.E., Bentley, B.I., Fletcher, T.H. (2007) High-Pressure Turbine Deposition in Land-Based Gas Turbines From Various Synfuels, Joumal of Enginering for Gas Turbinesand Power, 129 (1), 135-143. http://dx.doi.org/10.1115/1.2181181 